MARCELO ROSÁRIO DA BARROSA

APLICAÇÃO DE MÉTODOS COMPUTACIONAIS MULTIDISCIPLINARES DE ENGENHARIA PARA OTIMIZAÇÃO DE CARTEIRAS DE INVESTIMENTOS 
MARCELO ROSÁRIO DA BARROSA

\section{APLICAÇÃO DE MÉTODOS COMPUTACIONAIS MULTIDISCIPLINARES DE ENGENHARIA PARA OTIMIZAÇÃO DE CARTEIRAS DE INVESTIMENTOS}

Dissertação apresentada à Escola Politécnica da Universidade de São Paulo para obtenção do título de Mestre em Engenharia de Produção

Área de concentração:

Economia da Produção e Engenharia Financeira

Orientador:

Prof(a). Doutora Celma de Oliveira Ribeiro

São Paulo

Fevereiro de 2015 
Catalogação-na-publicação

Barrosa, Marcelo Rosário da

Aplicação de métodos computacionais multidisciplinares de engenharia para otimização de carteiras de investimentos / M.R.. da Barrosa -- São Paulo, 2015.

p.

Dissertação (Mestrado) - Escola Politécnica da Universidade de São Paulo. Departamento de Engenharia de Produção.

1.Otimização global 2.Interpolação estatística 3.Investimentos 4.Estatísticas de ordem 4.Inferência não paramétrica 5.Redes neurais I.Universidade de São Paulo. Escola Politécnica. Departamento de Engenharia de Produção II.t. 


\section{DEDICATÓRIA}

Dedico este trabalho a todos os meus professores e alunos, do passado, do presente e do futuro. 


\section{AGRADECIMENTOS}

Atingir o nível de maturidade necessário para desenvolver uma dissertação de mestrado exige um elevado grau de esforço, seja na obtenção do conhecimento requerido, seja no desenvolvimento das habilidades exigidas. Este esforço, porém, não é exclusivo do autor desta dissertação. Inúmeros profissionais trabalharam ao meu lado ao longo de toda a carreira, invariavelmente apresentado contribuições valiosas à minha formação pessoal e profissional. A todos estes profissionais, colegas e amigos, ficam meus sinceros agradecimentos. Em destaque, gostaria de agradecer aos valiosos ensinamentos e à dedicada orientação da Professora Doutora Celma de Oliveira Ribeiro, cuja habilidade gerencial, seriedade, inteligência e profissionalismo saltam aos olhos, e com quem gostaria de dividir todos os méritos desta conquista. Agradeço também aos alunos de Iniciação Científica, Pedro Araújo e Arthur Salles, cujo esforço, pragmatismo e agilidade de raciocínio contribuíram significativamente para a obtenção dos resultados aqui apresentados. Por último, agradeço a toda a minha família pelo constante estímulo transmitido durante a realização do trabalho, em especial ao meu filho, Raul, quem constantemente me relembra o valor e a importância de tudo o que se faz nesta vida. 


\section{EPÍGRAFE}

"É melhor correr o risco de salvar um homem culpado do que condenar um inocente."

(Voltaire) 


\section{RESUMO}

Este trabalho apresenta uma nova metodologia para otimizar carteiras de ativos financeiros. A metodologia proposta, baseada em interpoladores universais tais quais as Redes Neurais Artificiais e a Krigagem, permite aproximar a superfície de risco - e consequentemente a solução do problema de otimização associado a ela - de forma generalizada e aplicável a qualquer medida de risco disponível na literatura. Além disto, a metodologia sugerida permite que sejam relaxadas hipóteses restritivas inerentes às metodologias existentes, simplificando o problema de otimização e permitindo que sejam estimados os erros na aproximação da superfície de risco. Ilustrativamente, aplica-se a metodologia proposta ao problema de composição de carteiras com a Variância (controle), o Valor-em-Risco (VaR) e o Valor-em-Risco Condicional (CVaR) como funções objetivo. Os resultados são comparados àqueles obtidos pelos modelos de Markowitz e Rockafellar, respectivamente.

Palavras-chave: Otimização, Gestão de Carteiras, Risco, Kriging, Redes Neurais. 


\begin{abstract}
This work presents a new methodology for optimizing financial asset portfolios. The proposed methodology, based on universal interpolators such as Artificial Neural Networks and the Kriging Method, allows for approximating the risk surface - and thus the optimal solution to the problem - in a generalized fashion and applicable to any risk measure known in literature, relaxing every restrictive hypothesis inherent to the available methods and with the ability to estimate the error in the approximation. Illustratively, the proposed methodology is applied to the portfolio problem with the Variance (control), Value-at-Risk and Conditional Value-at-Risk as objective functions. Results are compared to those obtained by Markowitz and Rockafellar models, respectively.
\end{abstract}

Key-words: Optimization, Portfolio Management, Risk, Kriging, Neural Networks. 


\section{LISTA DE FIGURAS}

Figura 1: Resumo da revisão de literatura sobre medidas de risco de investimentos financeiros

Figura 2: Curva Retorno versus Risco para uma carteira composta por três ativos.

Figura 3: Fronteira Eficiente de Markowitz para uma carteira composta por três ativos.

Figura 4: Representação gráfica do Valor em Risco (VaR) para um nível de confiança a e para uma distribuição simétrica de probabilidades de retornos.

Figura 5: Valor em Risco (VaR) calculado através dos Métodos Paramétrico e Não Paramétrico, para carteira composta dos ativos ITUB4 e PETR4, com amostra obtida entre os períodos 27 Maio 2009 e 11 Maio 2012, totalizando 718 observações

Figura 6: Representação gráfica do Valor em Risco (VaR) e do Valor em Risco Condicional (CVaR) para um nível de confiança a e para uma distribuição simétrica de probabilidades de retornos.

Figura 7: Valor em Risco Condicional (CVaR) calculado pela estimação do Valor em Risco (VaR) através do método Não Paramétrico, para carteira composta dos ativos ITUB4 e PETR4, entre os períodos 27 Maio 2009 e 11 Maio 2012.

Figura 8: Representação de uma Rede Neural Artificial com três células de entrada e duas camadas internas de oito neurônios cada.

Figura 9: Representação de uma Rede Neural conforme aplicada neste trabalho, exemplificada por uma carteira de dois ativos.

Figura 10: Representação gráfica das técnicas de amostragem utilizadas para

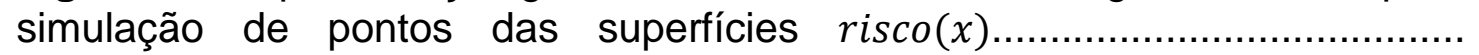

Figura 11: Fronteira Eficiente de Markowitz para carteira composta pelos ativos ITUB4, CZLT11, OGXP3 e PETR4, através do método de Kuhn-Tucker e das Redes Neurais Artificiais.

Figura 12: Composições ótimas de carteiras obtidas através da aplicação da metodologia proposta, aplicando-se as Redes Neurais Artificiais como técnica de interpolação, e do modelo de MARKOWITZ (1952), utilizando a variância como medida de risco. 
Figura 13: Erro Quadrático Médio calculado para cada um dos resultados apresentados para otimização de carteira de investimentos utilizando a variância como função objetivo, e aplicando-se as Redes Neurais Artificiais como técnica de interpolação.

Figura 14: Fronteiras eficientes obtidas através da metodologia proposta, aplicando-se as Redes Neurais Artificiais como técnica de interpolação, para otimização de carteira de quatro ativos utilizando o VaR Não-paramétrico como medida de risco

Figura 15: Composições ótimas de carteiras obtidas através da aplicação da metodologia proposta, aplicando-se as Redes Neurais Artificiais como técnica de interpolação, utilizando 0 VaR Não-paramétrico como medida de risco.

Figura 16: Erro Quadrático Médio calculado para cada um dos resultados apresentados para otimização de carteira de investimentos utilizando o VaR Não-paramétrico como função objetivo, aplicando-se as Redes Neurais Artificias como técnica de interpolação.

Figura 17: Fronteiras Eficientes obtidas para o CVaR como função objetivo, calculadas conforme metodologia proposta, aplicando-se as Redes Neurais Artificiais como técnica de interpolação, e o método proposto por ROCKAFELLAR et.al. (2002).

Figura 18: Composições ótimas de carteiras obtidas através da solução do problema de otimização de carteiras de investimentos tendo o $\mathrm{CVaR}$ como função objetivo, calculada conforme metodologia proposta, aplicando-se as Redes Neurais Artificiais como técnica de interpolação, e conforme o método proposto por ROCKAFELLAR et.al. (2002).

Figura 19: Erro Quadrático Médio calculado para cada um dos resultados apresentados para otimização de carteira de investimentos utilizando o CVaR como função objetivo, através da metodologia proposta e aplicando-se as Redes Neurais Artificiais como técnica de interpolação.

Figura 20: Fronteira Eficiente para carteira de cinco ativos com a Variância como medida de risco calculada através do método de Kuhn-Tucker (azul) e através da metodologia sugerida, aplicando-se a Krigagem como método de interpolação, para diferentes grids 
Figura 21: Composição ótima de carteira de cinco ativos para diferentes níveis de risco com a Variância como medida de risco, calculada através da metodologia proposta, aplicando-se a Krigagem como método de interpolação para diferentes grids, e através do método de Kuhn-Tucker.

Figura 22: Erro Quadrático Médio calculado para cada um dos resultados apresentados para otimização de carteira de investimentos utilizando a Variância como função objetivo, através da metodologia proposta e aplicandose a Krigagem como técnica de interpolação.

Figura 23: Fronteira Eficiente para carteira de cinco ativos com o VaR NãoParamétrico como medida de risco calculada através da metodologia proposta, aplicando-se a Krigagem como método de interpolação para diferentes grids.

Figura 24: Composição ótima de carteira de cinco ativos para diferentes níveis de risco com o VaR como medida de risco, calculada através da metodologia sugerida, aplicando-se a Krigagem como método de interpolação, para o grid $\mathrm{d}=0.1$

Figura 25: Fronteira Eficiente para carteira de cinco ativos com o CVaR como medida de risco calculada através do método de ROCKAFELLAR et. al. (2002), com diferentes quantidades de pontos simulados, e através da metodologia proposta, aplicando-se a Krigagem como método de interpolação, para diferentes grids.

Figura 26: Composição ótima de carteira de cinco ativos para diferentes níveis de risco com o CVaR como medida de risco, calculada através da metodologia proposta, aplicando-se a Krigagem como método de interpolação, para o grid $\mathrm{d}=0.1$, e aplicando-se o método de ROCKAFELLAR et. al. (2002), para diferentes quantidades de cenários simulados.

Figura 27: Fronteira Eficiente para carteira de dez ativos com a Variância como medida de risco calculada através do método Kuhn-Tucker e através da metodologia proposta, aplicando-se a Krigagem como método de interpolação, para diferentes grids.

Figura 28: Composição ótima de carteira de dez ativos para diferentes níveis de risco com a Variância como medida de risco, calculada através da metodologia proposta para o grid $\mathrm{d}=0.2$, e aplicando-se o método de KuhnTucker.

Figura 29: Composição ótima de carteira de dez ativos utilizando a Variância como medida de risco para cada ciclo de aplicação da metodologia proposta e segundo técnica o modelo de MARKOWITZ (1952) 
Figura 30: Fronteira Eficiente para carteira de dez ativos com o VaR NãoParamétrico como medida de risco calculada através da metodologia proposta aplicando-se a Krigagem como método de interpolação, para diferentes grids...

Figura 31: Composição ótima de carteira de dez ativos para diferentes de VaR não-paramétrico, calculada através da metodologia proposta para o grid $\mathrm{d}=0.2$

Figura 32: Composição ótima de carteira de dez ativos utilizando o VaR nãoparamétrico como medida de risco para cada ciclo de aplicação da metodologia proposta.

Figura 33: Fronteira Eficiente para carteira de dez ativos com o CVaR como medida de risco calculada através do método ROCKAFELLAR et. al. (2002), com 2.224 cenários, e através da metodologia proposta, aplicando-se a Krigagem como método de interpolação para diferentes grids.

Figura 34: Composições ótimas de carteira de dez ativos para diferentes níveis de CVaR, calculadas através do método de ROCKAFELLAR et. al. (2002) e através da metodologia proposta, aplicando a Krigagem como técnica de interpolação para o grid $\mathrm{d}=0.2$

Figura 35: Composição ótima de carteira de dez ativos utilizando o CVaR como medida de risco para cada ciclo de iteração da metodologia proposta e segundo método de ROCKAFELLAR et. al. (2002).

Figura 36: Erro Quadrático Médio na aproximação da superfície de risco pela metodologia proposta, aplicando-se a Krigagem como método de interpolação e variando o grid de simulação para amostra determinística, para a Variância, o VaR e o CVaR 


\section{LISTA DE TABELAS}

Tabela 1: Exemplos de distribuição de probabilidade dos retornos e retornos logarítmicos para amostras selecionadas de ações.

Tabela 2: Categorização e classificação das medidas de risco em investimentos financeiros propostas no período pós teoria moderna de portfólios (MPT).

Tabela 3: Resumo de características das medidas de risco selecionadas para aprofundamento neste trabalho: Variância $\left(\sigma^{2}\right)$, Valor em Risco (VaR) e Valor em Risco Condicional (CVaR)

Tabela 4: Algoritmo de aproximação do mínimo global de $\operatorname{Risco}(X)$

Tabela 5: Algoritmo de busca local em torno de $X^{*}$

Tabela 6: Carteira analisada para aplicação da metodologia proposta, utilizando-se a Krigagem como método de interpolação de dados.

Tabela 7: Dimensão de amostra determinística no processo de simulação, para carteira com dez ativos em diferentes grids. 


\section{LISTA DE ABREVIATURAS E SIGLAS}

$\begin{array}{ll}M A D: & \text { Desvio Absoluto da Média } \\ \text { MPT: } & \text { Teoria Moderna de Portfólios, ou Modern Portfolio Theory } \\ \text { MSE: } & \text { Erro-Médio-Quadrático, ou Mean-Squared-Error } \\ \text { NN: } & \text { Redes Neurais Artificiais } \\ \text { CVaR: } & \text { Valor em Risco Condicional } \\ \text { VaR: } & \text { Valor em Risco }\end{array}$




\section{LISTA DE SÍMBOLOS}

$\rho$ : Coeficiente de Correlação de Pearson

$\sigma e \sigma^{2}$ : Desvio Padrão e Variância, respectivamente

$a$ : Dimensão da carteira de investimentos, ou quantidade de ativos que compõem a carteira

$d$ : Espaçamento entre pontos simulados para um dado ativo na amostra determinística

$\hat{F}_{\alpha}(x, v)$ : Estimador da Função Valor em Risco Condicional em função da composição da carteira e do Valor em Risco

$F_{\alpha}(x, v)$ : Função Valor em Risco Condicional em função da composição da carteira e do Valor em Risco

$z_{\alpha}$ : Inverso da distribuição cumulativa Normal ou Gaussiana

$\Gamma$ : Matriz de Correlação

$\Sigma$ : Matriz de Covariância

$\bar{x}$ : Média Amostral

$\mu$ : Média da População

$\theta$ : Nível de ativação da Rede Neural

$\alpha$ : Nível de Confiança

$G$ : Nível mínimo de retorno exigido por um dado investidor

$x$ : Peso de um ativo em uma determinada carteira de investimentos

$P$ : Preço do Ativo

$p$ : Probabilidade

$A_{0}$ : Quantidade inicial de recursos disponíveis para investimentos

$q$ : Quantidade de cenários gerados através de simulação

$M(R)$ : Representação de ordenação sequencial dos retornos

$X_{i}$ : Representação de um dado ativo $i$

$R_{L N}$ : Retorno Logarítmico

$R$ : Retorno de um dado investimento

$\varsigma$ : Semi-Variância

$v$ : Valor em Risco (VaR) 


\section{SUMÁRIO}

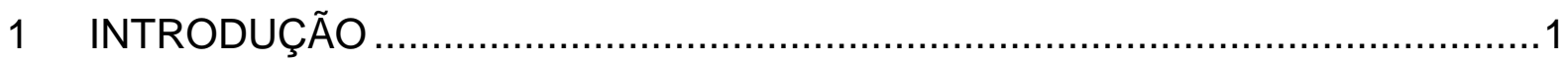

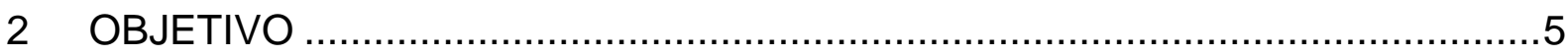

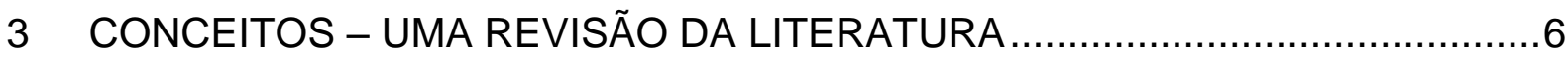

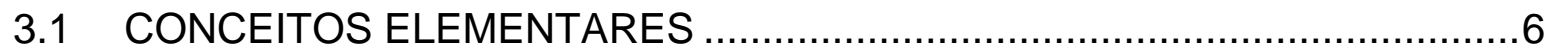

3.2 PERFORMANCE DE INVESTIMENTOS ...........................................

3.2.1 RETORNO

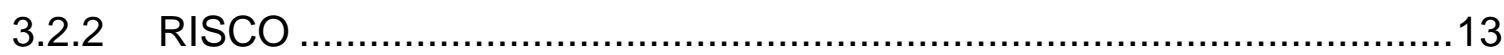

3.3 O PROBLEMA DE GESTÃO DE CARTEIRAS DE INVESTIMENTOS ........22

3.3.1 VARIÂNCIA E O MODELO DE MARKOWITZ ..................................24

3.3.2 VALOR EM RISCO (VaR) ……...............................................28

3.3.3 VALOR EM RISCO CONDICIONAL (CVaR) ......................................35

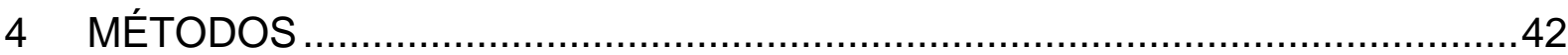

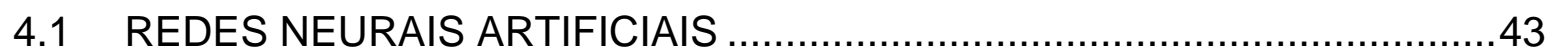

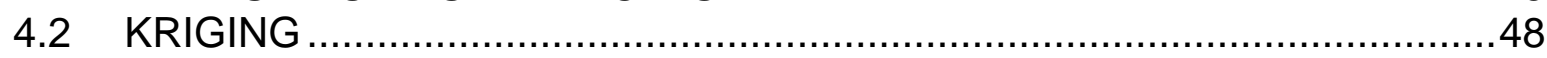

5 METODOLOGIA PROPOSTA

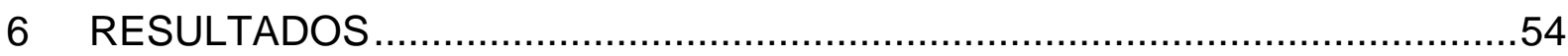

6.1 GERAÇÃO DE AMOSTRA PARA ANÁLISE .......................................56

6.2 INTERPOLAÇÃO POR REDES NEURAIS ARTIFICIAIS .........................58

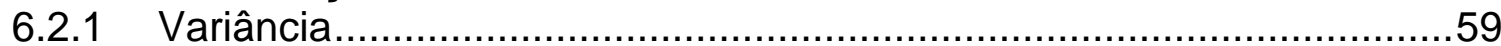

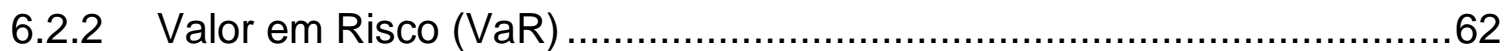

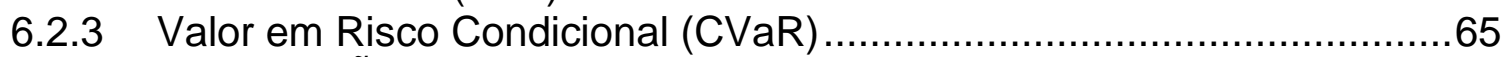

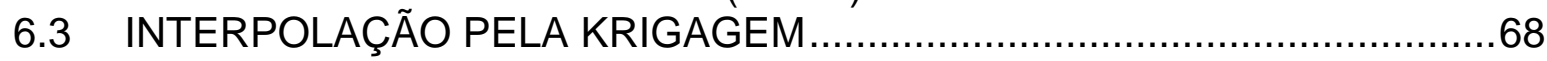

6.3.1 Aplicação (Direta) a Carteiras Pequenas..............................................69

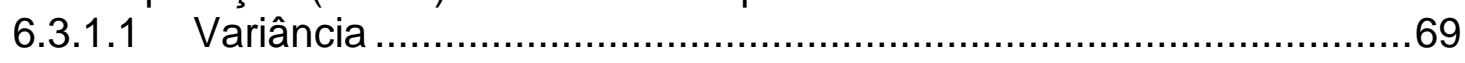

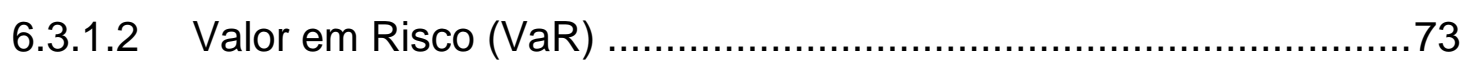

6.3.1.3 Valor em Risco Condicional ........................................................ 75

6.3.2 Aplicação (iterativa) a carteiras grandes...........................................

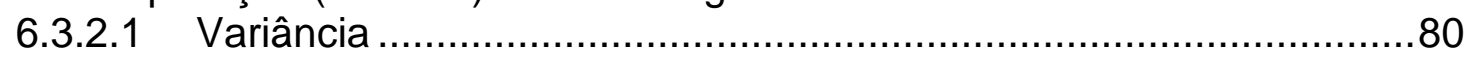

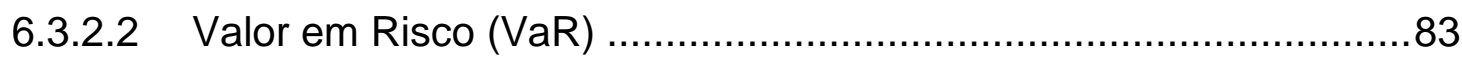

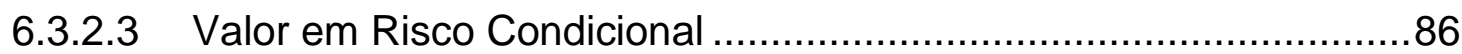

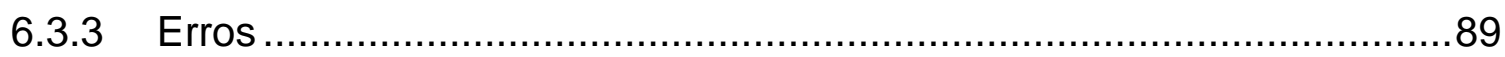

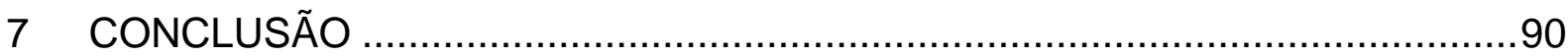

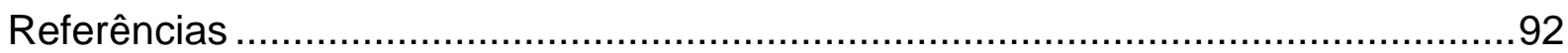




\section{INTRODUÇÃO}

É amplamente conhecido e aceito no estudo de finanças que investimentos financeiros envolvendo riscos apresentam maior potencial de ganhos quando comparados a investimentos livres de risco (BERK e DEMARZO, 2009; BREALEY e MEYERS, 2003). Estes riscos, porém, estão associados à probabilidade de obtenção dos retornos desejados, e, ao longo da história, nem sempre foram conhecidos (JORION, 1999). O desconhecimento de tais riscos, e mesmo o comportamento racional humano, incluindo, por um lado, a não saciedade e, por outro, a aversão ao risco (LUENBERGER, 2008), invariavelmente levam o mercado financeiro a situações de estresse, causando impactos significativos na vida dos cidadãos. Exemplos clássicos incluem as grandes depressões econômicas de 1929 e 2009, além de crises menores, frequentemente enfrentadas nas décadas de 1970, 1980 e 1990, cujos impactos são potencializados pelo crescente efeito da globalização.

Dentre outros aspectos, os impactos destas crises motivaram acadêmicos em todo o mundo a buscar meios de mensurar tais riscos e, mais importante, encontrar o equilíbrio entre os riscos e os retornos associados a um investimento. Assim, ao longo do último século foram desenvolvidas diversas formas de medir os riscos de investimentos (MARKOWITZ, 1952; ROY, 1952; MARKOWITZ, 1970; FISHBURN, 1977; BAWA, 1978; KONNO e YAMAZAKI, 1992; G-30, 1994; ROCKAFELLAR e URYASEV, 2000). Em todos os casos, utilizam-se dados históricos como forma de estimar os principais parâmetros que caracterizam a distribuição de probabilidade dos retornos de um dado investimento, invariavelmente recaindo em um problema de otimização, cujo objetivo é minimizar os riscos para um dado nível de retorno 
desejado, ou, alternativamente, maximizar os retornos para um dado nível de risco, necessariamente conhecido (LIM, 2011; PEROLD, 1984).

Muitas destas medidas de risco e dos modelos de otimização associados a elas, porém, são lastreadas em premissas nem sempre verdadeiras, a exemplo da hipótese de simetria na distribuição de probabilidade dos retornos (SZEGO, 2002). Além disto, a noção de que características passadas da distribuição de probabilidades dos retornos representam seu comportamento futuro também apresenta erro, sendo o exemplo da heterocedasticidade um fenômeno bastante representativo (BANGIA e DIEBOLD, 1999).

Neste contexto, a literatura recente apresenta duas tendências principais: (1) o desenvolvimento de novas medidas de risco, em extensão ou substituição às existentes (BANGIA e DIEBOLD, 1999; BERKOWITZ, 2000; JANABI, 2012; MARKOWITZ, 2012) e (2) o aprofundamento no conhecimento das medidas de risco existentes, principalmente nas modelagens da cauda (tail risk, do inglês) da distribuição de probabilidades dos retornos (ARTZNER, 1999; ESTRADA, 2003; LIM, 2011; MARKOWITZ, 2012).

Este trabalho se concentra em ambas as tendências apresentadas, buscando-se aprofundar o conhecimento sobre distintas medidas de risco e, consequentemente, sobre o comportamento dos problemas de otimização de carteiras associados a elas. Para tanto, sugerem-se abordagens comumente aplicadas a problemas de engenharia, as quais se fazem necessárias conforme se eleva a complexidade das medidas de risco propostas pela literatura. ROCKAFELLAR e URYASEV (2002) propuseram uma metodologia estruturada de otimização de problemas de composição de carteiras utilizando o Valor em Risco Condicional (CVaR) como medida de risco, através da simulação de cenários e da aplicação de técnicas de programação linear. 
Assim, admitindo-se $\boldsymbol{x} \in \boldsymbol{X} \subset R^{N}$ um vetor de decisão representando uma carteira, $\mathbf{y} \in \boldsymbol{Y} \subset R^{N}$ o retorno aleatório dos ativos que compõem esta carteira e $z=f(x, y)$ a função que representa as perdas desta carteira, faz-se possível a simulação de distintos cenários e a consequente obtenção de pontos da superfície de resposta representativa do risco. Alternativamente à formulação analítica e transformação do problema de otimização em um problema de programação linear, demonstra-se, neste trabalho, a aplicação das técnicas multidisciplinares de engenharia, tais quais as Redes Neurais Artificiais e da Krigagem, para interpolação dos dados obtidos através da simulação, e a consequente aproximação da superfície de resposta representativa do risco, para posterior otimização.

A aplicação da metodologia sugerida acima caracteriza contribuição significativa para o entendimento do comportamento de diversas medidas de risco de investimentos, com distintos graus de complexidade e aplicadas em suas versões mais amplas, ou não paramétricas. Sua característica universal permite que sejam relaxadas hipóteses restritivas características das metodologias atualmente disponíveis, ampliando, assim, sua aplicabilidade, inclusive servindo de base para o entendimento eventuais novas medidas de risco que venham a ser desenvolvidas no futuro.

A fim de exemplificar a aplicação da metodologia proposta, são selecionados três dos principais modelos de risco atualmente discutidos na literatura, seja pela sua vasta aplicação prática, seja pela sua sólida fundamentação teórica: (1) o modelo médiavariância, de Markowitz, (2) o Valor em Risco (VaR) e (3) o Valor em Risco Condicional (CVaR), sendo o primeiro baseado em medida de risco de dispersão, e as demais medidas de cauda.

O trabalho se inicia com a apresentação dos fundamentos teóricos e dos conceitos que circundam o problema de otimização de carteiras de investimentos. Em seguida, 
uma revisão de literatura sobre as principais medidas de risco desenvolvidas ao longo do último século é apresentada, seguida de um aprofundamento no estudo das medidas selecionadas para este trabalho. O trabalho segue com o detalhamento conceitual da metodologia sugerida, e, por último, apresentam-se os resultados de sua aplicação de forma comparativa àqueles obtidos através dos modelos atualmente disponíveis. 


\section{OBJETIVO}

O objetivo deste trabalho é apresentar uma metodologia universal aplicável a problemas de otimização de carteiras de investimentos utilizando distintas medidas de risco como função objetivo. Busca-se, através da aplicação desta metodologia, aprofundar o conhecimento sobre o comportamento das diferentes medidas de risco desenvolvidas ao longo do último século. Conforme novas medidas de risco são propostas pela literatura, comumente com elevado grau de sofisticação, faz-se necessária a definição de hipóteses restritivas para possibilitar a otimização de carteiras de investimentos, a exemplo dos modelos propostos por MARKOWITZ (1952) e ROCKAFELLAR et. al. (2002). Neste contexto busca-se, com este trabalho, demonstrar a aplicação de diferentes métodos computacionais de aproximação de superfícies de resposta, comumente utilizados em problemas de engenharia, a fim de relaxar tais hipóteses. Espera-se, assim, apresentar métodos que possibilitem solucionar o problema apresentado de forma global, aplicável a distintas medidas de risco e a distintos ativos financeiros. 


\section{CONCEITOS - UMA REVISÃO DA LITERATURA}

Esta seção inicial do trabalho se concentra na definição dos principais conceitos que circundam o problema de gestão de carteiras de investimentos. Inicia-se, assim, com a apresentação dos conceitos elementares do problema, tais quais gestão de carteiras e investimentos. Em seguida, são apresentadas as principais formas de se avaliar a performance de um investimento, incluindo as definições de retorno e as diversas formas de se medir os riscos, bases para a formalização do problema de composição de carteiras de investimentos como problema de otimização. Por último, apresentamse os modelos de otimização de carteiras utilizando as principais medidas de risco disponíveis na literatura como funções objetivo, incluindo uma discussão acerca das características da superfície representativa do risco e dos métodos disponíveis para suas otimizações. Conceitos de estatística multivariada de vital importância para a interpretação deste trabalho são relembrados ao longo do texto.

\subsection{CONCEITOS ELEMENTARES}

Conforme mencionando anteriormente, este trabalho se concentra no estudo da gestão de carteiras de investimentos. Daqui, alguns conceitos importantes devem ser introduzidos afim de facilitar o entendimento do trabalho, incluindo: gestão, carteiras e investimentos.

Especificamente para o estudo apresentado, a gestão de carteiras (ou portfolio management, em inglês) é definida como a constante decisão do percentual dos recursos pré-determinados que são alocados em cada ativo que compõe uma carteira (i.e. decisão quanto à composição ótima de uma carteira de investimentos). 
Uma carteira (ou portfolio, do inglês) é um conjunto de dois ou mais ativos nos quais um investidor aloca uma quantidade pré-determinada de recursos financeiros, objetivando uma configuração ótima entre risco e retorno.

LUENBERGER (2008), apresenta duas definições para o termo investimento. A primeira, tradicional, indica que um investimento é definido como o compromisso de recursos assumido hoje, com vias a obter benefícios futuros. A segunda, mais ampla, é baseada na ideia de fluxos de gastos e recebimentos em um dado período de tempo. Neste caso, o investidor objetiva atingir padrões para tal fluxo de pagamentos que se aproximem ao máximo daquele desejado. Em ambas as definições, a prática comum é que tanto os gastos quando os recebimentos sejam medidos em valores monetários, geralmente em moeda corrente. A definição tradicional do termo investimento está alinhada aos objetivos deste trabalho.

Da discussão acima, portanto, pode-se definir conceitualmente o problema de gestão de carteiras de investimentos como o processo decisório de alocação de uma dada quantidade de recursos em dois ou mais ativos financeiros realizada hoje, cujo objetivo é obter composições ótimas entre risco e retorno, e assim elevar a probabilidade de se maximizar os benefícios futuros para um determinado nível de risco, necessariamente conhecido. 


\subsection{PERFORMANCE DE INVESTIMENTOS}

Conforme mencionado anteriormente, define-se um investimento como a alocação de recursos financeiros realizada hoje com vias a se obter benefícios futuros. De forma geral, pode-se classificar um investimento de duas formas principais: (1) investimentos cujo retorno esperado é conhecido, não envolvendo incertezas, e (2) investimentos cujo retorno esperado é desconhecido e envolve incertezas.

A primeira forma trata de investimentos na chamada renda-fixa (fixed-income securities, do inglês), indicando que o ativo remunera o investidor de forma fixa e prédefinida no ato do investimento. Assim, de modo geral, o investidor conhece tanto sua alocação inicial de recursos quanto os retornos futuros de seu investimento, não envolvendo, portanto, aleatoriedade e incertezas (a exceção da probabilidade de default ${ }^{1}$ ou das variações do benchmark ${ }^{2}$ ao qual são atrelados os retornos). Exemplos incluem: (1) depósitos bancários, tais quais Certificado de Depósito Bancário (CDB), Certificado de Depósito Interbancário (CDI), etc. (2) Títulos Públicos e Privados, sejam de curto ou longo prazos, (3) Créditos Imobiliários, (4) Anuidades, como Fundos de Pensão, etc. (LUENBERGER, 2008). Embora investimentos em renda fixa sejam vastamente utilizados em todo o mundo, não é escopo deste trabalho o aprofundamento do seu estudo, sendo sua menção e utilização meramente ilustrativas.

A segunda forma de investimentos inclui aqueles onde a quantidade inicial de capital investido é conhecida, porém com recebimentos futuros incertos, aleatórios. Desta

\footnotetext{
10 termo default é comumente utilizado em finanças para representar o caso onde o devedor (emissor do título, por exemplo) não cumpriu com suas obrigações de pagamento segundo contrato, não honrando com os pagamentos, por exemplo.

$2 \mathrm{O}$ termo benchmark se refere a alguma taxa de mercado à qual comumente os retornos de um investimento de renda fixa são atrelados.
} 
forma, trata-se o preço de um determinado ativo, em diferentes momentos, como uma variável aleatória.

Ambas formas de investimento definidas acima são avaliadas através dos retornos esperados sobre o investimento. Porém, apenas na segunda forma, os retornos são incertos devido às características da variável aleatória que os compõe, o preço, fazendo-se necessária a avaliação dos riscos associados ao investimento.

Por simplificação, os conceitos aqui apresentados consideram investimentos em único período de tempo, oferecendo maior facilidade de compreensão sem perda significativa de informações e generalidade (BANGIA e DIEBOLD, 1999), conforme práticas comuns no estudo das finanças (LUENBERGER, 2008). O período elegido para análise dos investimentos neste trabalho é de um dia. Tal período é comumente denominado horizonte de tempo, e está diretamente relacionado com as características dos ativos que compõem a carteira analisada. De modo geral, para ativos de elevada liquidez (i.e. com elevados volumes de negociação), horizontes curtos de tempo, como um dia, por exemplo, podem ser empregados. Já para ativos com menor liquidez, sugere-se a utilização de horizontes de tempo maiores, como, por exemplo, um mês (RIBEIRO, 2004). Por último, os exemplos de aplicações financeiras apresentados neste texto incluem investimentos em ações negociadas na Bolsa de Valores de São Paulo, BOVESPA. 


\subsubsection{RETORNO}

Seja $P_{t}$ uma variável aleatória que representa o preço de um determinado ativo financeiro no instante $t$, define-se o retorno $(R)$ de um investimento em um determinado período de tempo $\delta t$ como a variação de $P$ entre os períodos inicial $\left(t_{0}\right)$ e final $\left(t_{1}\right)$ de $\delta t$. Ou seja,

$$
\mathrm{R}=\frac{P_{t_{1}}}{P_{t_{0}}}
$$

Alternativamente à definição de retorno apresentada acima, uma prática comum no estudo de composição de carteiras de investimentos é a utilização dos retornos logarítmicos. Ou seja,

$$
R_{\text {log }}=\ln \left[\frac{P_{t_{1}}}{P_{t_{0}}}\right]
$$

Esta segunda definição de retorno de investimentos é conveniente porque, em diversos casos práticos, e principalmente quanto os ativos em estudo são ações, a distribuição de probabilidades de $R$ pode ser aproximada por Log-Normal, possibilitando a aproximação de $R_{\log }$ por uma distribuição Normal, cujas características facilitam substancialmente a solução do problema de composição de carteiras de forma analítica.

llustrativamente, a Tabela 1, abaixo, mostra a distribuição de probabilidade dos retornos e dos retornos logarítmicos diários de amostras das ações das empresas Banco Itaú (ITUB4), Banco do Brasil (BBAS3), Companhia Siderúrgica Nacional (CSNA3) e Cosan (CZLT11), negociadas na BOVESPA, obtidas em diferentes períodos de tempo. 
Tabela 1: Exemplos de distribuição de probabilidade dos retornos e retornos logarítmicos para amostras selecionadas de ações.

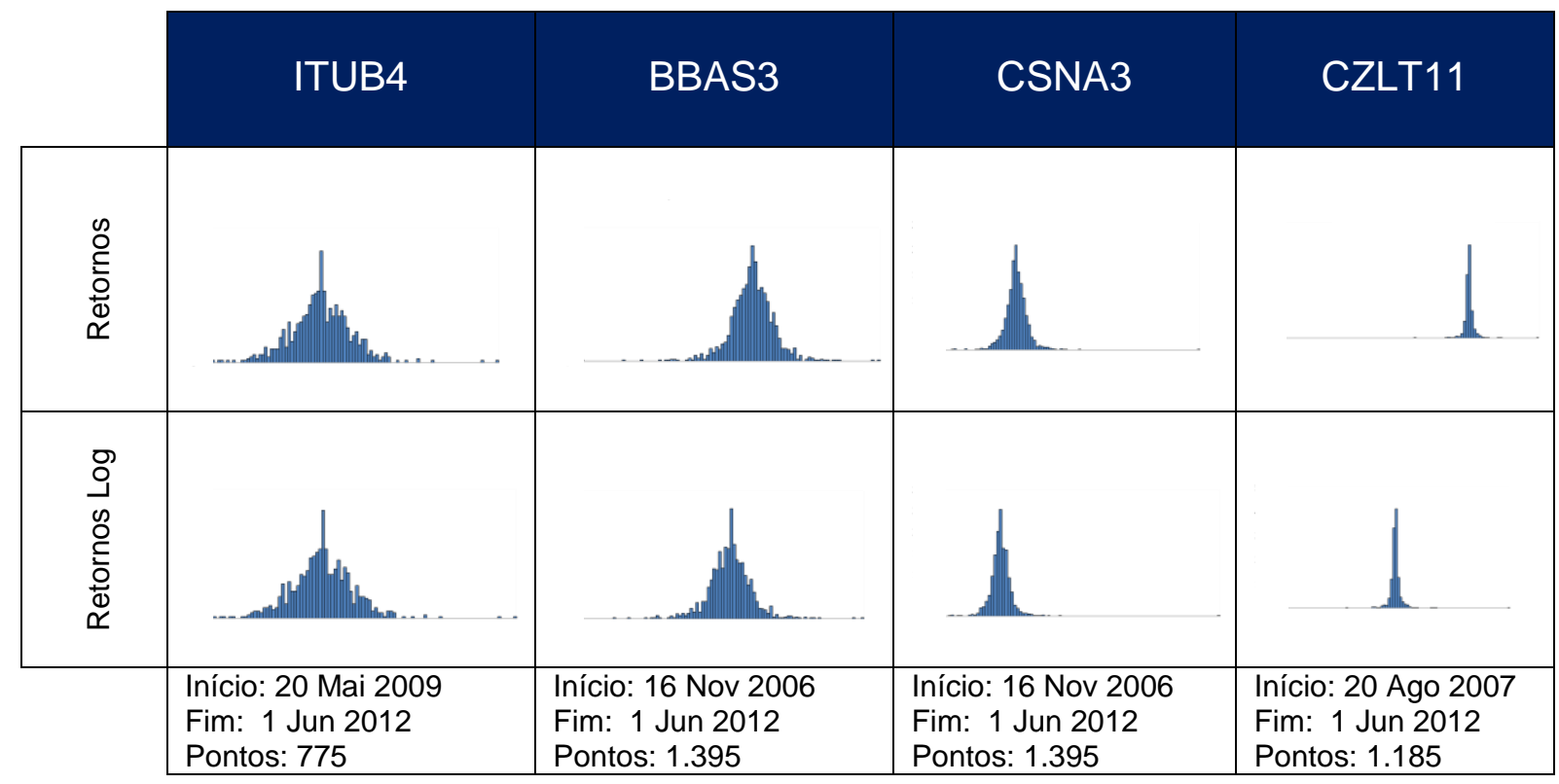

Notoriamente, as amostras apresentadas acima possuem características significativamente distintas. De fato, testes Jarque-Bera indicam que as distribuições de probabilidade dos retornos logarítmicos das duas primeiras amostras, ITUB4 e BBAS3, confirmam, com 95\% de confiança, a hipótese de normalidade. Para as distribuições dos retornos logarítmicos de CSNA3 e CLZT11, principalmente devido às suas elevadas curtoses (105,26 e 148,04, respectivamente) e às suas consequentes características leptocúrticas, rejeita-se a hipótese de normalidade.

A importância das amostras apresentadas na Tabela 1 não se limita ao conhecimento das distribuições de probabilidade dos retornos de diferentes ativos financeiros. Este exercício é também a base fundamental para o entendimento de praticamente todas as medidas de risco já apresentadas na literatura. Aplicando-se técnicas de amostragem, obtém-se estimadores de parâmetros fundamentais das distribuições de 
probabilidades dos retornos, caracterizando as principais variáveis que definem as distintas medidas de risco. 


\subsubsection{RISCO}

Situações indesejáveis do ponto de vista financeiro incentivaram, ao longo da história, a definição de métricas de medição e controle dos riscos de mercado associados a investimentos financeiros. Dentre outros exemplos, destacam-se as crises financeiras de 1929 e de 2009, ambas com consequências catastróficas para a economia global, mas que contribuíram para motivar a comunidade acadêmica a desenvolver medidas de risco cada vez mais robustas e cientificamente coerentes. Mais ainda, após os anos 1970, com as diversas mudanças ocorridas no cenário mundial (como por exemplo, o fim do regime de taxa de câmbio fixa e introdução do sistema de taxa de câmbio flutuante) e a crescente globalização, que alterou parâmetros econômicos e socioculturais, as economias dos países tornaram-se mais dependentes umas das outras. Os efeitos locais de guerra, inflação, mudanças políticas e desastres naturais passaram a refletir, em maior intensidade, em outras economias, inclusive de países e continentes diferentes daquele que os originou. Esse fato contribuiu ainda mais para a necessidade das instituições financeiras minimizarem sua exposição aos efeitos externos, os quais não podem controlar, fazendo com que a mensuração e estudo de medidas de risco fossem ganhando cada vez mais importância.

Em sua forma mais geral, o risco pode ser definido como o produto do resultado de um evento indesejado, medido em valores monetários, por sua probabilidade de ocorrência. A determinação deste evento indesejado e o conhecimento de sua probabilidade de ocorrência representam o foco da definição de diversas medidas de risco. Mais especificamente, JORION (1997) indica que risco pode ser definido como a variabilidade de resultados inesperados, seja de preços de ações, taxas de câmbio, taxas de juros, etc. ARTZNER (1999) enfatiza que o risco está relacionado à variabilidade dos valores futuros das posições de uma carteira devido às mudanças 
de mercado e efeitos nas variáveis aleatórias que compõem e caracterizam os investimentos. Ambas definições podem ser representadas formalmente por diversas medidas de risco atualmente disponíveis na literatura.

Embora eventos recentes tenham incentivado o desenvolvimento de medidas de risco cada vez mais robustas, o início dos estudos sobre risco não é recente. Seus primórdios datam de 1738, quando Bernoulli definiu pela primeira vez o conceito de Função Utilidade ${ }^{3}$ (BERNOULLI, 1738). Ainda que revolucionária em termos econômicos, a aplicação da função utilidade para medir riscos de investimentos apresenta uma dificuldade: a subjetividade. Funções utilidades costumam assumir forma exponencial, logarítmica, potencial, quadrática, etc., e variam de acordo com as preferências de um determinado agente econômico. Tal dificuldade foi parcialmente superada na metade do século XX, com a introdução, em 1952, da Teoria Moderna de Carteiras de Investimentos (MPT - Modern Portfolio Theory, do inglês), desenvolvida por Harry Markowitz. Em trabalho considerado revolucionário e ponto de partida para desenvolvimentos modernos de métricas de mensuração de risco, MARKOWITZ (1952) desenvolveu o modelo de Média-Variância para avaliação de carteiras de investimentos, introduzindo, pela primeira vez, o conceito de diversificação (RUBINSTEIN, 2002). Nele, demonstra-se que a diversificação de um investimento (i.e. a aplicação do capital inicial disponível em dois ou mais ativos) permite atingir melhores composições entre risco e retorno quando comparado a investimentos em um único ativo (BREALEY-MEYERS, 2003). A métrica de risco

\footnotetext{
${ }^{3} \mathrm{~A}$ utilidade pode ser definida como uma medida de satisfação relativa de um agente da economia. A análise de sua variação permite explicar o comportamento que resulta em opções tomadas por cada agente para aumentar sua satisfação, e é comumente usada em economia para estudar decisões de consumo entre opções de bens e serviços. Esta grandeza, porém, apresenta apenas dimensão ordinal, não existindo uma dimensão universal. A modelagem do conceito de utilidade resulta em uma função matemática denominada Função Utilidade (SARAIVA, 2002).
} 
desenvolvida por Markowitz foi o segundo momento central da distribuição de probabilidade dos retornos de um determinado ativo. Assim, $\sigma^{2}{ }_{R}=E\left[(R-\mu)^{2}\right]$, onde $\mu=E(R)$ é a média ou esperança dos retornos. Esta métrica, comumente denominada volatilidade, não só permitiu o alinhamento e a padronização conceitual da mensuração de risco, mas também gerou a noção de que certas composições de carteiras de investimentos podem apresentar configurações entre risco e retorno mais vantajosas que outras. Analisando a covariância dos retornos de dois ativos $i$ e $j$ (i.e. $\left.\sigma_{R_{i} R_{j}}=E\left[\left(R_{i}-E\left(R_{i}\right)\right)\left(R_{j}-E\left(R_{j}\right)\right)\right]\right)$, pode-se verificar que carteiras compostas por ativos de covariância negativa apresentam menor risco, a um dado nível de retorno, quando comparados a carteiras compostas por ativos de covariância positiva.

A contribuição do modelo de Markowitz para a ciência dos investimentos o logrou o prêmio Nobel das Ciências Econômicas em 1990, e seu modelo é o mais frequentemente utilizado por instituições financeiras em todo o mundo nos dias de hoje (ESTRADA, 2003), além de premissa básica para importantes métodos de precificação de ativos, como o Capital Asset Princing Model - CAPM (LUENBERGER, 2008). Embora revolucionário e sofisticado, atualmente entende-se que o modelo de MARKOWITZ (1952) apresenta algumas deficiências do ponto de vista científico, dentre os quais se destacam: (1) a aplicação exclusiva a distribuições simétricas de probabilidade dos retornos quando o objetivo é analisar perdas, (2) a não consideração de diferenças entre desvios negativos (perdas) e positivos (ganhos), e (3) a desconsideração de análises da cauda de distribuição de probabilidade dos retornos, sendo frágil para cenários de estresse. Porém, dada sua importância no estudo de investimentos financeiros e sua ampla utilização prática até os dias de hoje, o Modelo de Markowitz será aprofundado neste trabalho. 
Paralelamente ao trabalho desenvolvido por Markowitz, ROY (1952) desenvolveu o Safety First Criterion, no qual o risco é medido como a probabilidade do retorno de uma dada carteira estar abaixo de um nível pré-definido, considerado desastroso. Este trabalho representa a primeira menção do conceito de medidas de risco chamado Below-Target Models, ou Modelos Abaixo da Meta, sendo uma introdução ao conceito de avaliação das caudas de distribuição dos retornos como forma de medir o risco (ROMAN, 2008). Assim, seja $R$ o retorno de um dado investimento e $\tau$ o nível de retorno definido como desastroso, o Safety First Criterion é representado formalmente como $P(R \leq \tau)$, uma medida de probabilidade. Sua aplicação, porém, ficou limitada à arbitrariedade da determinação de qual seria o nível retorno tomado como referência, não sendo amplamente utilizada na prática.

Embora o Safety First Criterion não tenha seu desenvolvimento prático aprofundado, seus conceitos foram de suma importância para o desenvolvimento de novas medidas de risco, principalmente no que tange a observação de distribuições assimétricas de probabilidades dos retornos, com foco no lado da distribuição que representa as perdas (ou downside risk, do inglês). Foi então na década de 1970 que MARKOWITZ (1970) desenvolveu o modelo dos Momentos Parciais (Partial Moments), o qual considera a semi-variância como medida de Risco. A semi-variância amostral pode ser definida como $\varsigma_{i}=\int \operatorname{Max}\left[0,\left(E\left(R_{i t}\right)-R_{t}\right)\right]^{2} d t$ (Andrade, 2006), sendo $\varsigma_{i}$ a semivariância do ativo $i, R_{i t}$ é o retorno do ativo $i$ no instante $t$ e $E\left(R_{i}\right)$ a esperança dos retornos do ativo $i$. Esta definição garante a consideração apenas ao lado indesejável da distribuição de probabilidades dos retornos (MARKOWITZ, 1970). Em paralelo, FISHBURN (1977) e BAWA (1978) aprofundaram os estudos através do desenvolvimento do modelo $(\alpha, \tau)$, utilizando o menor momento parcial (Lower Partial 
Moment) como medida de risco, em trabalho que consolida os conceitos das medidas de risco desenvolvidas anteriormente.

Até as décadas de 1970 e 1980, métodos computacionais sofisticados para a solução de problemas de otimização quadrática (ou não lineares) de grande porte não eram disponíveis como nos dias de hoje (PEROLD, 1984), incentivando acadêmicos a desenvolverem métricas de risco lineares. Assim, em 1991, KONNO e YAMAZAKI (1991) propuseram a utilização do primeiro momento absoluto da distribuição de retornos como métrica de risco (RIBEIRO, 2004), em modelo denominado Mean Absolute Deviation (MAD), aperfeiçoando o trabalho pioneiro de SHARPE (1971). Formalmente, $\operatorname{MAD}\left(R_{i}\right)=E\left[\left|R_{i}-\mu\right|\right]$, o que leva o problema de composição de carteiras de investimentos a um problema de programação linear, representando uma alternativa ao modelo da Média-Variância. Porém, a função absoluta definida acima apresenta descontinuidades na derivada, o que dificulta sua otimização, seja através de métodos analíticos ou numéricos - dada a quantidade de restrições inerentes ao problema de otimização - e, portanto, sua aplicação prática.

Ainda na década de 1990, dando continuidade ao desenvolvimento de medidas de risco que considerem apenas retornos extremamente indesejáveis (ou seja, situados na cauda da distribuição de probabilidade de perdas), o G-30 propôs, em 1994, uma medida de Risco que respondesse a uma simples pergunta: "Quão grande pode ser a perda em um dado horizonte de tempo e a uma dada probabilidade?" (ROMAN, 2008). Esta métrica de Risco é denominada Valor em Risco, ou Value at Risk (VaR), do inglês, e é definida como $\operatorname{VaR}_{\alpha}\left(R_{i}\right)=-q^{\alpha}\left(R_{i}\right)=q_{1-\alpha}\left(R_{i}\right)$, sendo $R_{i}$ o retorno de um dado ativo $i$ e $q^{\alpha}$ o percentil definido a um nível de confiança $\alpha$ (G-30,1994). O Valor em Risco (VaR) é atualmente utilizado não só como uma ferramenta de gestão em 
modelos de decisão de composição ótima de carteiras de investimentos, mas também amplamente aplicado como medida regulatória de risco em todo o planeta, especialmente após a primeira publicação do texto Risk Metrics: Technical Report, a serviço público pelo banco JP Morgan, em 1994 (ROMAN, 2008).

Apesar de sua vasta aplicação, o Valor em Risco (VaR) não é considerado uma medida coerente de risco, conforme critérios definidos por ARTZNER (1999). Especificamente por não atender à propriedade da subaditividade (i.e. $\operatorname{VaR}\left(R_{1}+\right.$ $\left.\left.R_{2}\right) \leq \operatorname{VaR}\left(R_{1}\right)+\operatorname{VaR}\left(R_{2}\right)\right)$, esta medida de risco não premia necessariamente a diversificação. Ou seja, não se pode garantir que o risco de uma carteira composta por dois ativos com risco $\mathrm{VaR}_{1}$ e $\mathrm{VaR}_{2}$, respectivamente, seja igual ou menor a $\mathrm{VaR}_{1}+$ $V a R_{2}$. Além disto, seja $x$ o vetor que representa a alocação de uma quantidade prédeterminada de recursos em uma carteira, $\operatorname{com} \sum_{i} x_{i}=1$, a função $\operatorname{VaR}(\boldsymbol{x})$, em sua versão não paramétrica, apresenta diversos mínimos locais, conforme será apresentado mais adiante, dificultando sua otimização (QUARANTA e ZAFFARONI, 2008). Ainda assim, a vasta disseminação do Valor em Risco como medida de risco e sua facilidade de compreensão conceitual fazem com que esta medida seja selecionada para aprofundamento neste trabalho.

Dadas as inconveniências apresentadas pelo Valor em Risco (VaR) como medida de risco, propôs-se em 2000 a criação de uma nova medida, denominada Valor em Risco Condicional, ou Conditional Value at Risk (CVaR). Como definição, esta medida é a média dos valores que excedem o Valor em Risco, ou $\operatorname{CVaR}\left(R_{i}\right)=E\left\{\left(R_{i}\right) \mid R_{i} \leq v\right\}$, onde $R_{i}$ representa o retorno de um dado ativo $i$ e $v$ representa o Valor em Risco (VaR) da distribuição de probabilidade dos retornos deste mesmo ativo (ROCKAFELLAR e URYASEV, 2000). Esta medida de risco atende às propriedades 
definidas por ARTZNER (1999), sendo, assim, coerente (LIM, 2011). Por outro lado, sua função, representativa da modelagem da cauda da distribuição de probabilidade dos retornos, apresenta elevada complexidade, sendo sua otimização difícil e não trivial (RIBEIRO, 2004).

O Valor em Risco Condicional (CVaR) é atualmente alvo de estudo por acadêmicos em todo o globo, e técnicas sofisticadas de otimização desta função foram propostas por ROCKAFELLAR e URYASEV (2002). Assim, seu aprofundamento será parte integrante deste texto, sendo o $\mathrm{CVaR}$ também selecionado para análises mais aprofundadas neste trabalho.

A Figura 1, abaixo, resume a perspectiva histórica acerca de medidas de risco de investimentos financeiros propostas na literatura até os dias de hoje.

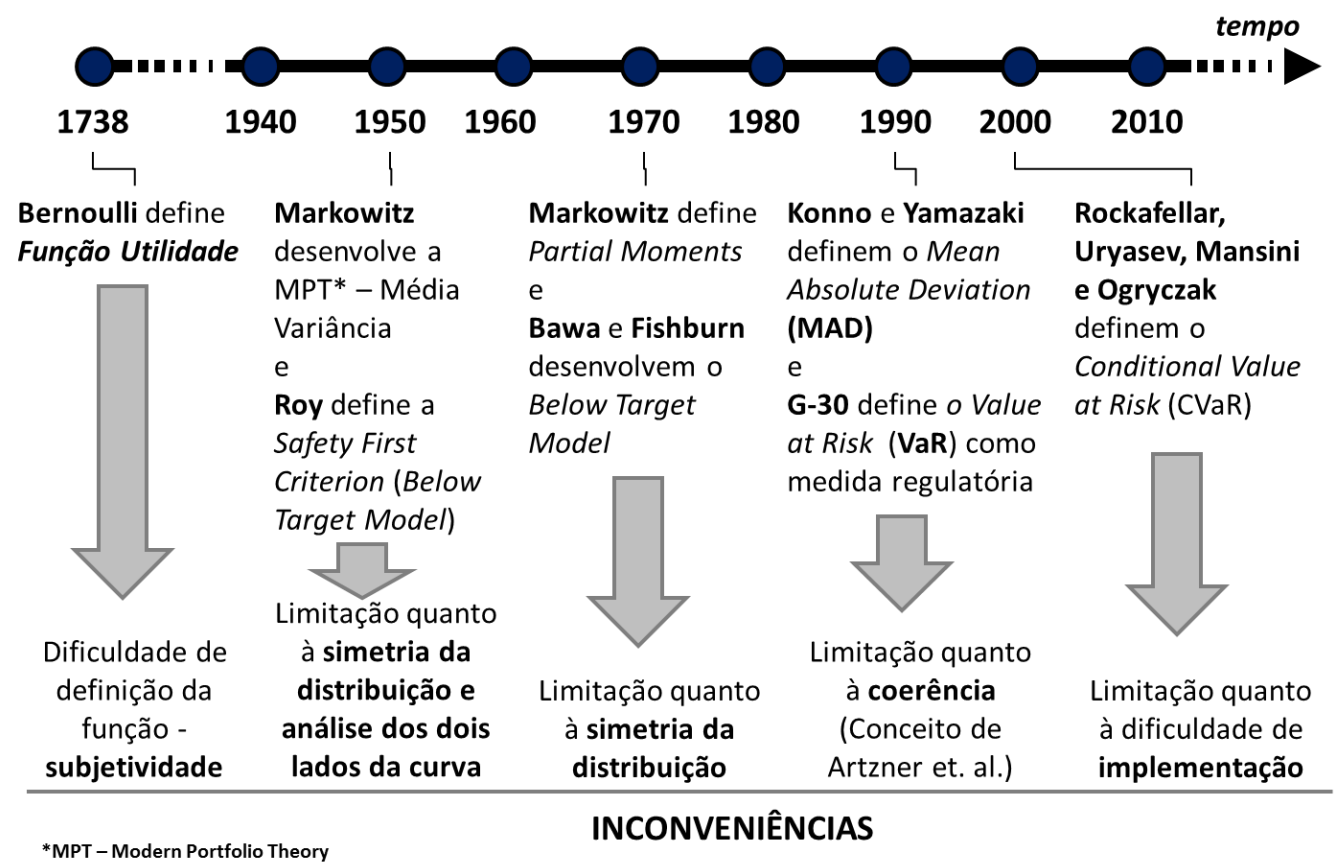

Figura 1: Resumo da revisão de literatura sobre medidas de risco de investimentos financeiros. 
Do exposto acima, pode-se classificar as principais medidas de risco propostas na literatura em duas categorias: (1) Medidas de Desvio (Deviation From Target) e (2) Medidas de Cauda (Seriedade da Perda Potencial). A primeira categoria pode, então, ser descrita em duas subcategorias: (1.1) Simétricas, as quais consideram ambos os lados da curva distribuição dos retornos, e as (1.2) Assimétricas, as quais consideram apenas o lado das perdas da distribuição de probabilidade dos retornos. A Tabela 2, abaixo, atribui estas classificações a cada uma das medidas de Risco discutidas anteriormente.

Tabela 2: Categorização e classificação das medidas de risco em investimentos financeiros propostas no período pós teoria moderna de portfólios (MPT).

\begin{tabular}{lcc}
\multicolumn{1}{c|}{ Categoria } & Descrição & Exemplos \\
\hline $\begin{array}{l}\text { Deviation from Target } \\
\text { (Desvio) }\end{array}$ & Simétricas & $\begin{array}{c}\text { Variância } \\
\text { MAD }\end{array}$ \\
\cline { 2 - 3 } & Assimétricas & $\begin{array}{c}\text { CentralSemideviation } \\
\text { Lower PartialMoments }\end{array}$ \\
\hline $\begin{array}{l}\text { Tail Risk Measures } \\
\text { (Seriedade de Perda } \\
\text { Potencial) }\end{array}$ & $\begin{array}{c}\text { Consideração do pior } \\
\text { cenário com nível de } \\
\text { confiança } \alpha\end{array}$ & $\begin{array}{c}\text { Safety First Criterion } \\
\text { Below Target Model }\end{array}$ \\
\end{tabular}

Atualmente não existe consenso entre os acadêmicos acerca de qual a medida de risco de investimentos financeiros mais adequada para aplicação prática. Assim, a literatura se concentra em dois tópicos principais: (1) a definição de novas medidas de Risco, a fim de caracterizar melhor a distribuição de probabilidades dos retornos, e (2) o aprofundamento dos estudos das medidas de risco existentes, com maior ênfase tanto àquelas que são mais utilizadas em termos práticos, tais quais a Variância e o Valor em Risco (VaR), quanto às medidas de risco vanguardistas e coerentes, como o Valor em Risco Condicional (CVaR), a fim de se analisar seu 
comportamento e, finalmente, possibilitar sua utilização como função objetivo na tomada de decisões gerenciais.

Tomando as três principais medidas de risco apresentadas na literatura ao longo do último século como objeto de aprofundamento deste trabalho, a Tabela 3, abaixo, resume suas principais características, incluindo sua categorização e suas limitações.

Tabela 3: Resumo de características das medidas de risco selecionadas para aprofundamento neste trabalho: Variância $\left(\sigma^{2}\right)$, Valor em Risco (VaR) e Valor em Risco Condicional (CVaR)

\begin{tabular}{|c|c|c|c|}
\hline Medida de Risco & Categoria & Coerência* & Limitações \\
\hline Variância $\left(\sigma^{2}\right)$ & Desvio & Sim & $\begin{array}{l}\text { - Aplicação a Distribuições Simétricas de Probabilidade; } \\
\text { - Não diferenciação entre retornos negativos (não } \\
\text { desejáveis) e positivos (desejáveis); } \\
\text { - Desconsideração da Cauda de Distribuição (fragilidade } \\
\text { para cenários de estresse - i.e. perdas significativas). }\end{array}$ \\
\hline Valor em Risco (VaR) & Cauda & $\begin{array}{c}\text { Não } \\
\text { (Subaditividade) }\end{array}$ & $\begin{array}{l}\text { - Não oferecimento de informações acerca de perdas que } \\
\text { excedam o percentil (VaR) definido a um dado nível de } \\
\text { confiança; } \\
\text { - Não Coerência. }\end{array}$ \\
\hline $\begin{array}{l}\text { Valor em Risco Condicional } \\
\text { (CVaR) }\end{array}$ & Cauda & Sim & - Dificuldade de aplicação prática. \\
\hline
\end{tabular}

As seções que seguem apresentam primeiramente o problema de composição de carteiras de investimentos como problema de otimização, em sua forma geral, e em seguida discutem este problema utilizando-se as três medidas de risco apresentadas na Tabela 3 como função objetivo. 


\subsection{O PROBLEMA DE GESTÃO DE CARTEIRAS DE INVESTIMENTOS}

Seja $A_{0}$ um valor fixo disponível para investimentos, medido em valores monetários, e $n$ uma quantidade de diferentes ativos financeiros pré-selecionados, uma carteira (ou portfólio) de investimentos é definida como um ativo obtido através da alocação de $A_{0}$ a $n$. Ou seja, $A_{0 i}=x_{i} A_{0}, \operatorname{com} \sum_{i=1}^{n} x_{i}=1$. O vetor $\boldsymbol{x}=\left[x_{1} x_{2} \ldots x_{n}\right]$ representa a alocação do montante $A_{0}$ em cada ativo $i$ que compõe a carteira, ou o peso de cada ativo na carteira, e, mais importante, representa as variáveis do problema de otimização para composição de carteiras de investimentos.

O retorno de uma carteira de investimentos é calculado pela média ponderada dos retornos individuais de cada ativo que compõe a carteira, podendo ser facilmente expresso por $R_{C}=\frac{\sum_{i=1}^{n} R_{i} x_{i} A_{0}}{A_{0}}=\sum_{i=1}^{n} R_{i} x_{i}$.

O problema de gestão de carteiras de investimentos objetiva minimizar uma certa função $\operatorname{Risco}(\boldsymbol{x})$, representativa do risco da carteira em função de sua composição, sujeito a restrições acerca do retorno $R_{C}$ esperado e determinado pelo investidor. Para definição mais precisa do problema, são necessárias duas premissas elementares representativas do comportamento racional humano (LUENBERGER, 2008):

(1) Não saciedade: o investidor prefere mais riqueza a menos riqueza;

(2) Aversão a risco: dadas duas carteiras com mesmo retorno e diferentes riscos, o investidor opta pelo menor risco.

Assim, o problema de otimização de carteiras de investimentos, em sua forma geral, é definido como: 
Minimizar: $\operatorname{Risco}(\boldsymbol{x})$

\section{Sujeito a:}

$$
\begin{aligned}
& \sum_{i=1}^{n} E\left(R_{i}\right) x_{i} \geq G \\
& \sum_{i=1}^{n} x_{i}=1 \\
& x_{i} \geq 0 ; i=1, \ldots, n
\end{aligned}
$$

A primeira restrição se refere à parametrização do modelo em relação ao retorno médio esperado da carteira, o qual necessariamente é maior ou igual ao valor mínimo estipulado pelo investidor, $G$.

A segunda restrição garante que será investida exatamente a quantidade de recursos financeiros fixada e pré-definida pelo investidor, $A_{0}$, uma vez que a soma dos pesos de todos os ativos que compõem a carteira é unitária.

Por fim, a terceira restrição garante alocação não negativa dos recursos nos ativos que constituem a carteira. Ou seja, esta restrição garante que nenhum ativo tenha alocação inferior a zero, o que representaria uma venda a descoberto ${ }^{4}$.

Apresentado o problema em sua forma geral, segue-se, nas próximas seções, com a sua aplicação específica das medidas de risco selecionadas para aprofundamento neste trabalho: a Variância, o Valor em Risco (VaR) e o Valor em Risco Condicional (CVaR), incluindo uma discussão acerca das suas superfícies Risco $(\boldsymbol{x})$ características e dos métodos atualmente disponíveis para suas soluções.

\footnotetext{
${ }^{4}$ Venda a descoberto (ou short selling, do inglês) é uma prática financeira que consiste na venda de um ativo financeiro ou derivativo que não se possui, esperando que seu preço caia para então comprálo de volta e lucrar na transação com a diferença (O'NEIL, 2005).
} 


\subsubsection{VARIÂNCIA E O MODELO DE MARKOWITZ}

Conforme introduzido anteriormente, a ideia original do modelo de Markowitz, publicado em 1952, consiste no desenvolvimento de uma métrica universal de mensuração de risco de mercado para um dado investimento. A medida de risco utilizada em seu modelo original é o segundo momento central da distribuição de probabilidade dos retornos.

Agora, seja $\sum$ a matriz de covariância entre os ativos que compõem uma determinada carteira, em que $\sum_{i j}=\operatorname{cov}\left(R_{i}, R_{j}\right)=\sigma_{R_{i} R_{j}}=E\left[\left(R_{i}-\mu_{R_{i}}\right)\left(R_{j}-\mu_{R_{j}}\right)\right]$, ou $\sum=$ $\left[\begin{array}{ccc}\sigma_{1}^{2} & \cdots & \sigma_{1 n} \\ \vdots & \ddots & \vdots \\ \sigma_{n 1} & \cdots & \sigma_{n}^{2}\end{array}\right]$, uma matriz simétrica com as variâncias individuais das séries históricas de cada ativo que compõe a carteira na diagonal principal, e com as covariâncias entre estes ativos, dois a dois, para todo $i \neq j$, tem-se que o risco desta carteira de investimentos é $\operatorname{Risco}(\boldsymbol{x})=\sigma_{C}^{2}=\boldsymbol{x}^{\prime} \sum \boldsymbol{x}$, uma função quadrática que representa a variância da carteira em função de sua composição.

Desta definição surgiu originalmente o conceito de diversificação de Markowitz, sob a hipótese de que a composição de uma carteira contendo ativos com covariância negativa pode apresentar uma melhor relação entre risco e retorno quando comparada ao investimento em um único ativo (LUENBERGER, 2008).

O problema de composição de carteiras de investimentos utilizando a variância como medida de risco pode ser expresso conforme segue. 
Minimizar: $\operatorname{Risco}(\boldsymbol{x})=\boldsymbol{x}^{T} \sum \boldsymbol{x}$,

\section{Sujeito a:}

$$
\begin{aligned}
& \sum_{i=1}^{n} E\left(R_{i}\right) x_{i} \geq G \\
& \sum_{i=1}^{n} x_{i}=1 \\
& x_{i} \geq 0 ; i=1, \ldots, n
\end{aligned}
$$

Na prática, os parâmetros da função $\boldsymbol{x}^{\prime} \sum \boldsymbol{x}$ são estimados através da avaliação amostral das séries históricas dos retornos dos ativos que compõem uma determinada carteira. Um exemplo de aplicação dos conceitos apresentados acima está representado na Figura 2, abaixo, para uma carteira composta por três ativos, assumindo diferentes composições de $\boldsymbol{x}$.

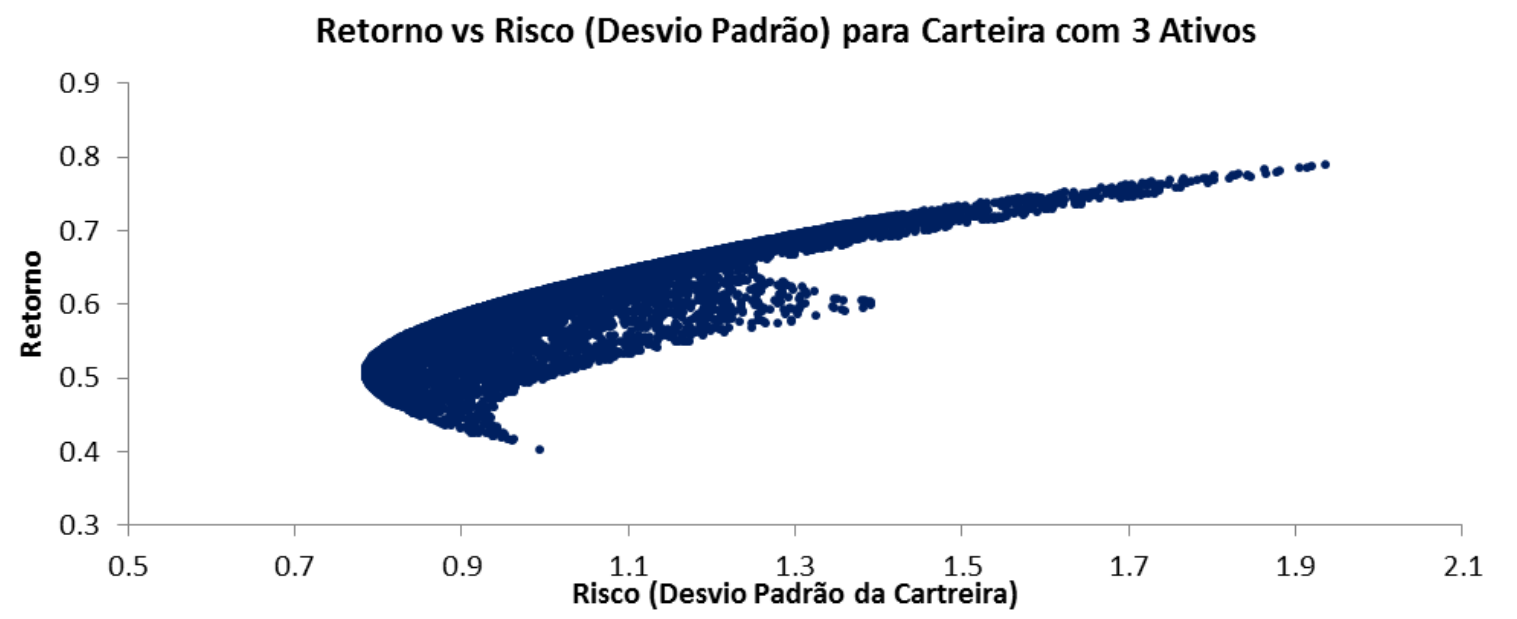

Figura 2: Curva Retorno versus Risco para uma carteira composta por três ativos.

Como as premissas do problema de composição de carteiras de investimentos apresentam objetivos conflitantes (i.e. não saciedade, maximizando o retorno, e aversão ao risco, minimizando as perdas potenciais), nota-se, pela Figura 2, que apenas uma pequena parcela das diferentes composições de carteira possíveis satisfaria ambas as premissas. Esta região do gráfico é obtida através da solução de 
diversos problemas de otimização, minimizando a função $\operatorname{Risco}(\boldsymbol{x})=\boldsymbol{x}^{\prime} \sum \boldsymbol{x}$ e parametrizando o retorno mínimo desejado pelo investidor através da restrição $R_{C} \geq$ G. Os resultados destes problemas de otimização assumindo diferentes valores de $G$ estão apresentados na Figura 3, abaixo. A esta curva dá-se o nome de Fronteira Eficiente de Markowitz, um clássico exemplo de Fronteira de Otimalidade de Pareto para objetivos conflitantes conforme definido em PAPALAMBROS (2000).

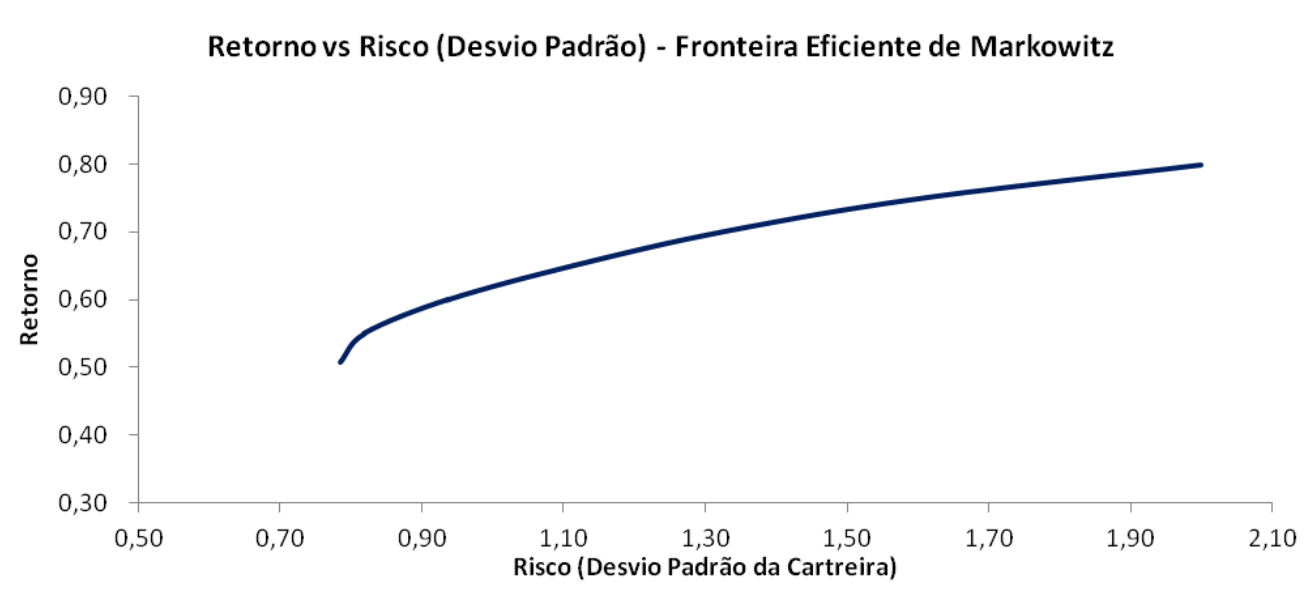

Figura 3: Fronteira Eficiente de Markowitz para uma carteira composta por três ativos.

Ou seja, quaisquer composições de carteira que não estejam sobre esta fronteira apresentam uma relação entre retorno e risco inferior (i.e. maior nível de risco para um dado retorno, ou menor retorno para um dado nível de risco) aos pontos que sobre ela residem.

A princípio, a decisão de utilização de uma dada composição de carteira sobre a Fronteira Eficiente está ligada ao apetite por risco do investidor, reforçando o conceito de função utilidade, a qual propõe uma maneira de ordenar os investimentos de acordo com o perfil de risco do investidor (LUENBERGER, 2008), considerando que maiores riscos implicam em maiores retornos, e vice-versa. 
Observa-se que o problema de composição de carteiras apresentado acima possui uma função objetivo quadrática, sujeita a restrições lineares. Desta forma, a solução do problema é facilmente obtida através de métodos vastamente utilizados para problemas desta natureza, tais quais o método de Kuhn-Tucker. Suas limitações, portanto, residem na hipótese de simetria das distribuições de probabilidade dos retornos dos ativos que compõem a carteira e à fragilidade para representação de cenários de estresse (risco de cauda). 


\subsubsection{VALOR EM RISCO (VaR)}

Dadas as limitações apresentadas para a utilização da variância como medida de risco, principalmente no que tange a desconsideração de análises da cauda de distribuição de probabilidade, fazem-se necessárias as definições de outras medidas de risco com objetivo específico de representar cenários de estresse (i.e. perdas significativas). Esta foi uma das motivações para o desenvolvimento do Valor em Risco (VaR) como medida de risco, originalmente proposto pelo G-30, em 1994. De fato, o Valor em Risco (VaR) mede "a pior perda esperada em um dado horizonte de tempo sob condições normais de mercado e a um dado nível de confiança" (JORION, 1997).

O Valor em Risco (VaR) é medido na mesma unidade dos resultados de uma instituição financeira, em moeda corrente, o que facilita sua interpretação imediata. Assim, acionistas e gestores de carteiras podem decidir facilmente se estão confortáveis ou não com um dado nível de exposição ao risco, realizando ajustes necessários em caso de resposta negativa (JORION, 1997).

Devido à sua vasta aceitação no mercado e à sua fácil interpretação, o Valor em Risco (VaR) é utilizado atualmente para diferentes propósitos, incluindo, mas não limitado a:

(1) reporte de informações e avaliação de performance, facilitando a comunicação e interpretação dos acionistas acerca dos riscos financeiros de uma dada operação, (2) alocação de recursos em instituições financeiras, estabelecendo limites de posição na alocação de recursos capitais, (3) regulação, garantindo os níveis mínimos de reserva a um dado risco financeiro, (4) instituições não-financeiras, especialmente multinacionais com fluxos de caixa em diversas moedas, e (5) gestão de carteiras, possibilitando medir o risco de mercado de forma integrada. Em suma, o grande benefício da utilização do Valor em Risco (VaR) como medida de Risco é 
provavelmente a imposição de uma metodologia estruturada para o pensamento crítico acerca do risco, forçando instituições a confrontar sua exposição a riscos financeiros e assim estabelecer métodos de gestão de risco tanto no front-office quanto no back-office de suas operações (JORION, 1997).

Essencialmente, o Valor em Risco (VaR) mede um percentil, a um dado nível de confiança, representando o limiar da cauda da distribuição de probabilidades.

Seja $A_{0}$ a quantidade de recursos disponível para investimentos e seja $R$ o retorno esperado deste investimento, tem-se o valor da carteira ao final do horizonte de tempo considerado, $A=A_{0}(1+R)$. Como anteriormente, o retorno esperado da carteira e sua volatilidade são representados por $E\left(R_{C}\right)$ e $\sigma_{C}$, respectivamente. Agora, definindo o menor valor desta carteira $\left(A^{*}\right)$ a um dado nível de confiança $(\alpha)$, tem-se: $A^{*}=$ $A_{0}\left(1+R^{*}\right)$. O VaR é, então, definido como a perda em moeda corrente relativa ao retorno esperado: $\operatorname{VaR}(A)=v=-A_{0}\left(R^{*}-E(A)\right)$. Em alguns casos, o VaR pode ser calculado em termos absolutos, e não em relação à média, como: $\operatorname{VaR}(A)=A_{0}-A^{*}=$ $-A_{0} R^{*}$ (JORION, 1997).

Graficamente, e tomando como exemplo uma distribuição de probabilidades simétrica, o Valor em Risco (VaR) pode ser representado conforme a Figura 4, abaixo.

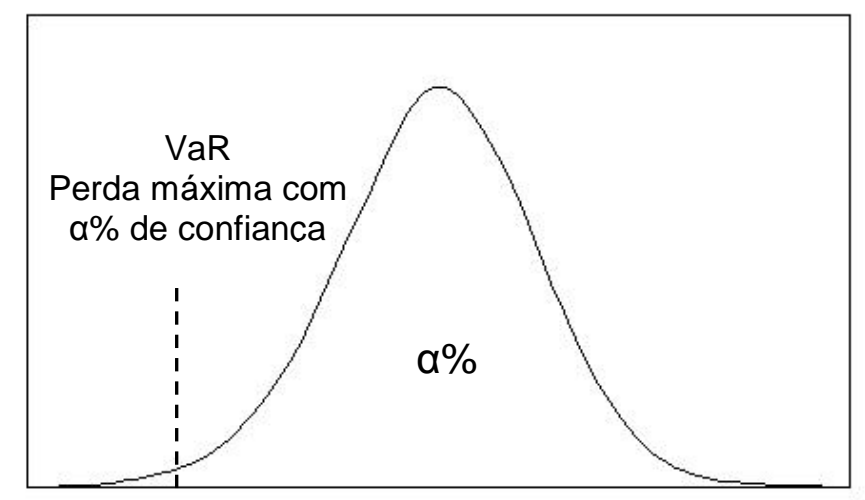

Figura 4: Representação gráfica do Valor em Risco (VaR) para um nível de confiança a e para uma distribuição simétrica de probabilidades de retornos. 
Ainda segundo JORION (1997), o Valor em Risco pode ser calculado através de diferentes métodos, dependendo da distribuição de probabilidades dos retornos. Dentre estes, destacam-se:

1) Método Paramétrico: aplica-se a distribuições Gaussianas de probabilidades de retornos, e é calculado através da formulação $\operatorname{VaR}_{\alpha}(A)=\mu-z_{\alpha} \sigma$, onde $\mu$ representa a média dos retornos, $\sigma$ o desvio padrão da série histórica dos retornos, e $\mathrm{z}_{\alpha}$ o inverso da distribuição cumulativa normal;

2) Método Não Paramétrico: também é chamado de método da série histórica e se aplica a distribuições assimétricas de probabilidades de retornos, consistindo no uso de estatísticas de ordem. Seja $\boldsymbol{R}$ um conjunto de observações de retornos de um ativo, um estimador de percentil é dado por $M_{[\alpha T: T]}(R)$, em que $M_{[1: T]}$ é o mínimo de $R$ e $M_{[T: T]}$ o máximo. $M_{[\alpha T: T]}$ é, então, o $\alpha T$ - ésimo valor em ordem crescente. Ou seja, segundo o modelo de série histórica para o cálculo do VaR é preciso, inicialmente, selecionar uma amostra de retornos para o ativo, ordenar estes valores e escolher um valor de acordo com a função $M_{[\alpha T: N]}(R)$, em que $\alpha$ é o nível de confiança desejado. (RIBEIRO, 2004).

Outras técnicas computacionalmente intensivas para o cálculo do $\mathrm{VaR}$, tais quais o bootstrapping ou a simulação Monte Carlo, também são comumente empregadas (RIBEIRO, 2004).

Novamente, é prática comum a amostragem de séries históricas de retornos para se obterem estimadores dos principais parâmetros que caracterizam sua distribuição de probabilidade, e logo os parâmetros da função Valor em Risco. Analogamente ao método de cálculo paramétrico da variância para uma carteira, pode-se calcular o 
Valor em Risco (VaR) de uma carteira em função de sua composição através da relação (JANABI, 2012):

$$
\operatorname{VaR}(\boldsymbol{x})=\operatorname{VaR}_{C}=\left[\boldsymbol{v}^{T} \boldsymbol{\Gamma} \boldsymbol{v}\right]^{1 / 2}
$$

Onde $\boldsymbol{v}$ representa o vetor dos $\mathrm{VaR}$ individuais de cada ativo, em função de seus pesos individuais, $\boldsymbol{x}$, e $\boldsymbol{\Gamma}$ representa a matriz de correlação entre os ativos que compõem a carteira, sendo:

$$
\Gamma=\left[\begin{array}{ccc}
1 & \cdots & \rho_{1 n} \\
\vdots & \ddots & \vdots \\
\rho_{n 1} & \cdots & 1
\end{array}\right]
$$

A matriz $\Gamma$ é simétrica com diagonal principal unitária, indicando a correlação entre a série histórica dos retornos do ativo $i$ com ele mesmo. Os outros valores da matriz de correlação representam o Coeficiente de Correlação de Pearson, obtido através da amostra dos retornos da série histórica entre cada ativo $i$ e $j$, dois a dois.

No caso do método da série histórica (não paramétrico), basta substituir a ordenação dos Valores em Risco do ativo pela ordenação dos diferentes valores do VaR da carteira, e assim aplicar a técnica conforme apresentada anteriormente.

Assim, o problema de composição ótima de carteira de investimento considerando o Valor em Risco como medida de risco pode ser escrito como segue. 
Minimizar: $\operatorname{Risco}(\boldsymbol{x})=\operatorname{VaR}(\boldsymbol{x})=\left[\boldsymbol{v}^{T} \boldsymbol{\Gamma} \boldsymbol{v}\right]^{1 / 2}$

Sujeito a:

$$
\begin{aligned}
& \sum_{i=1}^{n} E\left(R_{i}\right) x_{i} \geq G \\
& \sum_{i=1}^{n} x_{i}=1 \\
& x_{i} \geq 0 ; i=1, \ldots, n
\end{aligned}
$$

A título de exemplo, a Figura 5, abaixo, mostra o Valor em Risco (VaR) calculado para uma carteira composta por dois ativos, Itaú-Unibanco (ITUB4) e Petrobrás (PETR4), ambos negociados na BOVESPA e com amostra da série histórica entre 27 Maio 2009 e 11 Maio 2012, totalizando 718 observações. Os cálculos foram realizados tanto através do método paramétrico quanto através do método não paramétrico, conforme se observa na figura. Para facilitar a visualização da representação dos resultados, toma-se $\lambda=x_{1}$ e $x_{2}=1-\lambda$, com $\lambda$ representando a carteira, em abordagem similar a RIBEIRO (2004).

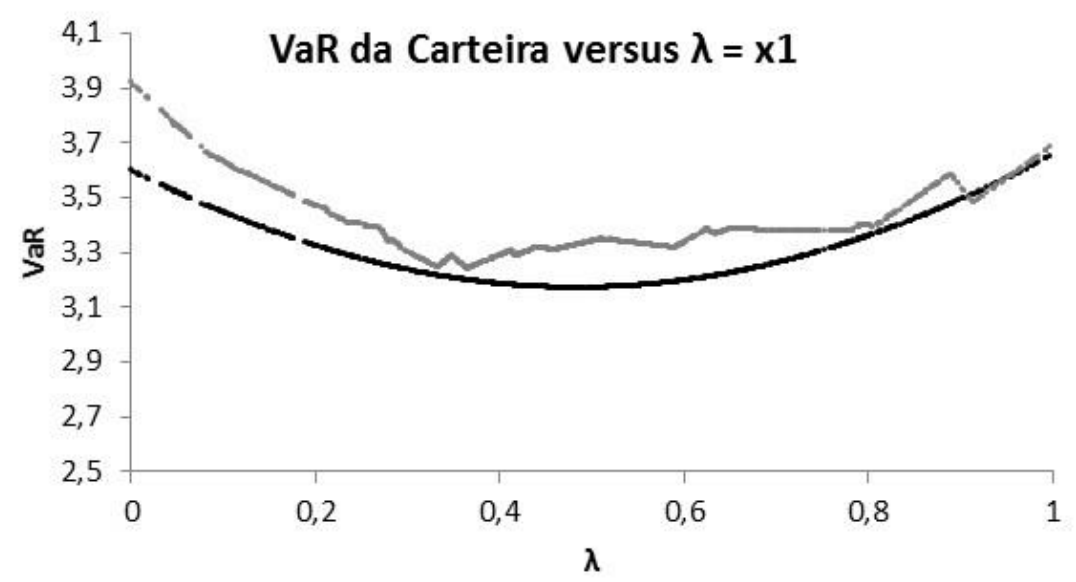

Figura 5: Valor em Risco (VaR) calculado através dos Métodos Paramétrico e Não Paramétrico, para carteira composta dos ativos ITUB4 e PETR4, com amostras de retornos logarítmicos obtidas entre os períodos 27 Maio 2009 e 11 Maio 2012, totalizando 718 observações. 
A análise da Figura 5, acima, mostra que a hipótese de normalidade dos retornos assumida na aplicação do método paramétrico não é necessariamente verdadeira, de forma que os estimadores obtidos através das amostras de séries históricas de retornos dos ativos, assumindo normalidade, apresenta erro. De fato, COSTA e BAIDYA (2001) verificaram empiricamente a não conformidade de diversos ativos brasileiros com a hipótese de simetria na distribuição de probabilidade dos retornos. A avaliação da superfície $\operatorname{VaR}(\boldsymbol{x})$ através do seu método mais amplo de cálculo, o não paramétrico, relaxa esta hipótese, porém sua otimização se torna significativamente mais complexa, principalmente devido à existência de diversos mínimos locais. É neste contexto que se propõe, com este trabalho, uma nova metodologia para otimização de carteiras de investimentos: através da simulação de diferentes cenários obtém-se pontos da superfície de resposta $\operatorname{VaR}(\boldsymbol{x})$, sobre os quais se aplicam métodos de interpolação universal que consideram incertezas e que fornecem aproximações desta superfície, suavizando-a e possibilitando sua otimização global.

Apesar de o Valor em Risco (VaR) fornecer informações sobre a cauda da distribuição de probabilidade dos retornos e ser vastamente utilizada na prática, SZEGÖ (2002) apresenta diversos problemas relacionados ao uso desta medida de Risco, a listar:

(1) O VaR não mede as perdas que excedem o seu valor calculado. Ou seja, esta medida de Risco não oferece informações sobre a dispersão da cauda da distribuição além do seu valor a um determinado nível de confiança;

(2) $\mathrm{O} V a R$ pode apresentar resultados conflitantes para diferentes níveis de confiança;

(3) O VaR não é uma medida de risco coerente. 
Com o intuito de superar as limitações apresentadas acima, ROCKAFELLAR e URYASEV (2000) desenvolveram o Valor em Risco Condicional (CVaR). 


\subsubsection{VALOR EM RISCO CONDICIONAL (CVaR)}

O Valor em Risco Condicional (CVaR) é definido como a média dos valores que excedem o Valor em Risco (VaR), para um determinado nível de confiança. Ou seja, considerando a ocorrência do pior cenário de retornos (cenário de estresse), o CVaR fornece o valor médio da cauda de distribuição de probabilidade. Tal definição garante que o VaR nunca exceda o CVAR em valor absoluto (ROCKAFELLAR e URYASEV, 2000).

Novamente, seja $x \in \mathbf{X} \subset \mathrm{R}^{\mathrm{N}}$ um vetor de decisão representando uma carteira de ativos, $\mathbf{y} \in \mathbf{Y} \subset \mathrm{R}^{\mathrm{N}}$ os valores futuros dos retornos dos ativos que compõe essa carteira e $\mathrm{z}=\mathrm{f}(\mathrm{X}, \mathrm{Y})$ a função de perdas da carteira, o CVaR será dado por (QUARANTA e ZAFFARONI, 2008):

$$
\Psi(\mathrm{x}, v)=\mathrm{E}\{\mathrm{y} \mid \mathrm{f}(\mathrm{x}, \mathrm{y}) \leq v\}
$$

Onde $v$ representa o Valor em Risco (VaR) da carteira.

Graficamente, e novamente tomando como exemplo uma distribuição de probabilidades simétrica, o Valor em Risco Condicional (CVaR) pode ser representado conforme a Figura 6, abaixo. 


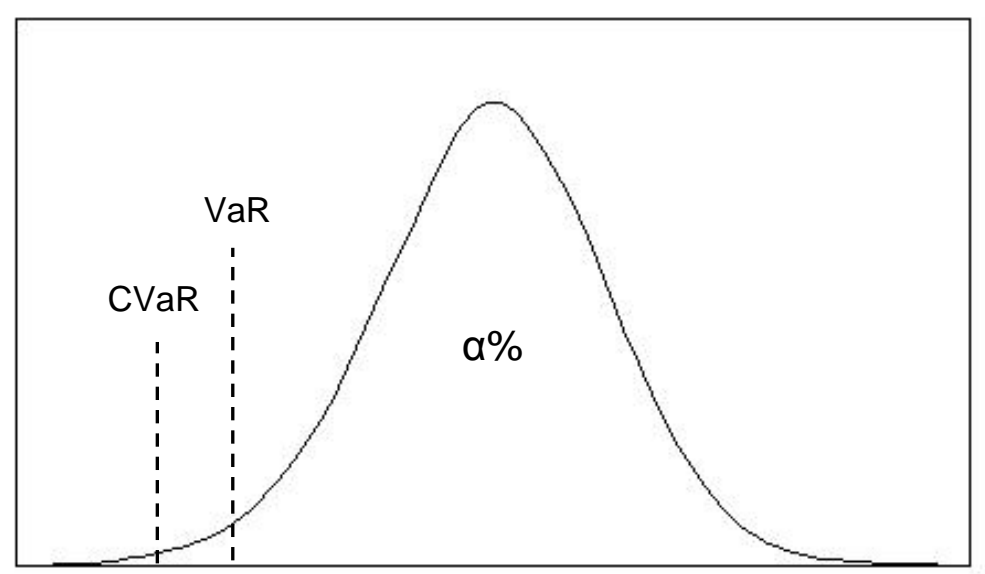

Figura 6: Representação gráfica do Valor em Risco (VaR) e do Valor em Risco Condicional (CVaR) para um nível de confiança a e para uma distribuição simétrica de probabilidades de retornos.

Observa-se que o Valor em Risco (VaR) e o Valor em Risco Condicional (CVaR) medem propriedades diferentes da distribuição dos retornos, pois o primeiro refere-se a percentil e o segundo à média da cauda de distribuição dos retornos (PFLUG, 2000). Assim, o Valor em Risco Condicional (CVaR) apresenta consistência com o Valor em Risco (VaR) apenas para distribuições normais ou elípticas (ROCKAFELLAR e URYASEV, 2002).

Além disto, o Valor em Risco Condicional (CVaR) depende, a princípio, do Valor em Risco (VaR) para sua determinação. Mais ainda, através do método não paramétrico (i.e. estatística de ordem) apresentado para o cálculo do VaR, é possível se calcular, simultaneamente, o VaR e o CVaR para amostras de séries históricas dos de retornos de uma carteira de investimentos, através da simulação de cenários. Como ilustração, considera-se o mesmo exemplo da seção anterior (i.e. uma carteira de dois ativos composta por Itaú-Unibanco (ITUB4) e Petrobrás (PETR4), ambos negociados na BOVESPA e com séries históricas entre 27 Maio 2009 e 11 Maio 2012, totalizando 
718 observações). Novamente, toma-se $\lambda=x_{1}$ e $x_{2}=1-\lambda$, com $\lambda$ representando a carteira. Os resultados estão apresentados na Figura 7, abaixo.

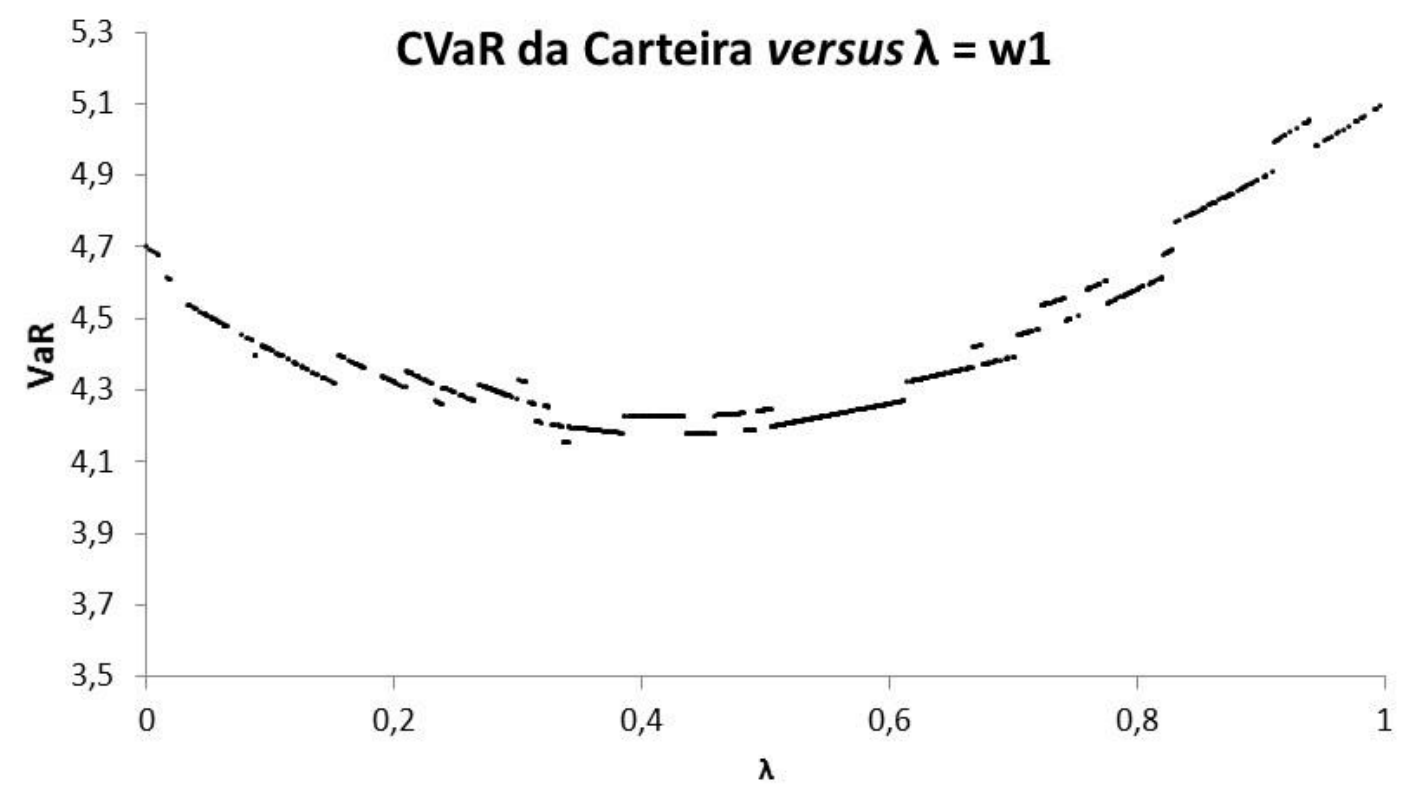

Figura 7: Valor em Risco Condicional (CVaR) calculado pela estimação do Valor em Risco (VaR) através do método Não Paramétrico, para carteira composta dos ativos ITUB4 e PETR4, entre os períodos 27 Maio 2009 e 11 Maio 2012.

O comportamento da curva apresentada na Figura 7, incluindo novamente a existência de diversos mínimos locais e descontinuidades, dificulta substancialmente sua otimização através de métodos convencionais, consequentemente inibindo sua aplicação prática em larga escala. Contornando esta dificuldade, ROCKAFELLAR e URYASEV (2002) propuseram uma formulação para o CVaR que possibilita sua transformação em problema de programação linear através da simulação de cenários.

Tomando a função $\mathrm{z}=\mathrm{f}(\mathrm{x}, \mathrm{y})$, representativa das perdas de uma carteira, uma variável aleatória de distribuição em $R$ induzida pelo vetor $\mathrm{Y}$, com densidade $p(\mathrm{Y})$, o retorno de uma carteira é calculado através do somatório do produto entre o peso dos ativos e seus retornos individuais. A função perda é, então, o negativo deste retorno, ou seja: 


$$
f(X, Y)=-\left[x_{1} y_{1}+\cdots+x_{n} y_{n}\right]=-x^{\prime} Y
$$

Observa-se que, quando o resultado desta função é negativo, representa um retorno positivo, ou um ganho.

Portanto, pode-se definir a média e a variância da função perda associado à carteira $\boldsymbol{x}$ em termos da média $\boldsymbol{m}$ e da matriz de covariância $\sum$ dos retornos. Assim, tem-se:

$$
\begin{gathered}
\mu=-x^{T} m \\
\sigma^{2}=x^{\prime} \sum x
\end{gathered}
$$

A probabilidade de que $f(\mathrm{X}, Y)$ não exceda um nível $v=V a R$ é:

$$
\Psi(x, v)=\int_{f(x, Y) \leq \nu} p(Y) d y
$$

Como forma de simplificar o cálculo do Valor em Risco Condicional (CVaR), assumese que $\Psi(x, v)$ é não decrescente e contínua em relação a $v$. Essa função determina o comportamento da variável aleatória e é fundamental para determinação do risco.

Para um nível de probabilidade $\alpha \in$ ]0; 1, o Valor em Risco (VaR) e o Valor em Risco Condicional (CVaR) podem ser definidos como:

$$
\begin{gathered}
v=\operatorname{VaR}(\mathrm{X}, \alpha)=\min \{v \in \mathrm{R}: \Psi(\mathrm{X}, v) \geq \alpha\}, \mathrm{e} \\
\mathrm{F}_{\alpha}(X, v)=\operatorname{CVaR}(\mathrm{X}, v)=v+\frac{1}{(1-\alpha)} \int_{\mathrm{Y} \in \mathrm{R}^{\mathrm{m}}}[\mathrm{f}(\mathrm{X}, \mathrm{Y})-v]^{+} \mathrm{p}(\mathrm{Y}) \mathrm{dy}
\end{gathered}
$$

Onde:

$[\mathrm{f}(\mathrm{X}, \mathrm{Y})-v]^{+}=[\mathrm{t}]^{+}=\operatorname{máx}\{0, \mathrm{t}\}$ 
Agora, assumindo a discretização da distribuição de probabilidade $Y$, gerando vetores $Y_{1}, \ldots, Y_{q}$ que representam $q$ diferentes cenários simulados, pode-se aproximar a função $\mathrm{F}_{\alpha}(\mathrm{X}, v)$ por:

$$
\widehat{F}_{\alpha}(X, v)=v+\frac{1}{q(1-\alpha)} \sum_{k=1}^{q}\left[f\left(X, Y_{k}\right)-v\right]^{+}
$$

Substituindo o termo $\left[f\left(X, Y_{k}\right)-v\right]^{+}$por variáveis auxiliares $\mu_{k}$, as quais obedecem às restrições e garantem que seu valor também seja igual ao máx\{0,t\}, transforma-se a resolução do modelo em um problema de programação linear, escrito conforme segue.

Minimizar: $\widehat{F}_{\alpha}(X, v)=v+\frac{1}{q(1-\alpha)} \sum_{k=1}^{q} \mu_{k}$

\section{Sujeito a:}

$$
\begin{aligned}
& X^{\prime} Y \geq G \\
& \sum_{i=1}^{n} x_{i}=1 \\
& x_{i} \geq 0 ; i=1, \ldots, n \\
& \mu_{k}+X^{\prime} Y_{k}+v \geq 0 \\
& \mu_{k} \geq 0, \quad k \in\{1,2, \ldots, q\}
\end{aligned}
$$

Onde,

$q$ é o número de cenários gerados

$G$ é o retorno mínimo admitido pelo investidor

$\mu_{k}$ são as variáveis auxiliares que substituem $\left[X^{T} Y_{k}-v\right]^{+}$

As três primeiras restrições do problema são as mesmas do problema originalmente apresentado. As quarta e quinta restrições tratam da variável $\mu_{k}$ que deve ser positiva, 
obedecendo a relação descrita na quarta restrição, garantindo tratativa apenas de valores situados na cauda da distribuição de probabilidades dos retornos.

A solução para o problema é a aproximação de $F_{\alpha}(x, v)$ por $\hat{F}_{\alpha}(x, v)$ para posterior minimização. Esta função é convexa, linear e diferenciável em relação a $x$ e a $v$, podendo ser minimizada com métodos usuais de programação linear, o que torna sua implementação atrativa.

A transformação do problema de minimização do Valor em Risco Condicional (CVaR) em um problema de programação linear, através da simulação de cenários, não depende de que $Y$ tenha uma distribuição normal previamente conhecida, o que também o torna o Modelo do Valor em Risco Condicional (CVaR) mais vantajoso que os anteriores, tendo sua aplicabilidade mais ampla.

A elevada complexidade da função $C V a R$ faz com que a simulação de cenários e a aproximação da superfície de resposta por interpolação seja uma alternativa para se otimizar carteiras de investimentos utilizando-a como função objetivo. Adiciona-se a isto o fato de que diferentes abordagens, considerando distintas premissas acerca da distribuição de probabilidade dos retornos, leva a diferentes superfícies $C \operatorname{VaR}(\boldsymbol{x})$. Desta forma, em adição à solução proposta por ROCKAFELLAR e URYASEV (2002), este trabalho propõe a utilização de outros métodos de interpolação, mais universais, para aproximar a superfície $\operatorname{Risco}(\boldsymbol{x})$ de forma mais abrangente, aplicável a distintos problemas de otimização de carteiras e com diferentes medidas de risco como função objetivo.

Por último, o Valor em Risco Condicional (CVaR) é normalmente representado através da grandeza de unidade monetária, embora muitos autores também utilizem sua definição como porcentagem, assumindo uma correspondência direta entre o retorno monetário e o retorno percentual. Embora o Valor em Risco Condicional (CVaR) seja 
objeto de crítica quanto à sua robustez como medida de risco (LIM, 2011), principalmente no que tange à dificuldade de aplicação prática, esta métrica é atualmente a mais aceita sob ótica científica para problemas de composição de carteiras de ativos. 


\section{MÉTODOS}

Conforme novas medidas de risco, com elevado grau de complexidade, são propostas para o problema de otimização de carteiras de investimentos, faz-se necessária a definição de hipóteses restritivas para que seja possível a solução do problema através de métodos convencionais de otimização. Porém, alternativas mais genéricas de aproximação da superfície $\operatorname{Risco}(\boldsymbol{x})$ podem levar à solução do problema de forma mais ampla, relaxando tais hipóteses. Desta forma, a geração de cenários para obtenção de pontos da superfície representativa do risco, combinada a métodos universais de interpolação de dados, permitem que a superfície $\operatorname{Risco}(\boldsymbol{x})$ possa ser aproximada de forma suavizada, possibilitando a aproximação da solução do problema de composição de carteiras de forma mais global.

Assim, com este trabalho, propõe-se a aproximação da superfície de risco através da simulação de cenários e da aplicação de dois métodos de interpolação comumente aplicados a problemas de engenharia: as Redes Neurais Artificiais e a Krigagem.

Esta seção foca na apresentação destes métodos, incluindo seus conceitos e melhores práticas de aplicação. 


\subsection{REDES NEURAIS ARTIFICIAIS 5}

As Redes Neurais Artificiais são técnicas computacionais que apresentam um modelo matemático inspirado no processo cognitivo do cérebro de organismos inteligentes, no qual o conhecimento é adquirido pela experiência. O processador básico é, neste caso, o neurônio ou nó, o qual é formado por inúmeras células de entrada conectadas em única saída. Esta saída é, então, conectada a outros neurônios, formando uma rede. Os estudos sobre Redes Neurais Artificiais foram inicialmente publicados por McCULLOCH (1943), onde um simples modelo de processador unitário foi proposto para simular o funcionamento de um neurônio. Neste modelo, o funcionamento do processador artificial neuronal é executado de acordo com sinais $\left(\mathrm{x}_{\mathrm{i}}\right)$, os quais são multiplicados pelos pesos correspondentes $\left(\mathrm{w}_{\mathrm{i}}\right)$, e a soma ponderada dos sinais resulta no nível de excitação das entradas. Se tal nível de excitação exceder um certo limite da função de ativação (Treshold Funcion, do inglês) definida, a unidade produz a sua resposta (y).

O modelo mais simples de um neurônio artificial soma as $n$ entradas ponderadas e passa o resultado através da não linearidade de acordo com a equação $y_{i}=$ $\mathrm{f}\left(\sum_{\mathrm{i}=1}^{\mathrm{n}} \mathrm{w}_{\mathrm{ji}} \mathrm{x}_{\mathrm{i}}-\theta_{\mathrm{j}}\right)$, onde $\mathrm{f}$ representa a função de ativação, $\theta_{\mathrm{j}}\left(\theta_{\mathrm{j}} \in \mathrm{R}\right)$ é a ativação externa (também denominada offset ou bias, do inglês), $\mathrm{w}_{\mathrm{ij}}$ são os pesos atribuídos às "sinapses", $x_{i}$ as entradas, $n$ a quantidade de entradas e $y_{i}$ as saídas (STEEB, 2008). MURRAY (1995) apresenta diversos tipos de funções de ativação, incluindo Hard Limiter, o Threshold Logic e o Sigmoid. Este último, aplicado a diversas situações reais com resultados significativamente precisos, é representado por

\footnotetext{
${ }^{5}$ Subcapítulo com significativa referência a PONTIN (2008).
} 
$\mathrm{g}(\mathrm{x})=\frac{1}{1+\mathrm{e}^{-\frac{\mathrm{x}}{\mathrm{T}}}}$, onde $\mathrm{T}$ indica a inclinação da função de ativação. Na Rede Neural Artificial, cada processador atua individualmente (i.e. opera apenas sobre seus dados locais), e o comportamento inteligente é obtido através da interação entre as diferentes unidades de processamento (HEBB, 1949).

Dentre os diversos algoritmos de aprendizado disponíveis atualmente, uma atenção especial é dada ao Modelo Perceptron, inicialmente proposto por ROSENBLATT (1958), o qual consiste na alteração dos pesos de cada conexão de forma proporcional ao erro apresentado pela rede. Assim, $w_{t}=w_{t-1}+\eta E X$, onde $\eta$ é a constante positiva que corresponde à velocidade do processo de aprendizado, $E=A_{d}-A_{o} 0$ erro calculado pela diferença entre a resposta observada e a resposta obtida pela rede e $X$ representa as entradas. $\mathrm{O} \mathrm{w}_{\mathrm{t}}$ é o novo peso calculado, e o $\mathrm{w}_{\mathrm{t}-1}$ representa o peso original, ou o valor do peso do processamento anterior.

De acordo com PONTIN (2008), o processo de aprendizado é também conhecido como ciclo de treinamento da rede, o qual pode ser executado através de dois métodos distintos:

(1) Modo Padrão (ou Standard Mode, do inglês): a correção dos pesos acontece em pares através do ciclo de treinamento da rede, e a correção é baseada apenas no erro da iteração apresentada;

(2) Modo Bach: apenas uma correção é realizada por ciclo global de treinamento, considerando o erro médio de todos os pesos atribuídos à rede.

As Redes Neurais Artificiais são comumente representadas através de sua topologia, a qual inclui (1) suas variáveis de entrada (as variáveis do problema), (2) camadas internas de processadores neuronais, indicando a quantidade de "neurônios" por camada e (3) sua única saída ou resposta. A Figura 8, abaixo, apresenta uma 
representação típica de uma rede neural artificial de um problema com três variáveis de entrada e duas camadas internas de oito neurônios cada.

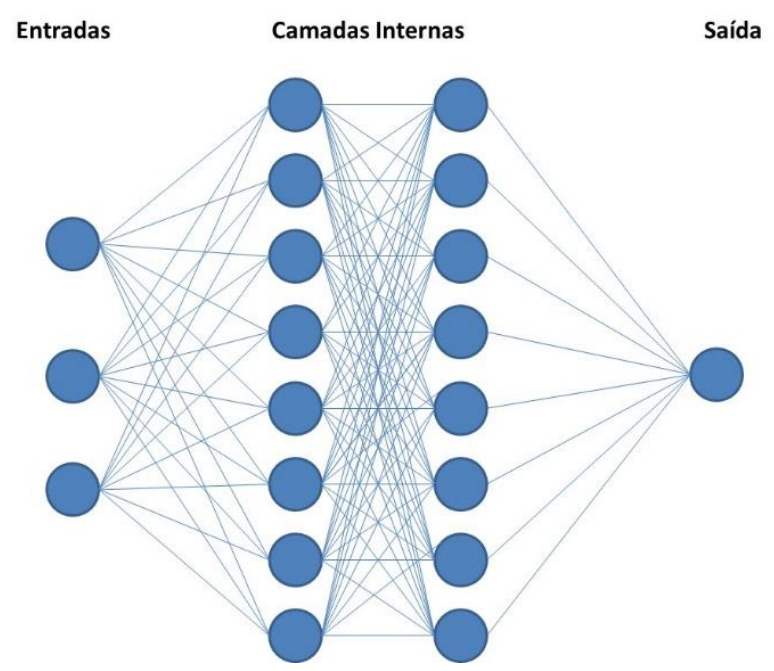

Figura 8: Representação de uma Rede Neural Artificial com três células de entrada e duas camadas internas de oito neurônios cada.

Sem as camadas internas, as Redes Neurais Artificiais são incapazes de formar uma representação interna da função de saída. A razão para isto reside no fato de que padrões das entradas implicam em saídas similares, oferecendo limitações consideráveis à aplicação da técnica (PONTIN, 2008). Porém, tal limitação foi superada nas publicações de HOPFIELD (1982) e RUMELHART (1986), na introdução do método de propagação reverso (Back Propagation Method, do inglês) para treinar camadas intermediárias das Redes Neurais Artificiais. Esta técnica resultou no algoritmo mais frequentemente utilizada na aplicação de Redes Neurais Artificiais nos dias de hoje, uma proposta moderna denominada Multilayer Perceptrons (MLP), as quais são representadas pela Figura 8, acima.

Atualmente, as técnicas de Redes Neurais Artificiais são aplicadas a problemas de engenharia de diversas naturezas. Exemplos podem ser encontrados em HOPFIELD (1982), BHADESHIA (1999), FERNÁNDEZ e GÓMEZ (2007) e LIU et. Al (2012). 
Segundo NASCIMENTO et. al. (2000), a prática comum na aplicação das Redes Neurais Artificiais é a divisão dos dados de entrada, obtidos através de experimentos empíricos, em dois grupos. O primeiro grupo de dados é utilizado para treinamento da rede neural, através dos quais são estabelecidos os parâmetros (pesos) de cada conexão entre os processadores. O segundo grupo é, então, utilizado para testar a capacidade de aproximação da rede obtida, através do cálculo dos erros. Ainda assim, o sucesso da obtenção de uma rede confiável e robusta reside fortemente na definição das variáveis do problema, nos dados disponíveis e no domínio utilizado para treinamento da rede.

$\mathrm{Na}$ aplicação específica para o problema de composição de carteiras de investimentos, tanto as variáveis do problema quanto o domínio da função representativa do risco são conhecidos, fazendo com que sua aplicação, obtendo-se dados de entrada através de simulação, seja direta. Resultados empíricos mostram que a topografia de rede que apresenta o melhor equilíbrio entre tempo de processamento e robustez (i.e. baixos níveis de erro) consiste em duas camadas internas de oito neurônios cada. A Figura 9, abaixo mostra a representação da Rede Neural utilizada neste trabalho, para uma carteira de investimentos contendo quatro ativos, cujos pesos na carteira, $x=\left[\begin{array}{llll}x_{1} & x_{2} & x_{3} & x_{4}\end{array}\right]$ são representados pelos inputs (variáveis de entrada), e a resposta, $\operatorname{Risco}(x)$, representada pelo output (saída). Através de simulação de cenários, obtém-se respostas (outputs) conhecidas, as quais são utilizadas para treinar a rede. 


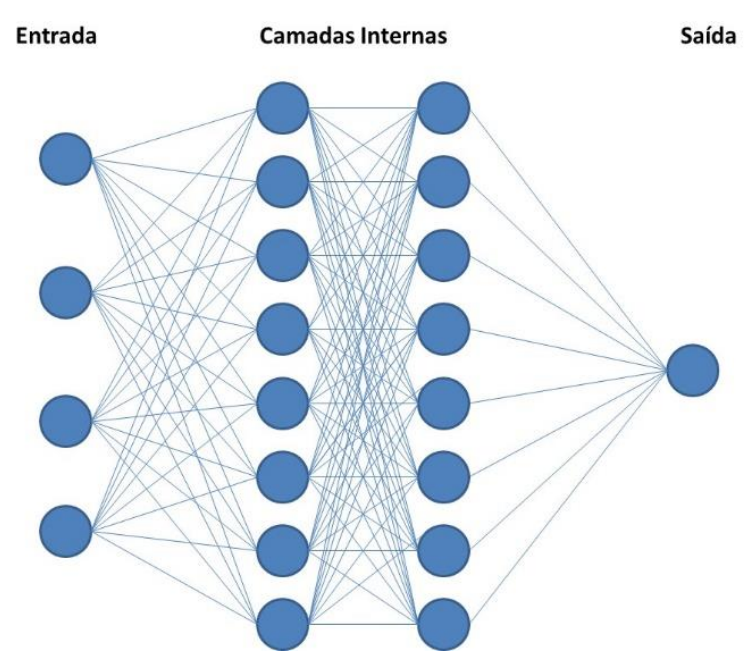

Figura 9: Representação de uma Rede Neural conforme aplicada neste trabalho, exemplificada por uma carteira de quatro ativos.

Aplica-se, a esta rede, o multilayer perceptron com propagação reversa e utilizando a sigmoide como função de ativação. A correção dos erros é feita pelo modo batch, e a taxa de progressão é constante. 


\subsection{KRIGING}

O método Kriging, ou Krigagem, é uma técnica de interpolação polinomial de dados e obtenção de superfície de resposta comumente aplicada para problemas de geologia (YIN, 2011). Esta superfície pode ser utilizada para análise das relações entre as variáveis de entrada e saída do problema, bem como para a estimação de seus mínimos e máximos globais (JONES, SCHONLAU e WELCH, 1998). Assim, dada sua natureza universal e multidisciplinar, esta técnica pode ser aplicada a problemas de otimização de diversas naturezas, incluindo o problema de otimização de carteiras de investimentos.

Frequentemente, modelos de interpolação de superfície são lastreados na premissa de que a função real, $Y(x)$, é aproximada por uma função $f(x)$ com erro $\varepsilon$. Assim, $Y(x)=f(x)+\varepsilon \cong \hat{f}(x)$. O erro $\varepsilon$ é, em geral, assumido como independente, identicamente e normalmente distribuído, com média nula e desvio padrão $\sigma$ (i.e. $\left.\varepsilon \sim N\left(0, \sigma^{2}\right)\right)$. Porém, em diversos casos reais, o erro observado não é independente e, pior, é uma função de $x$. Nestes casos, se $\hat{f}(x)$ é um valor distante de $Y(x)$, então espera-se que $\hat{f}(x+\delta)$, com $\delta$ significativamente pequeno, também esteja distante da função original.

Visando superar estas situações, o geologista sul-africano D. G. Krige desenvolveu um método de interpolação que consiste em duas partes: (1) a função polinomial que aproxima a função original, $\hat{f}(x)$ e (2) um processo Gaussiano estocástico, $Z(x)$, que representa incertezas acerca de $E(Y(x))$ e com $E(Z(x))=0$. A covariância de $Z(x)$ entre dois pontos quaisquer, $x_{i}$ e $x_{j}$ é dada por $\operatorname{cov}\left(Z\left(x_{i}\right), Z\left(x_{j}\right)\right)=\sigma^{2} \sum\left(x_{i}, x_{j}\right)$, onde $\sigma^{2}$ é chamada de variância do processo e $\sum\left(x_{i}, x_{j}\right)$ é chamada de função de correlação espacial, ou correlação entre os erros. A escolha da função de correlação 
espacial define quão rapidamente e suavemente a função se movimenta do ponto $x_{i}$ ao ponto $x_{j}$ e determina como o modelo se ajusta aos dados (PAPALAMBROS, 2000). Em aplicações do método Kriging, é comum escrever-se a expressão $\sum\left(x_{i}, x_{j}\right)$ como:

$$
\sum\left(x_{i}, x_{j}\right)=R\left(\theta, d_{h}\right)=e^{-\theta\left|x_{i}-x_{j}\right|^{2}}
$$

Onde $x_{i}, i=1, \ldots, m$ e $x_{j}, j=1, \ldots, m$ representam os dados do problema e $\theta$ representa o parâmetro do modelo. Assim, a função de correlação espacial, $\sum\left(x_{i}, x_{j}\right)$, tende a zero conforme a distância $d_{h}$ entre os pontos $x_{i}$ e $x_{j}$ cresce em valor absoluto. Ou seja, a influência dos pontos da amostra sobre o ponto da previsão se torna mais fraca conforme os dois pontos ficam mais distantes um do outro. O parâmetro $\theta$ define a velocidade, ou influência, de tal efeito (PAPALAMBROS, 2000; JONES et al, 1998). Além da forma apresentada, a função de correlação espacial pode admitir outras formas, tais quais (LOPHAVEN, NIELSEN e SONDERGAARD, 2002):

(1) Exponencial: $\mathrm{R}\left(\theta, \mathrm{d}_{\mathrm{h}}\right)=\exp \left(-\theta_{\mathrm{h}}\left|\mathrm{d}_{\mathrm{h}}\right|\right)$

(2) Gaussiana: $R\left(\theta, d_{h}\right)=\exp \left(-\theta_{h} d_{h}{ }^{2}\right)$

(3) Linear: $\mathrm{R}\left(\theta, \mathrm{d}_{\mathrm{h}}\right)=\max \left\{0,1-\theta_{\mathrm{h}}\left|\mathrm{d}_{\mathrm{h}}\right|\right)$

(4) Esférica: $\mathrm{R}\left(\theta, \mathrm{d}_{\mathrm{h}}\right)=1-1,5 \xi_{\mathrm{h}}+0,5 \xi_{\mathrm{h}}{ }^{3}, \xi_{\mathrm{h}}=\min \left\{1, \theta_{\mathrm{h}}\left|\mathrm{d}_{\mathrm{h}}\right|\right)$

(5) Spline: $R\left(\theta, d_{h}\right)=s\left(\xi_{h}\right), \xi_{h}=\theta_{h}\left|d_{h}\right|$

Como forma de tratar todos os pontos com o mesmo peso, a distância $d_{h}$ não é medida segundo o modelo Euclidiano $\left(\sqrt{\sum_{1}^{n}\left(x_{h}^{i}-x_{h}^{j}\right)^{2}}\right)$. Ao contrário, a medida dessa distância é uma função de parâmetros $\theta_{h}$ e $p_{h}$, como segue:

$$
d\left(x_{i}, x_{j}\right)=\sum_{h=1}^{n} \theta_{h}\left|x_{h}^{i}-x_{h}^{j}\right|^{p_{h}}
$$


O expoente $p_{h}$ está relacionado à suavidade da função em relação aos pontos $h$. Valores de $p_{h}=1$ correspondem a funções menos suaves e $p_{h}=2$ a funções mais suaves (JONES et al, 1998).

Quando a função objetivo depende de $n$ variáveis, a prática comum é a multiplicação das funções de correlação, $R\left(x_{i}, x_{j}\right)$, para cada dimensão utilizando a regra abaixo (PAPALAMBROS, 2000).

$$
R\left(x_{h}{ }^{i}, x_{h}{ }^{j}\right)=\prod_{h=1}^{n} R_{h}\left(x_{h}{ }^{i}-x_{h}{ }^{j}\right)
$$

Onde $n$ representa a quantidade de dimensões. Além disto, diferentes funções de correlação espacial podem ser utilizadas para cada $R_{h}$, incluindo diferentes escolhas de $\theta_{h}$ (PAPALAMBROS, 2000).

Em abordagem similar a QUEIPO et al (2002), adota-se, para este trabalho, $\theta_{h}=1 \mathrm{e}$ $p_{h}=2$. Assim, o estimador não viciado de mínimos quadrados para $\hat{f}($.$) é dado por$ (RIBEIRO, 2004; LOPHAVEN et al, 2002):

$$
\hat{f}\left(X^{*}\right)=\sum_{j=1}^{m} \beta_{j}^{*} f^{j}\left(X^{*}\right)+r^{\prime} \Sigma^{-1}\left(y-F \beta^{*}\right)
$$

Onde,:

$\beta=\left(F^{T} \Sigma^{-1} F\right)^{-1} F^{T} \Sigma^{-1} y$

$r$ é o vetor de correlações entre erros em relação ao ponto $X^{*}$ e os demais pontos da amostra

$\sum$ é a matriz de correlação entre os pontos da amostra

y é o vetor dos valores observados para a função risco.

F é a matriz com os valores das funções calculados nos pontos da amostra. 
Uma das vantagens de se aplicar o método Kriging é a habilidade deste método de atingir aproximações com precisão significativa, porém com pouca informação de entrada, uma característica desejada tanto na Geologia, onde o custo de obtenção de dados e significativo, quanto no problema de composição e carteiras de investimentos, onde o tamanho das amostras no processo de simulação cresce significativamente com aumento da quantidade de ativos na carteira.

\section{METODOLOGIA PROPOSTA}

Em sua forma geral, a metodologia proposta para solução do problema de otimização de carteiras de investimentos através dos interpoladores universais apresentados consiste em:

Tabela 4: Algoritmo de aproximação do mínimo global de $\operatorname{Risco}(X)$

\begin{tabular}{|l|l|}
\hline 1 & $\begin{array}{l}\text { Gerar uma amostra de pontos }\left\{X^{i}\right\}_{i=1}^{q} \text { satisfazendo as restrições } X^{i} \in R^{N}, 0 \leq \\
x_{j}^{i} \leq 1, j=1, \ldots, n \text { e } \sum_{j=1}^{n} x_{j}{ }^{i}=1, \text { de forma determinística com distância } d \text { entre } \\
\text { pontos simulados para um dado ativo; } \\
\text { Para cada vetor } X^{i}, \text { calcular } y^{i}=\operatorname{RISCO}\left(X^{i}\right) \text { por estatística de ordem, } \\
\text { relaxando qualquer hipótese restritiva acerca da distribuição de probabilidade } \\
\text { dos retornos; } \\
\text { Construir a superfície de risco aproximada, } \hat{y}=\hat{f}(X), \text { através da interpolação, } \\
\text { pela aplicação das Redes Neurais Artificiais ou da Krigagem, sobre os pontos } \\
\text { da amostra, }\left(X^{i} ; Y^{i}\right) ;\end{array}$ \\
\hline
\end{tabular}


$4 \quad$ Resolver o problema de otimização resultante, sobre a superfície de resposta aproximada, encontrando o ótimo global aproximado da função $\left(X^{*}\right)$.

Conforme será mostrado mais adiante, este Método de Superfície de Resposta (Response Surface Method, ou RSM, do inglês) apresenta resultados significativamente precisos para problemas de pequena dimensão (i.e. $n \leq 5$ ), com baixo custo computacional. Porém, conforme a dimensão do problema aumenta, os resultados obtidos por esta metodologia apresentam uma perda significativa na qualidade da aproximação da superfície de resposta (RIOS et. al., 2013), necessitando de mais informações (i.e. mais pontos no processo de amostragem) para atingir níveis satisfatórios de precisão, consequentemente elevando-se o custo computacional de sua aplicação.

Para problemas de maior dimensão (i.e. $n>5$ ), propõe-se, neste trabalho, a aplicação de algoritmos iterativos de busca local em torno do resultado ótimo aproximado $\left(X^{*}\right)$ obtido pela aplicação da metodologia descrita na Tabela 4. Embora exista o risco desta abordagem prender a solução do problema a um ótimo local, a aplicação do algoritmo simplificado apresentado na Tabela 5, abaixo, apresentou convergência para as soluções conhecidas em todos os resultados apresentados neste trabalho.

Tabela 5: Algoritmo de busca local em torno de $X^{*}$

\begin{tabular}{|l|l|}
\hline 1 & Aplicar o algoritmo descrito na Tabela 4 e encontrar $X^{*}$ \\
2 & Definir $h=1 \rightarrow X_{(h)}^{*}=X^{*}$ \\
3 & Para $X_{(h)}^{*}-X_{(h-1)}^{*} \geq 0,05 d, \forall h \geq 2$, fazer: \\
4 & Definir $l_{j}=\left\lfloor\frac{x_{j}^{*}}{d}\right\rfloor d$ e $u_{j}=\left\lceil\frac{x_{j}^{*}}{d}\right\rceil d$ \\
\hline
\end{tabular}




\begin{tabular}{|c|c|}
\hline 5 & $\begin{array}{l}\text { Gerar nova amostra de pontos }\left\{X^{i}\right\}_{i=1}^{q}, \text { tal que } \forall X_{j} \in\left\{L_{j} ; \frac{L_{j}+U_{j}}{2} ; U_{j}\right\}, \operatorname{com} X^{i} \in \\
R^{N} \text {, e } \sum_{j=1}^{n} x_{j}^{i}=1 ;\end{array}$ \\
\hline 6 & Para cada vetor $X^{i}$, calcular $y^{i}=R I S C O\left(X^{i}\right)$ por estatística de ordem; \\
\hline 7 & $\begin{array}{l}\text { Construir a superfície de risco aproximada, } \hat{y}=\hat{f}(X) \text {, através da } \\
\text { interpolação, pela aplicação das Redes Neurais Artificiais ou da Krigagem, } \\
\text { sobre os pontos da amostra, }\left(X^{i} ; Y^{i}\right) \text {; }\end{array}$ \\
\hline 8 & $\begin{array}{l}\text { Resolver o problema de otimização resultante, sobre a superfície de } \\
\text { resposta aproximada, encontrando o novo ótimo aproximado da função } \\
\operatorname{Risco}(\boldsymbol{x}), X_{(k)}^{*} \text { : }\end{array}$ \\
\hline 9 & Se $x_{j}^{*}=l_{j}$ \\
\hline 10 & Redefinir $u_{j}=x_{j}^{*}$ e $l_{j}=u_{j}-d$ \\
\hline 11 & $\operatorname{Se} x_{j}^{*}=u_{j}$ \\
\hline 12 & Redefinir $l_{j}=x_{j}^{*}$ e $u_{j}=l_{j}+d$ \\
\hline 13 & Caso contrário \\
\hline 14 & $d=\frac{d}{2}$ \\
\hline 15 & $\operatorname{Se}\left|x_{j}^{*}-l_{j}\right| \geq\left|x_{j}^{*}-u_{j}\right|$ \\
\hline 16 & $l_{j}=l_{j}+d$ \\
\hline 17 & $u_{j}=u_{j}$ \\
\hline 18 & Caso Contrário \\
\hline 19 & $l_{j}=l_{j}$ \\
\hline 20 & $u_{j}=u_{j}-d$ \\
\hline 21 & $h=h+1$ \\
\hline 22 & Fim Para \\
\hline 23 & Retornar $X_{(k)}^{*}$ \\
\hline
\end{tabular}




\section{RESULTADOS}

Nas seções anteriores deste trabalho, foi proposta uma nova metodologia para aproximar a solução do problema de composição ótima de carteiras de investimentos através (1) da simulação para obtenção de valores conhecidos de uma dada função $\operatorname{Risco}(\boldsymbol{x})$, e (2) da interpolação destes dados conhecidos através da aplicação de técnicas multidisciplinares de engenharia, tais quais as Redes Neurais Artificiais e a Krigagem, para posterior otimização. Esta abordagem possui característica universal, o que faz com que sua aplicação seja capaz de aproximar o resultado do problema para qualquer medida de risco já apresentada na literatura, considerando quaisquer ativos financeiros e desconsiderando hipóteses restritivas inerentes às metodologias atualmente disponíveis para solucionar o problema.

Nesta seção, ilustra-se a aplicação da metodologia proposta a carteiras compostas por ativos negociados na BOVESPA, utilizando três medidas de risco como função objetivo do problema: (1) Variância $\left(\sigma^{2}\right)$, (2) Valor em Risco (VaR) e (3) Valor em Risco Condicional (CVaR).

Novamente, assumindo $\boldsymbol{x} \in \mathbf{X} \subset \mathrm{R}^{N}$ um vetor de decisão representando uma carteira de ativos, $\mathbf{y} \in \mathbf{Y} \subset \mathrm{R}^{N}$ os valores futuros dos retornos dos ativos que compõem essa carteira e $\mathrm{z}=\mathrm{f}(\mathrm{x}, \mathrm{y})$ a função de perdas da carteira, pode-se obter valores conhecidos da superfície $\mathrm{z}=\mathrm{f}(\mathrm{x}, \mathrm{y})$ através de simulação para diferentes composições $\boldsymbol{x}$ da carteira. Para a Variância, os pontos da superfície são obtidos através da relação clássica $\sigma^{2}(\boldsymbol{x})=\boldsymbol{x}^{\prime} \sum \boldsymbol{x}$. Para o Valor em Risco (VaR), os pontos da superfície são obtidos através do método não paramétrico, aplicando-se técnicas de estatística de ordem. Para o Valor em Risco Condicional (CVaR), estima-se primeiramente o Valor em Risco através do método não-paramétrico, e assim aplica-se o conceito $\operatorname{CVaR}\left(R_{C}\right)=E\left\{\left(R_{C}\right) \mid R_{C} \leq v\right\}$, onde $v$ representa o VaR da carteira. 
Utilizando-se dos pontos da superfície $\operatorname{Risco}(\boldsymbol{x})$ obtidos através da simulação, aproxima-se a superfície $\hat{\mathrm{z}}=\mathrm{f}(\mathrm{X}, \mathrm{Y})$ aplicando-se os dois métodos universais de interpolação sugeridos neste trabalho. Por último, resolve-se o problema de otimização sobre a superfície aproximada.

A fim de se avaliarem os resultados obtidos através da metodologia proposta, estes são comparados com aqueles obtidos através do método de Kuhn-Tucker quando aplicada a Variância como função objetivo. Adicionalmente, aplica-se a metodologia sugerida por ROCKAFELLAR et. al. (2002) para comparar os resultados quando se utiliza o Valor em Risco Condicional (CVaR) como função objetivo do problema, embora, neste caso, ambas soluções sejam obtidas através de aproximação da superfície de risco, necessariamente apresentando erro. 


\subsection{GERAÇÃO DE AMOSTRA PARA ANÁLISE}

Duas técnicas de simulação foram empregadas para a obtenção dos cenários de cada uma das superfícies de risco em estudo: (1) amostragem aleatória e (2) amostragem determinística.

Na primeira, os pesos de cada um dos 4 ativos são gerados de maneira aleatória, tal que $0 \leq x_{j}^{(i)} \leq 1$ e $\sum_{i=1}^{4} x_{i}=1$. Na segunda, os valores de $x_{j}^{(i)}$ são obtidos de forma que estivessem igualmente espaçados no domínio da função, formando hipercubos de igual dimensão restringindo o domínio da função $\operatorname{Risco}(\boldsymbol{x})$. A Figura 10, abaixo, representa conceitualmente as diferentes técnicas de amostragem utilizadas para simulação, relaxando-se a condição $\sum_{i=1}^{4} x_{i}=1$ e aplicadas a dois ativos obtidos arbitrariamente, a fim de facilitar sua representação em $\mathcal{R}^{2}$.
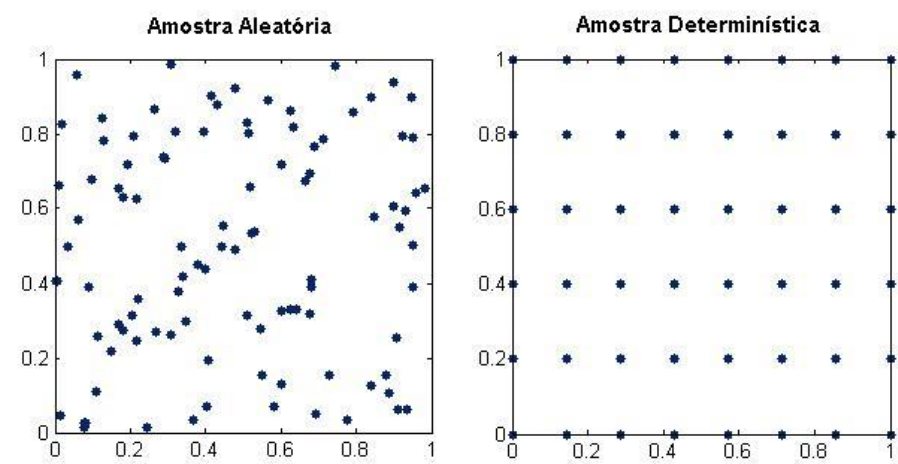

Figura 10: Representação gráfica das técnicas de amostragem utilizadas para simulação de pontos das superfícies $\operatorname{Risco}(x)$

Outro aspecto relevante na aplicação da metodologia proposta é a quantidade de cenários utilizados no processo de simulação. O tamanho da amostra determinística varia com tanto com a dimensão do problema (i.e. a quantidade de ativos que compõem a carteira) quanto com o espaçamento definido entre os pontos da simulação, no caso das amostras determinísticas. Assim, seja $n$ a quantidade de 
ativos em um dado portfólio e $d$ a distância entre os pontos simulados para um dado ativo, e definindo-se $k=d^{-1}$, o tamanho da amostra determinística, respeitando a restrição $\sum_{i=1}^{n} x_{i}=1$, é $q=\left(\begin{array}{c}k+n-1 \\ k\end{array}\right)=\frac{(k+n-1) !}{k !(n-1) !}$.

Por último, as aplicações das duas propostas de métodos para a aproximação das superfícies representativas do risco, Redes Neurais Artificiais e Krigagem, possuem características distintas quanto ao custo computacional. Avaliações empíricas mostram que a eficiência computacional da Krigagem é significativamente superior à eficiência das Redes Neurais, de forma que resultados podem ser obtidos com 0 mesmo nível de precisão em tempo significativamente mais curto. Como não é objetivo deste trabalho comparar os dois métodos entre si, mas sim apresentá-los como formas alternativas e universais de se aproximar os resultados do problema de composição de carteiras de investimentos, os resultados para as Redes Neurais serão apresentados para uma carteira composta por apenas quatro ativos, haja vista que problemas de maior dimensão impossibilitam a aplicação prática deste método com a utilização de computadores comerciais disponíveis atualmente. A Krigagem, por outro lado, será apresentada com aplicações a carteiras compostas por cinco ativos, com aplicação direta (vide Tabela 4), e com dez ativos, com aplicação iterativa (vide Tabela 5). 


\subsection{INTERPOLAÇÃO POR REDES NEURAIS ARTIFICIAIS}

Nesta seção, apresentam-se os resultados dos modelos de otimização obtidos através da aproximação da superfície $\operatorname{Risco}(\boldsymbol{x})$ pela aplicação das Redes Neurais Artificiais, conforme metodologia sugerida neste trabalho. Os resultados são apresentados para as três medidas de risco selecionadas como função objetivo e para os dois tipos de amostras de geração de cenários apresentados na seção anterior. Os resultados são apresentados tanto na forma de fronteira eficiente (i.e. curva retorno vs. risco) quanto na representação das composições ótimas de carteira para cada nível de risco. Além disto, com o intuito de se testar a metodologia proposta, variaram-se os tamanhos das amostras utilizadas na simulação. No caso determinístico, obtiveram-se amostras espaçando cada $x_{j}^{(i)}$ em 0,1 e 0,05 , totalizando 286 e 1.771 pontos, respectivamente. Duas amostras aleatórias de igual dimensão também foram obtidas, compondo um total de quatro amostras.

A carteira selecionada para aplicação das Redes Neurais Artificiais é composta por quatro ativos negociados na BOVESPA: Itaú-Unibanco (ITUB4), Cosan (CZLT11), OGX Petróleo (OGXP3) e Petrobrás (PETR4). Observa-se, para estes ativos, os retornos logarítmicos diários obtidos entre os períodos 27 Maio 2009 e 11 Maio 2012, totalizando 718 observações. 


\subsubsection{Variância}

A Figura 11, abaixo, mostra as fronteiras eficientes resultantes da solução do problema tomando-se a Variância como função objetivo, obtidas pelo método de MARKOWITZ (1952), como controle, e pela aplicação da metodologia proposta utilizando-se as Redes Neurais Artificiais como técnica de interpolação.

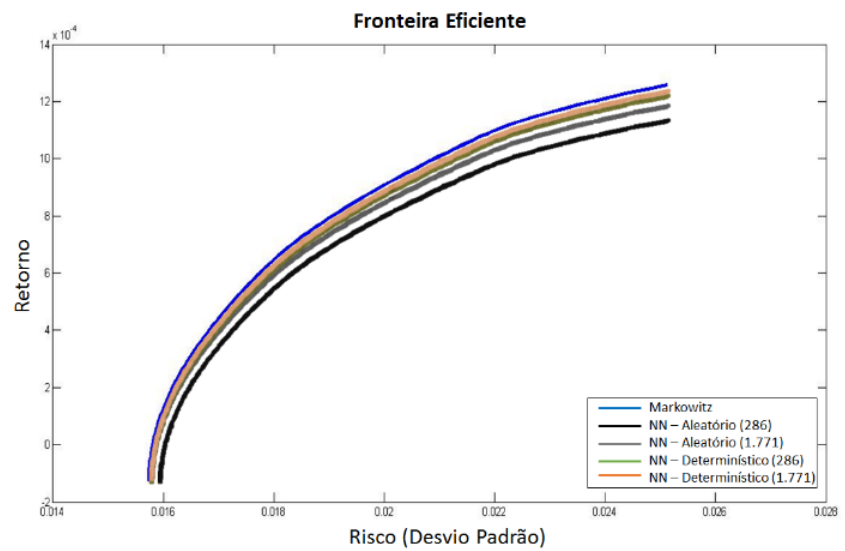

Figura 11: Fronteira Eficiente de Markowitz para carteira composta pelos ativos ITUB4, CZLT11, OGXP3 e PETR4, através do método de Kuhn-Tucker e das Redes Neurais Artificiais.

Em seguida, na Figura 12, abaixo, apresentam-se as composições ótimas de carteiras de investimentos, para distintos níveis de risco, calculados através da metodologia proposta com as Redes Neurais Artificias como técnica de interpolação de dados, e através do método de MARKOWITZ (1952). 

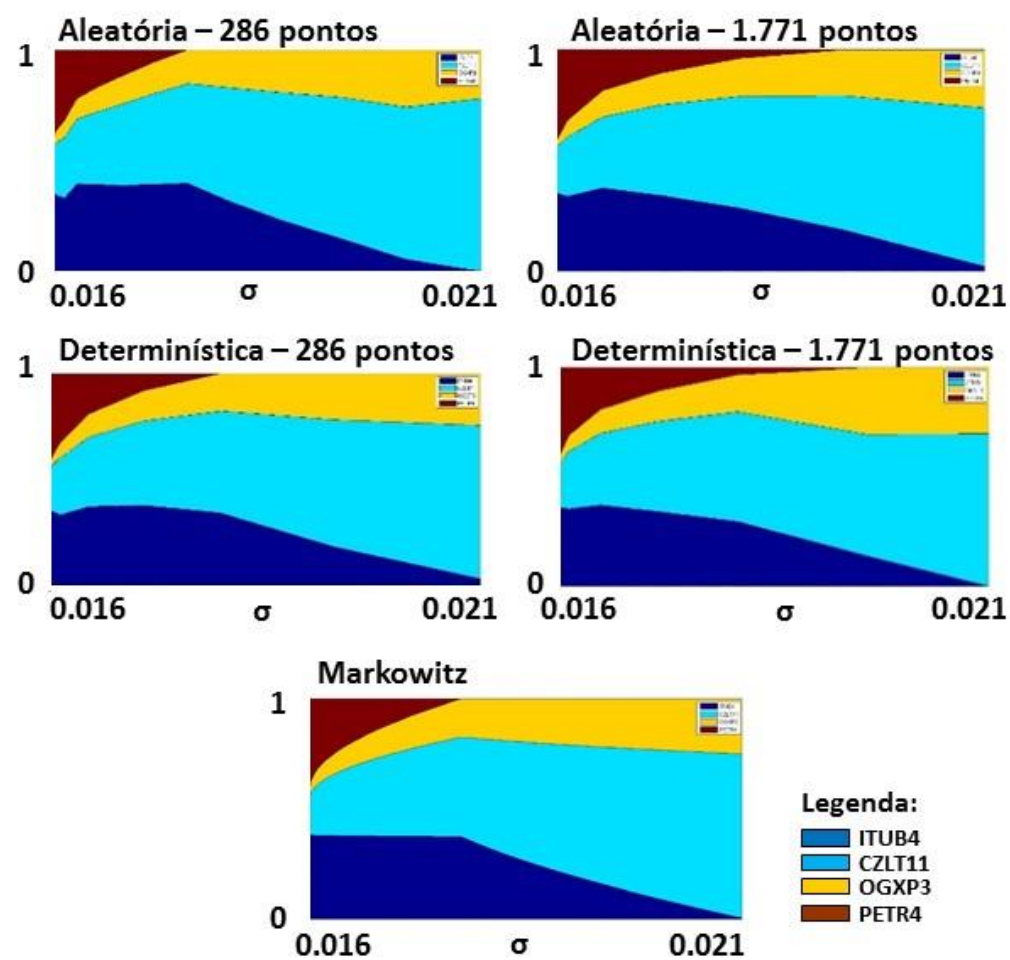

Figura 12: Composições ótimas de carteiras obtidas através da aplicação da metodologia proposta, aplicando-se as Redes Neurais Artificiais como técnica de interpolação, e do modelo de MARKOWITZ (1952), utilizando a variância como medida de risco.

Como se pode observar através da avaliação qualitativa das Figuras 11 e 12, acima, os resultados obtidos pela aplicação da metodologia proposta, com as Redes Neurais Artificiais como técnica de interpolação, são próximos à solução exata do problema, obtida pela aplicação do método de MARKOWITZ (1952). De fato, analisando-se o erro quadrático médio (i.e. $M S E=\frac{1}{q} \sum_{i=1}^{q}[f(x)-\hat{f}(x)]^{2}$ ) das superfícies de resposta aproximadas pela metodologia proposta, nota-se que, no pior caso (i.e. amostra aleatória com 286 pontos simulados), sua ordem de grandeza é de $10^{-7}$. A Figura 13, abaixo, apresenta o erro quadrático médio (mean-squared-error, do inglês) calculado para cada uma das quatro soluções aproximadas pela metodologia proposta. 


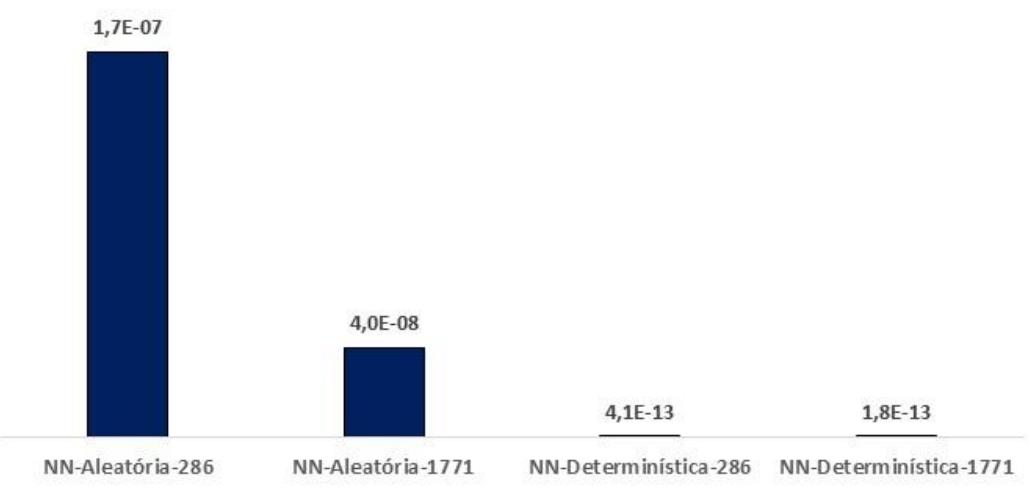

Figura 13: Erro Quadrático Médio calculado para cada um dos resultados apresentados para otimização de carteira de investimentos utilizando a variância como função objetivo, e aplicando-se as Redes Neurais Artificiais como técnica de interpolação.

Através da análise da Figura 13, acima, é notório que os resultados apresentados através da aplicação da metodologia proposta a amostras determinísticas apresentam maior precisão (ou menor erro) que aqueles obtidos através da aplicação da metodologia a amostras aleatórias. Mais ainda, a precisão da aproximação da superfície de resposta aumenta significativamente com o aumento da amostra de cenários gerados através do processo de simulação, como esperado. Os erros calculados em ambos os casos são normalmente distribuídos. 


\subsubsection{Valor em Risco (VaR)}

Conforme citado anteriormente, o Valor em Risco calculado em sua forma nãoparamétrica, obtida relaxando-se a hipótese de normalidade da distribuição de probabilidade dos retornos, apresenta diversos mínimos locais, o que gera um elevado grau de complexidade na função objetivo do problema de otimização de carteiras e sua consequente dificuldade de solução. Sendo assim, a literatura não apresenta uma solução universalmente aceita para otimização de carteiras utilizando esta medida de risco, em sua forma mais ampla, como função objetivo. Porém, devido às suas características universais, a metodologia proposta neste trabalho permite a solução deste problema, caracterizando sua maior contribuição. Os resultados obtidos através da aplicação das Redes Neurais Artificiais para o problema de otimização de carteiras de investimentos utilizando o VaR não-paramétrico como função objetivo estão apresentados nas Figuras 14 e 15, abaixo.

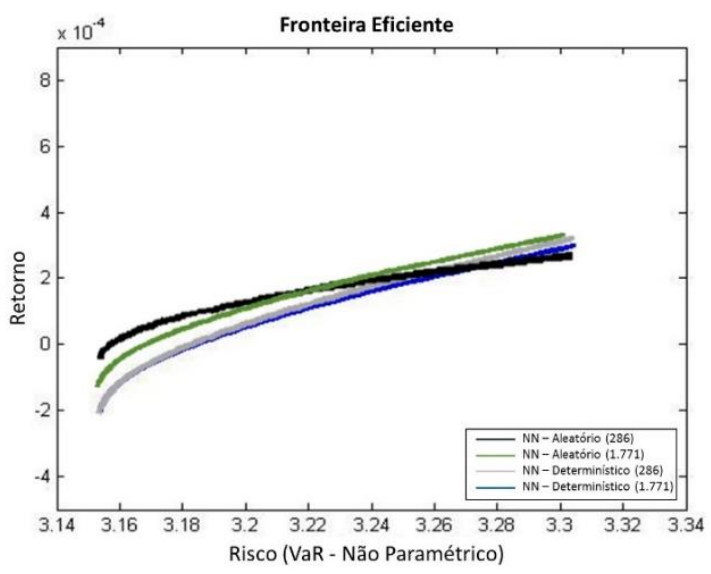

Figura 14: Fronteiras eficientes obtidas através da metodologia proposta, aplicando-se as Redes Neurais Artificiais como técnica de interpolação, para otimização de carteira de quatro ativos utilizando o VaR Não-paramétrico como medida de risco. 

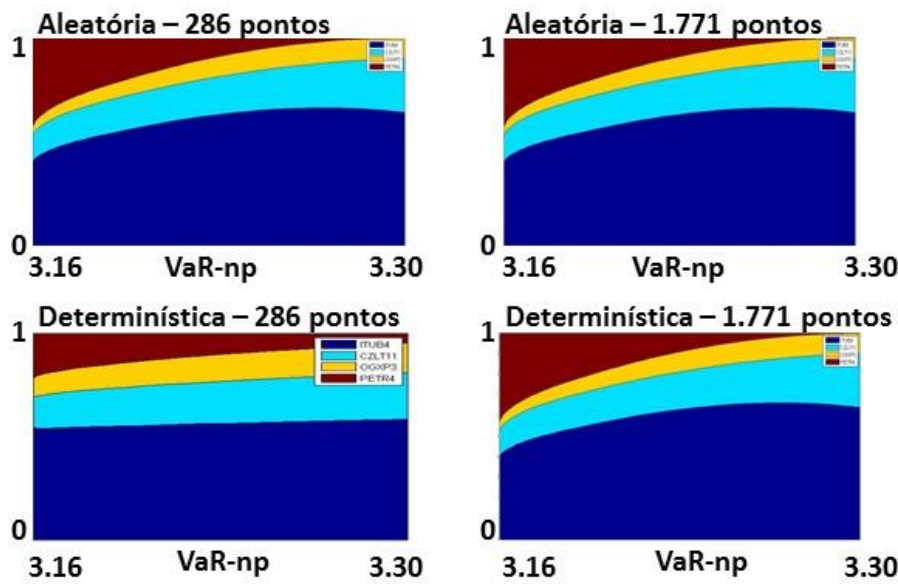

Legenda:

$\square$ ITUB4 $\square$ CZLT11 $\square$ OGXP3 $\square$ PETR4

Figura 15: Composições ótimas de carteiras obtidas através da aplicação da metodologia proposta, aplicando-se as Redes Neurais Artificiais como técnica de interpolação, utilizando o VaR Não-paramétrico como medida de risco.

Como não existem métodos universalmente aceitos de otimização de carteiras utilizando-se o Valor em Risco não-paramétrico como função objetivo, a análise dos resultados apresentados acima se dá através do erro da aproximação da superfície de resposta representativa do risco. Os erros quadráticos médios calculados nas quatro aproximações apresentadas acima estão apresentados na Figura 16, abaixo.

MSE - VaR Não-paramétrico

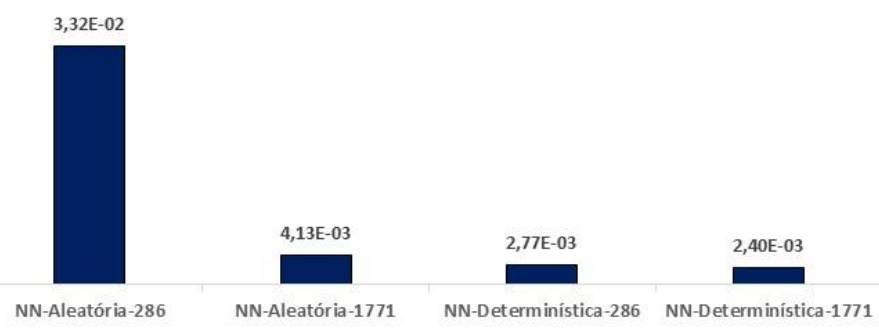

Figura 16: Erro Quadrático Médio calculado para cada um dos resultados apresentados para otimização de carteira de investimentos utilizando o VaR Não-paramétrico como função objetivo, aplicando-se as Redes Neurais Artificias como técnica de interpolação. 
Através da análise da Figura 16, acima, nota-se um substancial aumento do erro quadrático médio calculado na aproximação da superfície do Valor em Risco Nãoparamétrico quando comparado aos erros na aproximação da superfície da Variância. Este comportamento é esperado uma vez que a variância é uma função quadrática, o que facilita sua aproximação, enquanto a função VaR não-paramétrico apresenta elevada complexidade. Além disto, os métodos aqui propostos visam suavizar a superfície de resposta, procedimento que se faz menos preciso conforme o comportamento da superfície $\operatorname{Risco}(\boldsymbol{x})$ se torna mais complexo. Ainda assim, os resultados obtidos através da aproximação da superfície de risco pelas Redes Neurais Artificiais se fazem suficientemente precisos, com destaque aos cenários gerados pela amostra determinística de 1.771 pontos, a qual apresenta a melhor precisão da análise. Mais uma vez, nota-se que as amostras determinísticas apresentam aproximações de superfície mais precisas que as amostras aleatórias, assim como amostras maiores elevam o nível de precisão quando comparados com amostras menores, conforme esperado. 


\subsubsection{Valor em Risco Condicional (CVaR)}

Por último, a metodologia sugerida neste trabalho é aplicada para a otimização de carteiras de investimentos utilizando o Valor em Risco Condicional (CVaR) como função objetivo do problema de otimização. Analogamente ao Valor em Risco Nãoparamétrico, a função $C \operatorname{VaR}(\boldsymbol{x})$ possui comportamento complexo, fazendo com que a resolução do problema de otimização associado a ela seja não trivial. Desta forma, o controle do experimento é realizado comparando-se os resultados obtidos através da metodologia proposta com aqueles obtidos através da aplicação do método proposto por ROCKAFELLAR et. al. (2002), este último admitindo 718 cenários de simulação, representando sua melhor performance sem a necessidade de se estabelecerem hipóteses restritivas ao modelo. Os resultados seguem apresentados nas Figuras 17 e 18, abaixo.

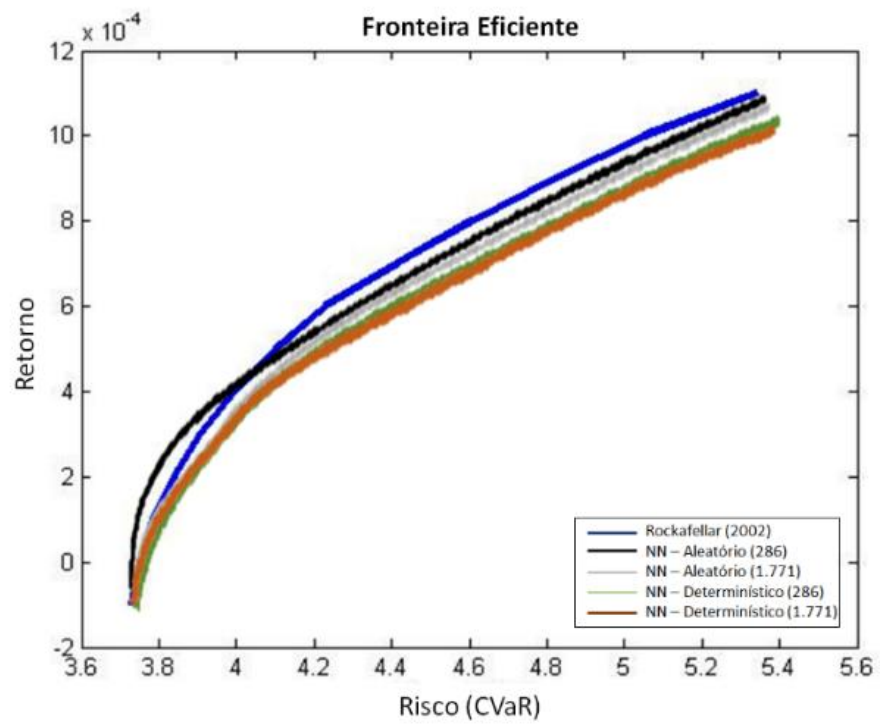

Figura 17: Fronteiras Eficientes obtidas para o CVaR como função objetivo, calculadas conforme metodologia proposta, aplicando-se as Redes Neurais Artificiais como técnica de interpolação, e o método proposto por ROCKAFELLAR et.al. (2002). 

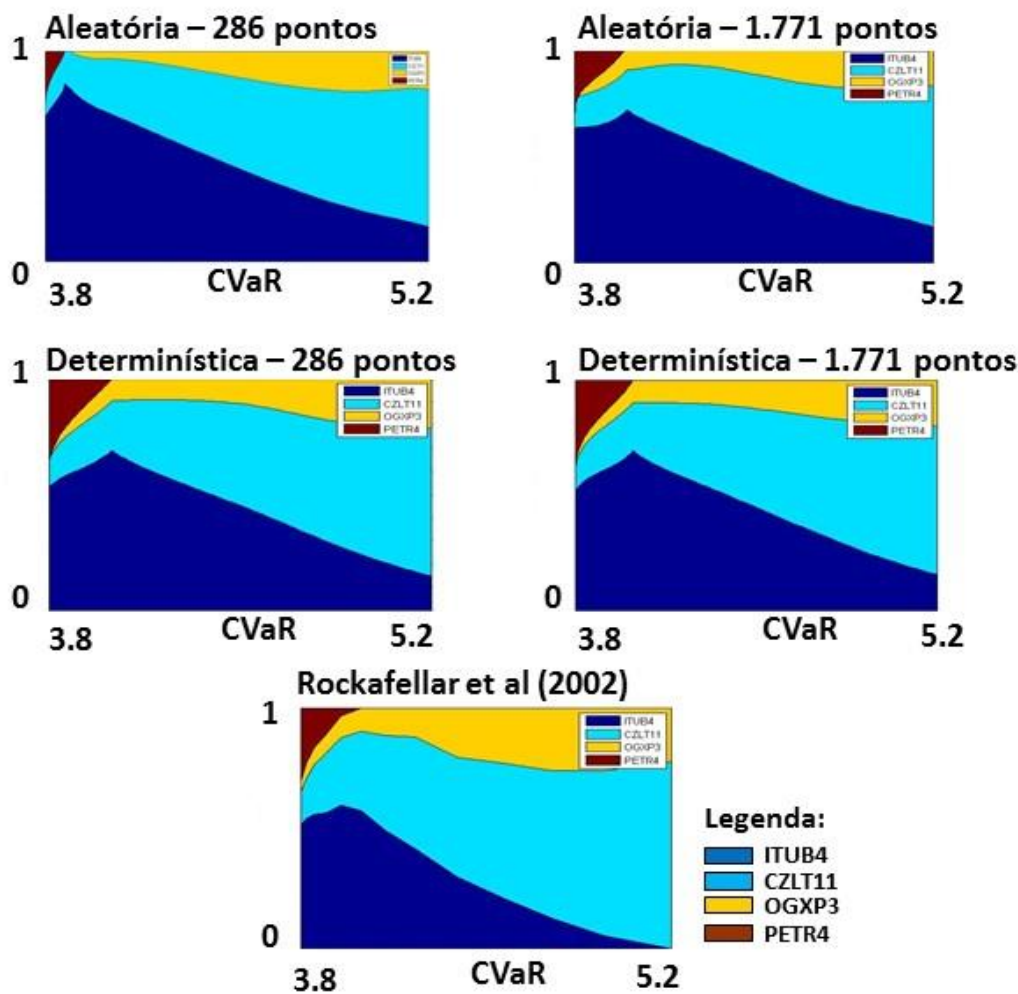

Figura 18: Composições ótimas de carteiras obtidas através da solução do problema de otimização de carteiras de investimentos tendo o CVaR como função objetivo, calculada conforme metodologia proposta, aplicando-se as Redes Neurais Artificiais como técnica de interpolação, e conforme o método proposto por ROCKAFELLAR et.al. (2002).

Analisando-se as figuras acima sob ótica qualitativa, as soluções apresentadas pela aproximação da superfície $C \operatorname{VaR}(\boldsymbol{x})$ através da aplicação da metodologia proposta, utilizando-se as Redes Neurais Artificiais como técnica de interpolação, apresentam comportamento semelhante à solução obtida pelo método de ROCKAFELLAR et. al. (2002). Novamente, as superfícies de risco obtidas através da interpolação de dados observados em amostras determinísticas apresentam resultados mais precisos que aqueles obtidos através da observação de amostras aleatórias. De fato, estas colocações são corroboradas pela avaliação dos erros quadráticos médios na aproximação da superfície de risco para cada uma das soluções apresentadas nas Figuras 17 e 18, conforme apresentado na Figura 19, abaixo. 


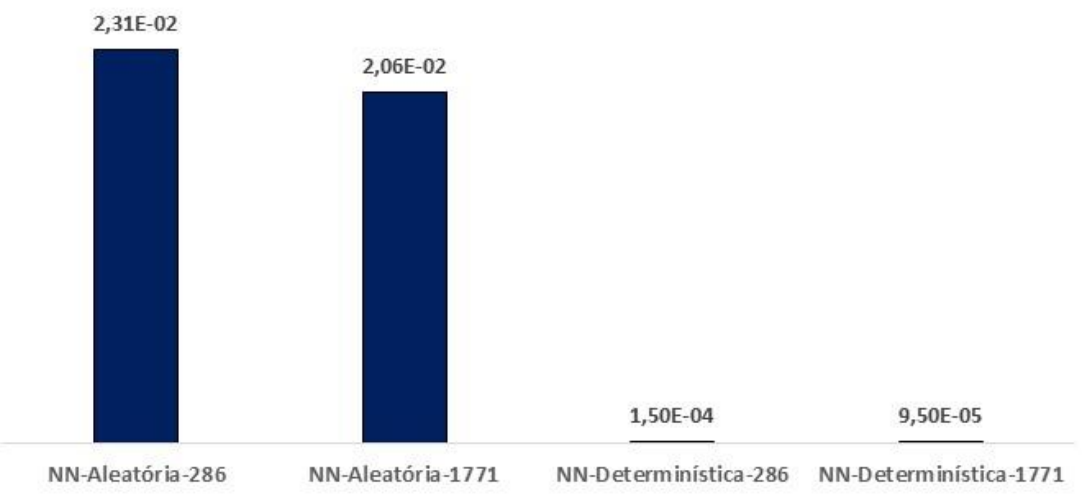

Figura 19: Erro Quadrático Médio calculado para cada um dos resultados apresentados para otimização de carteira de investimentos utilizando o $\mathrm{CVaR}$ como função objetivo, através da metodologia proposta e aplicando-se as Redes Neurais Artificiais como técnica de interpolação.

Daqui, nota-se que os resultados obtidos pela metodologia proposta apresentam resultados suficientemente precisos, quando comparados às metodologias disponíveis na literatura.

Embora a metodologia proposta aplicada com as Redes Neurais Artificiais como método de interpolação apresente satisfatórios níveis de precisão, sua aplicação apresenta um considerável inconveniente: o custo computacional necessário para se obter uma superfície de resposta com os níveis de erro apresentados. Em média, os resultados apresentados acima foram obtidos com processamentos que variam de dois a quatro dias em um computador comercial convencional. Este fato faz com que a aplicação da metodologia conforme apresentada não seja atrativa sob ponto de vista prático, sendo recomendada a problemas de pequena dimensão (i.e. $n \leq 4$ ). Para problemas de maior dimensão, sugere-se a aplicação da metodologia proposta utilizando-se a Krigagem como método de interpolação dos dados obtidos através do processo de simulação, uma vez que este processo é computacionalmente mais eficiente. 


\subsection{INTERPOLAÇÃO PELA KRIGAGEM}

Nesta seção, apresentam-se os resultados dos modelos de otimização obtidos através da aproximação da superfície $\operatorname{Risco}(\boldsymbol{x})$ pela aplicação da Krigagem, conforme metodologia sugerida neste trabalho. Os resultados são apresentados para as três medidas de risco selecionadas como função objetivo, mas apenas para amostragem determinística no processo de simulação, uma vez que esta técnica já se mostrou mais eficiente. Porém, dentro desta técnica de amostragem, consideram-se quatro distintos espaçamentos entre os pontos simulados para um dado ativo $(d=$ $[0,50 ; 0,25 ; 0,20 ; 0,10])$, para carteiras menores, e três distintos espaçamentos $(d=$ $[0,50 ; 0,25 ; 0,20])$ para carteiras maiores. Os resultados são apresentados tanto na forma de fronteira eficiente (i.e. curva retorno vs. risco) quanto na representação das composições ótimas de carteira para diferentes nível de risco. A carteira selecionada para aplicação da metodologia proposta com a Krigagem como método de interpolação está apresentada na Tabela 6, abaixo.

Tabela 6: Carteira analisada para aplicação da metodologia proposta, utilizando-se a Krigagem como método de interpolação de dados.

\begin{tabular}{|c|c|}
\hline 1 & BBDC3 \\
\hline 2 & PETR4 \\
\hline 3 & VALE3 \\
\hline 4 & VIVT4 \\
\hline 5 & ITUB4 \\
\hline
\end{tabular}

\begin{tabular}{|c|c|}
\hline 6 & CPLE6 \\
\hline 7 & GGBR4 \\
\hline 8 & BBAS3 \\
\hline 9 & USIM5 \\
\hline 10 & LIGT3 \\
\hline
\end{tabular}

A fim de se apresentar a metodologia proposta em suas duas formas (direta, conforme

Tabela 4, e iterativa, conforme Tabela 5), utiliza-se primeiramente uma carteira de 
cinco ativos, composta pelas ações elencadas de 1 a 5 na Tabela 6, com aplicação direta, e posteriormente a uma carteira composta pelos dez ativos apresentados na tabela acima, com aplicação iterativa.

Os retornos logarítmicos diários das carteiras em questão foram obtidos entre 14 Dezembro 2004 e 3 Fevereiro 2014, totalizando 2.224 observações.

\subsubsection{Aplicação (Direta) a Carteiras Pequenas}

Nesta seção, considera-se uma carteira composta pelos primeiros cinco ativos apresentados na Tabela 6, para aplicação a metodologia proposta utilizando-se a Krigagem como método de interpolação de dados simulados.

\subsubsection{Variância}

Para controlar o experimento, considera-se primeiramente uma carteira com a variância como medida de risco, e consequentemente a função objetivo do problema de otimização, uma vez que é possível atingir os resultados exatos deste problema através da aplicação do método de Kuhn-Tucker. A Figura 20, abaixo, mostra a Fronteira de Otimalidade de Pareto para a carteira de cinco ativos, com a variância como medida de risco, quando resolvida através do método de Kuhn-Tucker e da metodologia proposta, esta última aplicando-se a Krigagem como método de interpolação e amostra determinística no processo de simulação, variando-se a distância entre os pontos simulados para um dado ativo entre $d=0.5$ (grid grosseiro) e $d=0.1$ (grid fino), e respeitando as restrições $\sum_{i=1}^{n} x_{i}=1$ e $x_{i} \geq 0, i=1, \ldots, n$. 


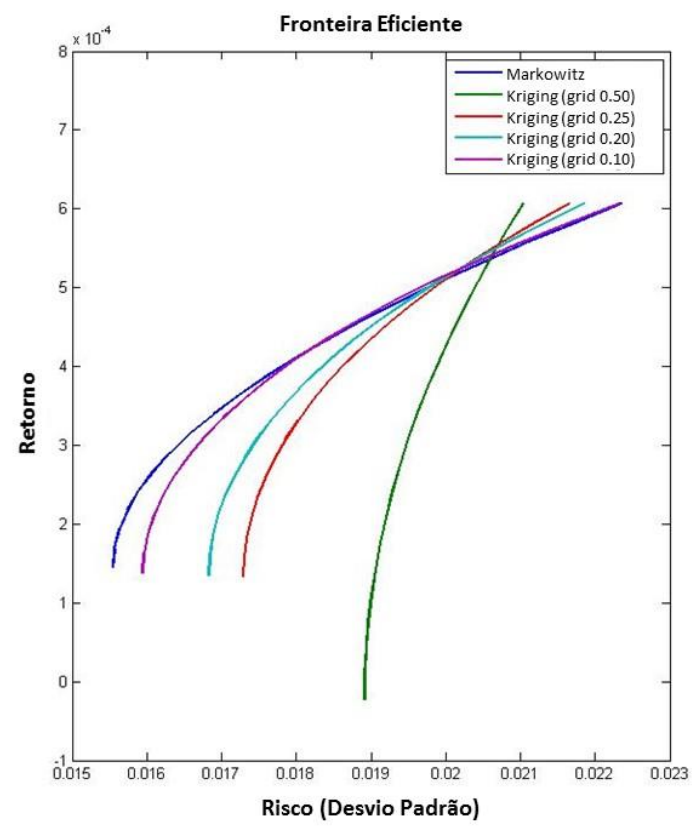

Figura 20: Fronteira Eficiente para carteira de cinco ativos com a Variância como medida de risco calculada através do método de Kuhn-Tucker (azul) e através da metodologia sugerida, aplicando-se a Krigagem como método de interpolação, para diferentes grids.

Analisando-se a Figura 20, fica claro que a precisão dos resultados obtidos aumenta conforme se aplicam grids mais finos no processo de simulação, como esperado. Além disto, o grid mais fino aplicado neste exemplo (i.e. $d=0.1$ ) apresenta uma fronteira eficiente similar àquela obtida pela aplicação do modelo de MARKOWITZ (1952), convergindo para a solução exata na região de maior risco, onde a concentração da carteira em um único ativo é esperada. De fato, a Figura 21, abaixo, mostra as diferentes composições das carteiras ótimas para distintos níveis de risco, considerando as mesmas aplicações apresentadas na Figura 20. 

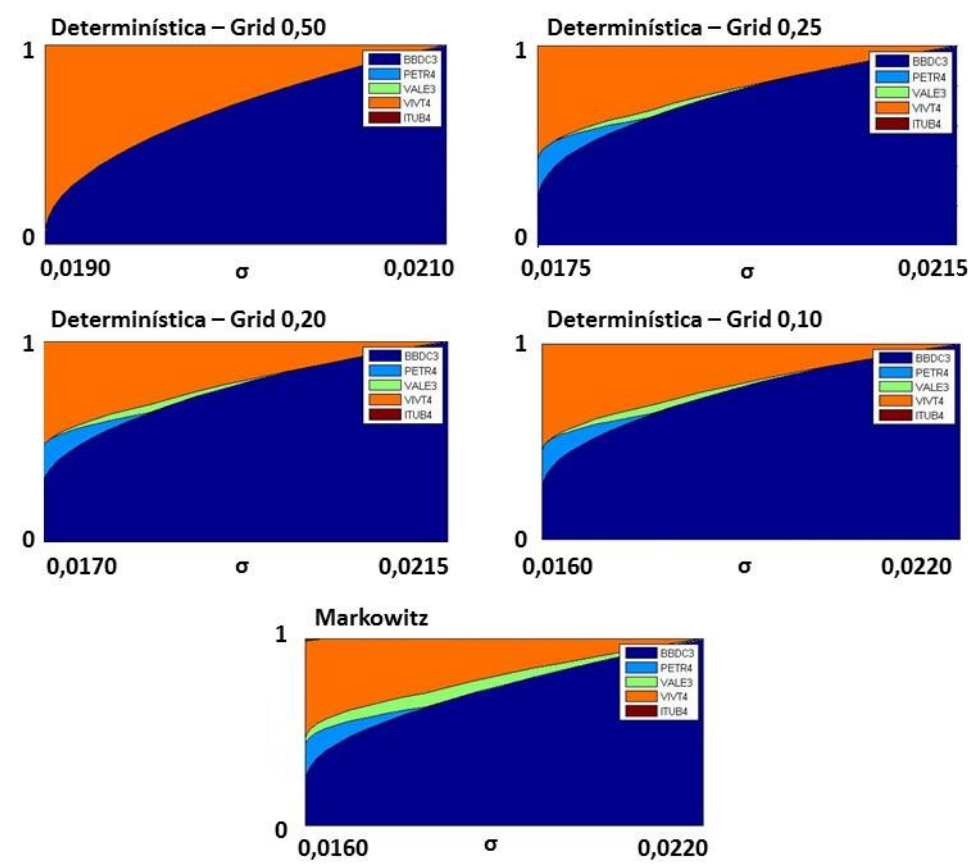

Figura 21: Composição ótima de carteira de cinco ativos para diferentes níveis de risco com a Variância como medida de risco, calculada através da metodologia proposta, aplicando-se a Krigagem como método de interpolação para diferentes grids, e através do método de KuhnTucker.

Uma análise qualitativa da Figura 21 mostra que a metodologia proposta é capaz de aproximar razoavelmente a solução do problema. As diferenças explícitas entre os resultados obtidos pela metodologia proposta, em sua configuração mais precisa (i.e. $d=0.1$ ), e a solução exata do problema estão em (1) uma alocação pequena de recursos no ativo ITUB4 no portfólio de mínimo risco, a qual a metodologia proposta não capturou, e (2) uma alocação levemente superior no ativo VALE3 na solução exata, para distintos níveis de risco. Mais ainda, observa-se que a solução aproximada do problema converge para a solução exata conforme se afina o grid no processo de simulação, conforme esperado.

Quantitativamente, a Figura 22, abaixo, mostra o Erro Quadrático Médio (MeanSquared-Error, do inglês, ou MSE) calculado na aproximação da superfície de risco, variando os grids do processo de simulação. 


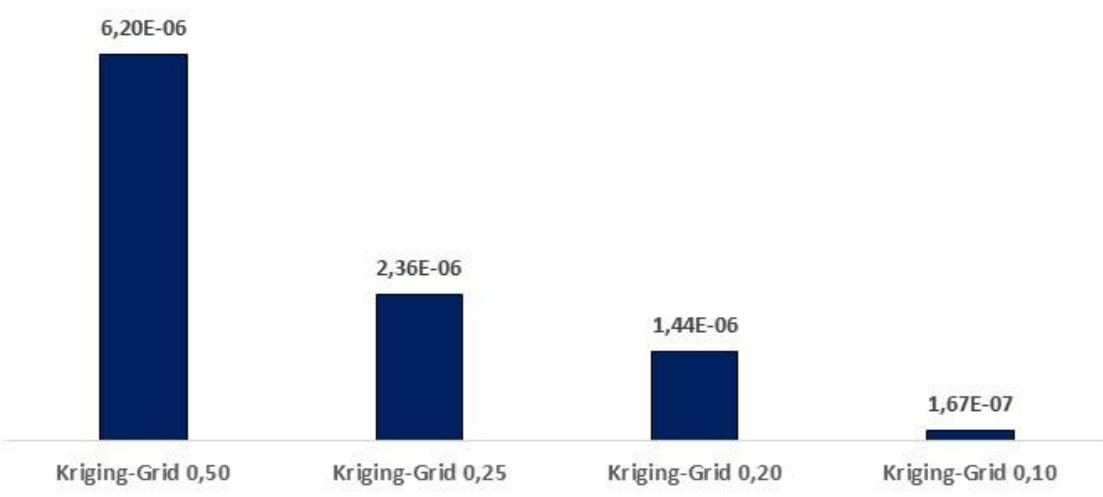

Figura 22: Erro Quadrático Médio calculado para cada um dos resultados apresentados para otimização de carteira de investimentos utilizando a Variância como função objetivo, através da metodologia proposta e aplicando-se a Krigagem como técnica de interpolação.

Os resultados apresentados acima demonstram que a metodologia proposta é perfeitamente capaz de aproximar a solução exata do problema, utilizando-se a Variância como medida de risco, com erro aceitável. 


\subsubsection{Valor em Risco (VaR)}

A Figura 23, abaixo, mostra a Fronteira de Otimalidade de Pareto para a carteira de cinco ativos quando resolvida aplicando-se a metodologia proposta, utilizando-se a Krigagem para interpolação de dados simulados para o VaR Não-Paramétrico, variando a distância entre os pontos simulados para um dado ativo de $d=0.5$ (grid grosseiro) a $d=0.1$ (grid fino), e respeitando as restrições $\sum_{i=1}^{n} x_{i}=1$ e $x_{i} \geq 0, i=$ $1, \ldots, n$.

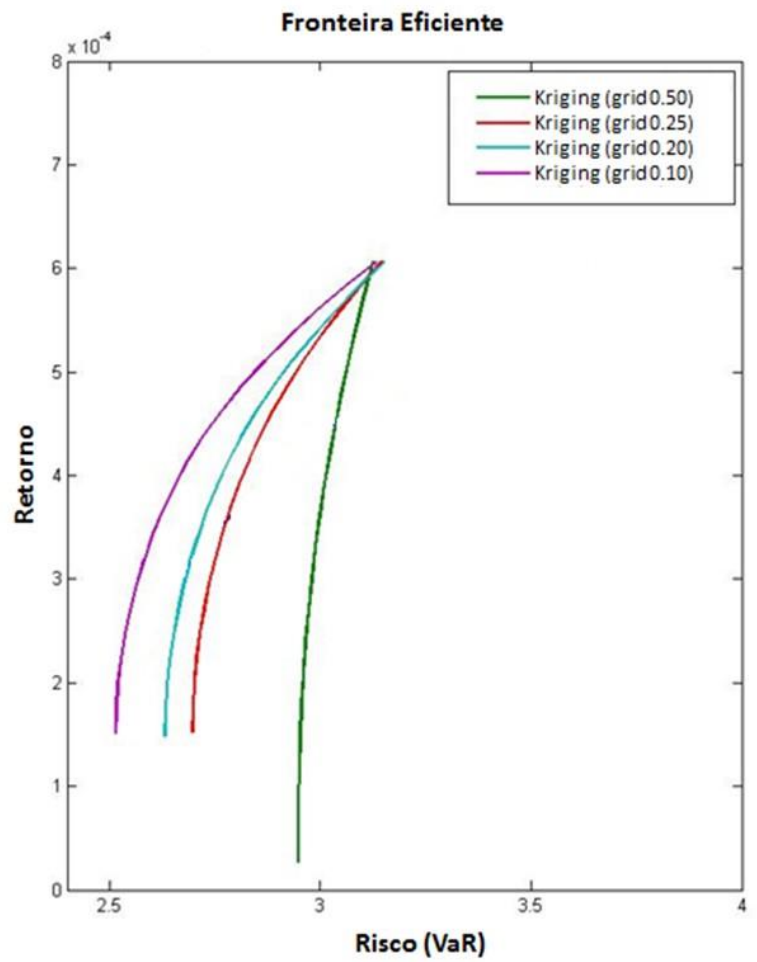

Figura 23: Fronteira Eficiente para carteira de cinco ativos com o VaR Não-Paramétrico como medida de risco calculada através da metodologia proposta, aplicando-se a Krigagem como método de interpolação para diferentes grids.

A Figura 24, abaixo, apresenta as composições ótimas de carteiras ao longo da fronteira eficiente para o VaR Não-Paramétrico, calculado para o grid mais fino (i.e. $d=0.1)$ 


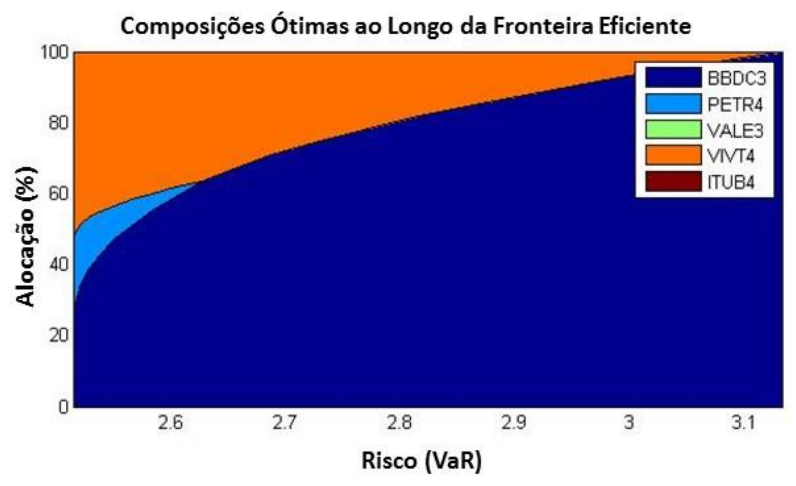

Figura 24: Composição ótima de carteira de cinco ativos para diferentes níveis de risco com o VaR não-paramétrico como medida de risco, calculada através da metodologia sugerida, aplicando-se a Krigagem como método de interpolação, para o grid $d=0.1$.

Como não existe uma referência para se compararem os resultados apresentados acima, a análise de precisão da aproximação da solução obtida pela metodologia proposta se faz através da avaliação do Erro Quadrático Médio na aproximação da superfície de risco. Neste caso, o MSE é de $3,67 \times 10^{-7}$, indicando que a aproximação obtida é satisfatória. 


\subsubsection{Valor em Risco Condicional}

Os resultados obtidos através da metodologia proposta com o CVaR como medida de risco são comparados àqueles obtidos pelo método de ROCKAFELLAR et. al. (2002). Como este último é também baseado em uma aproximação amostral da função CVaR, os resultados obtidos por esta técnica variam de acordo com o tamanho da amostra obtida no processo de simulação. Para efeito de comparação, o método de ROCKAFELLAR et. al. (2002) foi aplicado utilizando-se quantidade de pontos simulados equivalente à aplicação mais precisa da metodologia proposta (i.e. $d=$ 0.10, ou 1.001 pontos simulados), além de uma segunda aplicação contendo quantidade de pontos tão grande quanto a amostra original de observações dos retornos logarítmicos da série histórica (i.e. 2.224 pontos), representando sua melhor performance sem a necessidade de se assumirem hipóteses restritivas quanto à distribuição de probabilidade dos retornos. A Figura 25, abaixo, mostra a Fronteira Eficiente para a carteira de cinco ativos, calculada através do método de ROCKAFELLAR et. al. (2002), conforme descrito acima, e através da metodologia proposta, esta última aplicando-se a Krigagem como técnica de interpolação de dados e variando a distância entre os pontos simulados para um único ativo entre $d=0.5$ (grid grosseiro) e $d=0.1$ (grid fino), sempre respeitando as restrições $\sum_{i=1}^{n} x_{i}=1$ e $x_{i} \geq 0, i=1, \ldots, n$. 

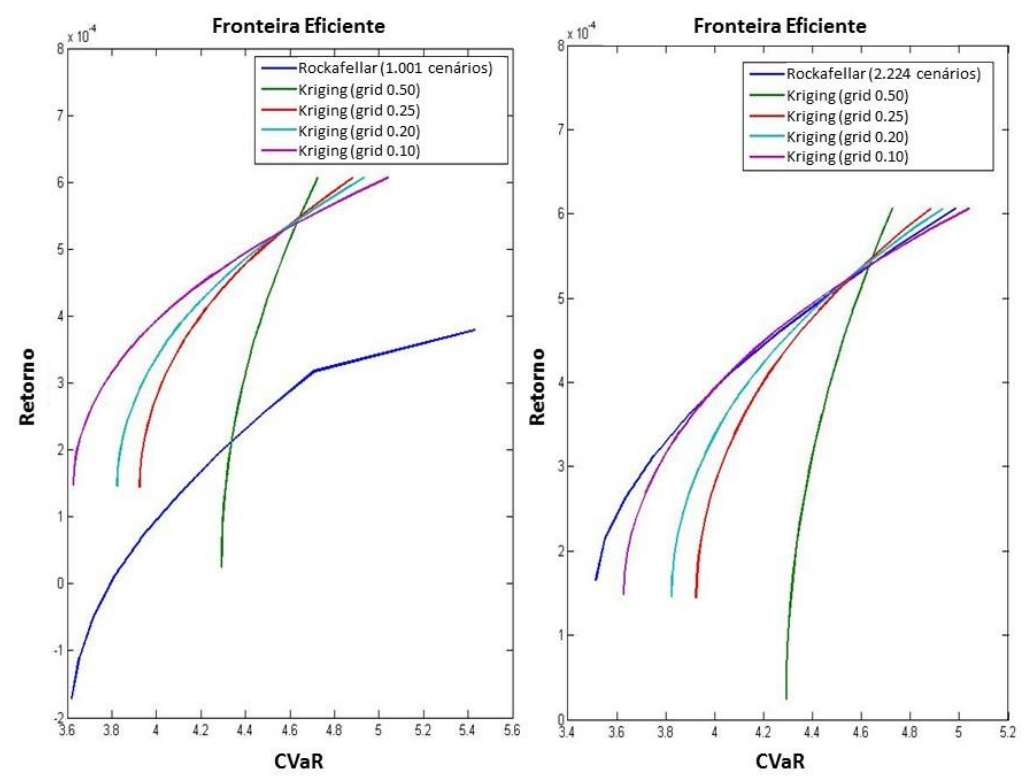

Figura 25: Fronteira Eficiente para carteira de cinco ativos com o CVaR como medida de risco calculada através do método de ROCKAFELLAR et. al. (2002), com diferentes quantidades de pontos simulados, e através da metodologia proposta, aplicando-se a Krigagem como método de interpolação, para diferentes grids.

Uma análise qualitativa da Figura 25 indica que os resultados obtidos pela metodologia proposta se aproximam daqueles obtidos pelo método de ROCKAFELLAR et. al. (2002) apenas se, na aplicação deste último, for utilizada uma quantidade de pontos substancialmente superior no processo de simulação. No caso das aplicações realizadas com a mesma quantidade de pontos simulados, é nítido que o método de ROCKAFELLAR et. al. (2002) não oferece resultados aproximados com o comportamento esperado. Esta observação é corroborada pelos resultados apresentados na Figura 26, abaixo, onde se apresentam as composições ótimas de carteiras ao longo da fronteira eficiente para a metodologia proposta, com $d=0.1$, e para o método de ROCKAFELLAR et. al. (2002), para simulações com 1.001 e 2.224 pontos. 

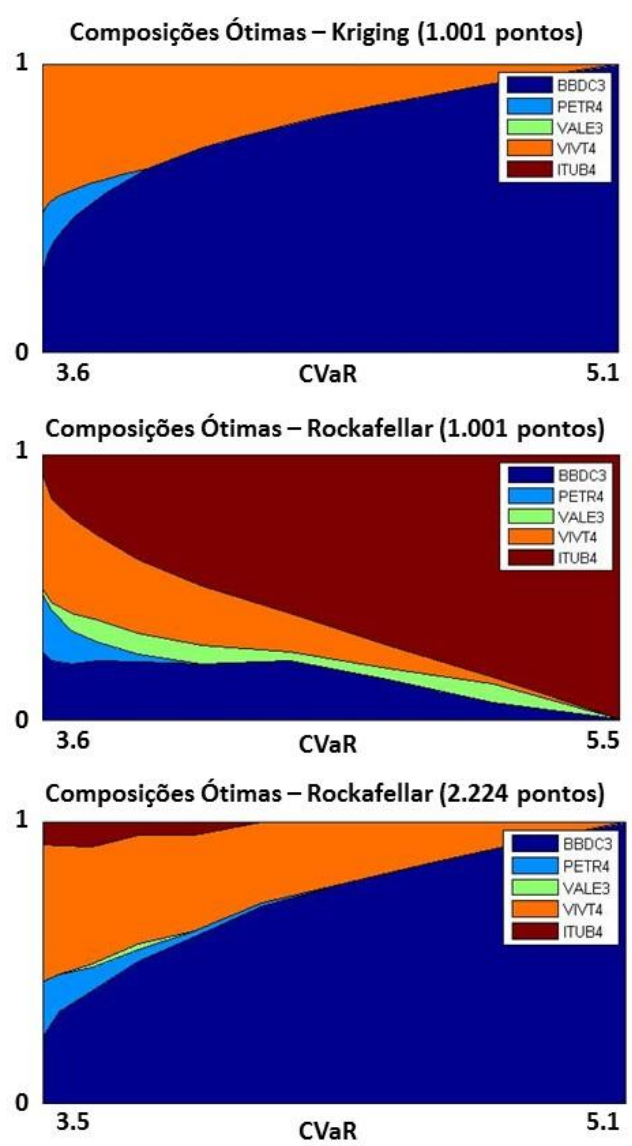

Figura 26: Composição ótima de carteira de cinco ativos para diferentes níveis de risco com o CVaR como medida de risco, calculada através da metodologia proposta, aplicando-se a Krigagem como método de interpolação para o grid $d=0.1$, e aplicando-se o método de ROCKAFELLAR et. al. (2002), para diferentes quantidades de cenários simulados.

Uma análise qualitativa da Figura 26 indica que o método de ROCKAFELLAR et.al. (2002) é extremamente sensível à quantidade de cenários simulados. De fato, múltiplas aplicações deste método podem apresentar resultados significativamente distintos quando uma quantidade insuficiente de cenários simulados é considerada. A metodologia proposta, por outro lado, oferece resultados com precisão suficiente através da observação de quantidades consideravelmente inferiores de informação. Por exemplo, para os resultados apresentados na Figura 26, o MSE na superfície aproximada do CVaR é de $8,42 \times 10^{-7}$. Mais ainda, este resultado somente será 
alterado caso a simulação seja aplicada a diferentes grids, seja em tamanho ou forma, uma característica não compartilhada pelo método de ROCKAFELLAR et. al. (2002). 


\subsubsection{Aplicação (iterativa) a carteiras grandes}

Conforme se busca analisar portfólios de maior dimensão (i.e. maior quantidade de ativos compondo a carteira), a complexidade computacional dos métodos aproximação de superfície de resposta se eleva, uma vez que se faz necessária a observação de cada vez mais informação no processo de simulação. Tomando como exemplo uma carteira composta pelos dez ativos apresentados na Tabela 6, a quantidade de pontos observados através da simulação por amostragem determinística, para grids variando de $d=0.5$ (grid grosseiro) e $d=0.1$ (grid fino) está apresentada na Tabela 7, abaixo.

Tabela 7: Dimensão de amostra determinística no processo de simulação, para carteira com dez ativos em diferentes grids.

\begin{tabular}{|c|c|}
\hline $\begin{array}{c}\text { Grid } \\
\text { (amostra determinística) }\end{array}$ & $\begin{array}{c}\text { Quantidade de Pontos no } \\
\text { Processo de Simulação }\end{array}$ \\
\hline$d=0.50$ & 55 \\
\hline$d=0.25$ & 715 \\
\hline$d=0.20$ & 2.002 \\
\hline$d=0.10$ & 92.378 \\
\hline
\end{tabular}

No caso do grid $d=0.10$, por exemplo, a capacidade computacional de processadores comerciais disponíveis atualmente impossibilita a aplicação de técnicas de interpolação de dados para amostras desta dimensão em tempo razoável a aplicações práticas. Nestes casos, alternativamente, aplica-se o processo iterativo da metodologia proposta, conforme descrito na Tabela 5. 


\subsubsection{Variância}

A Figura 27, abaixo, apresenta a Fronteira Eficiente do problema de dez ativos com a Variância como medida de risco, calculado através do método de Kuhn-Tucker (controle) e da metodologia proposta, aplicando-se a Krigagem como método de interpolação de dados a amostra determinística, variando a distância entre pontos simulados para um dado ativo entre $d=0.50$ (grid grosseiro) e $d=0.20$ (grid fino), respeitando as restrições $\sum_{i=1}^{n} x_{i}=1$ e $x_{i} \geq 0, i=1, \ldots, n$.

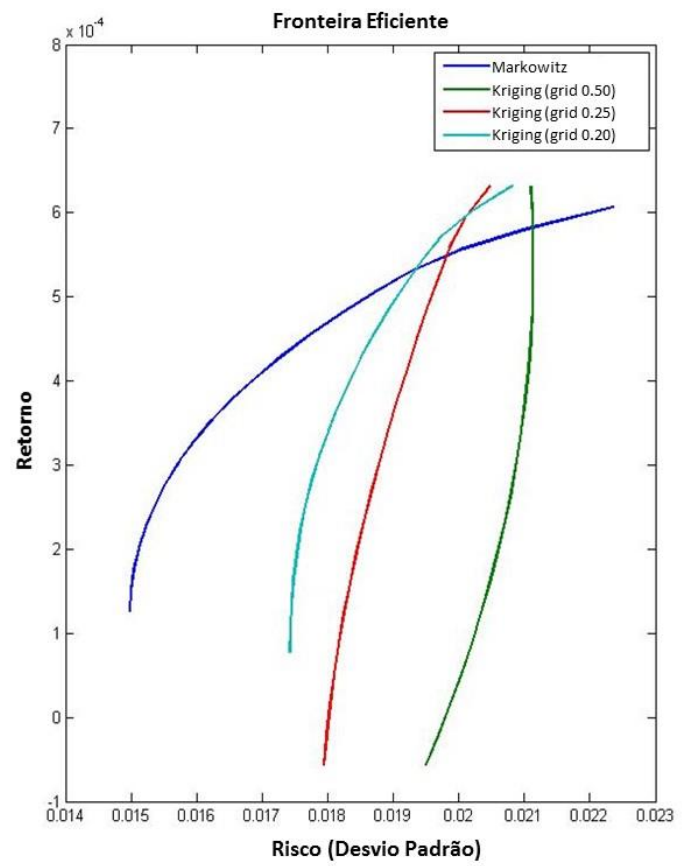

Figura 27: Fronteira Eficiente para carteira de dez ativos com a Variância como medida de risco calculada através do método Kuhn-Tucker e através da metodologia proposta, aplicandose a Krigagem como método de interpolação, para diferentes grids.

Uma análise qualitativa da Figura 27, acima, indica que a metodologia proposta não é capaz de aproximar, de forma razoável, a Fronteira Eficiente de Markowitz em sua melhor aplicação (i.e. $d=0.20$ ). De fato, a Figura 28 mostra as composições ótimas de carteira ao longo das fronteiras eficientes, calculada através do modelo de Markowitz e através da metodologia proposta, esta última com $d=0.20$. 

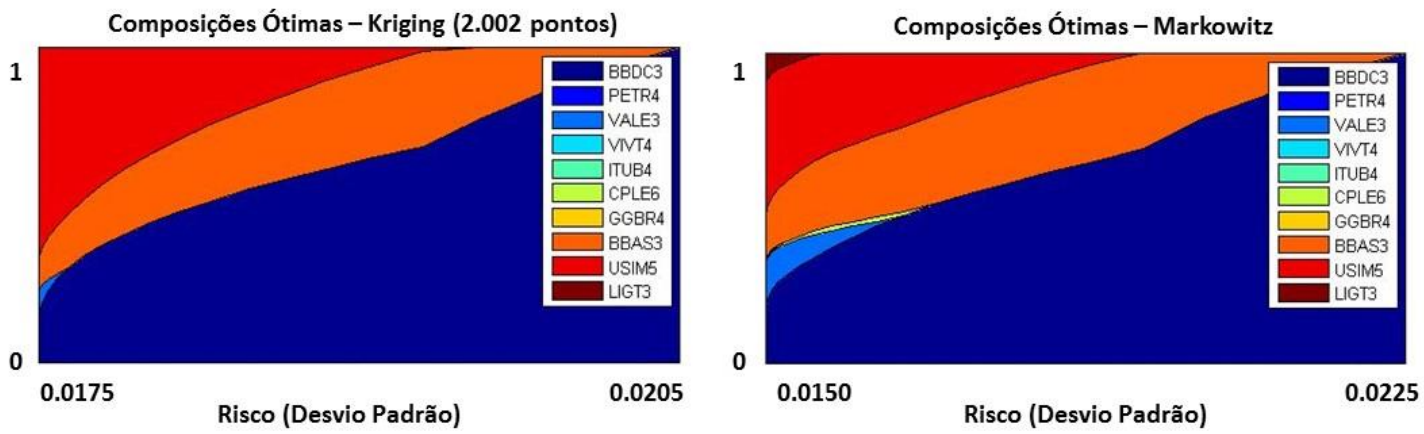

Figura 28: Composição ótima de carteira de dez ativos para diferentes níveis de risco com a Variância como medida de risco, calculada através da metodologia proposta para o grid $d=0.2$, e aplicando-se o método de Kuhn-Tucker.

Embora se note uma clara convergência da solução obtida através da metodologia proposta à solução obtida pelo método de Markowitz (1952) conforme se utilize grids mais finos (vide Figura 27), os resultados obtidos pela metodologia proposta não aproximam a solução exata do problema de forma satisfatória. Uma análise quantitativa mostra que o MSE obtido na aproximação da superfície de risco é de $1,25 \times 10^{-6}$, substancialmente superior ao obtido no caso de cinco ativos. Neste caso, melhores aproximações de solução para o problema são obtidas pela aplicação iterativa da metodologia proposta em torno de $X^{*}$. A sequência de busca pela melhor solução aproximada do problema, após três iterações de aplicação da metodologia proposta está apresentada na Figura 29, abaixo. 
Portfólio de Mínimo Risco (Variância)

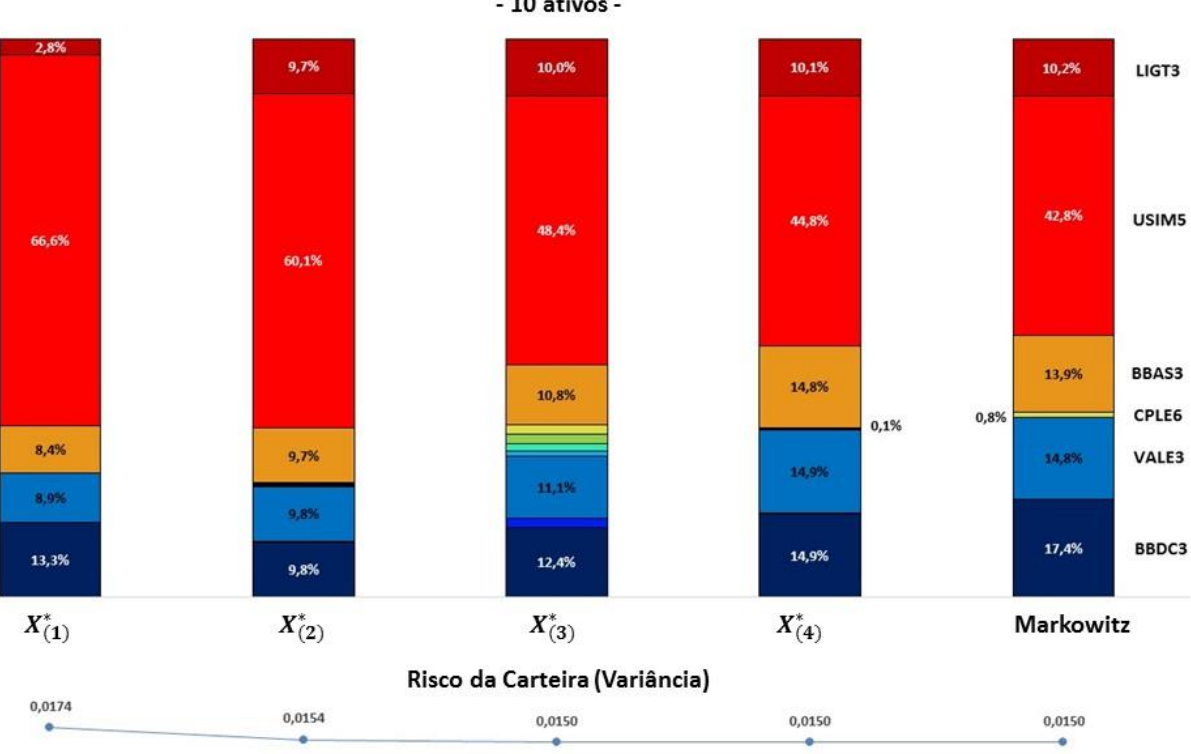

Figura 29: Composição ótima de carteira de dez ativos utilizando a Variância como medida de risco para cada iteração da metodologia proposta e segundo técnica o modelo de MARKOWITZ (1952).

Daqui, nota-se uma clara convergência da aproximação da solução ótima do problema para a sua solução exata, conforme se aplicam ciclos adicionais da metodologia proposta. Mais ainda, o valor da função $\sigma(\boldsymbol{x})$ também converge para aquele obtido pelo método de Kuhn-Tucker, demonstrando a capacidade da metodologia proposta de se aproximar satisfatoriamente a solução para o problema. 


\subsubsection{Valor em Risco (VaR)}

Para a carteira de 10 ativos, a Figura 30, abaixo, mostra a Fronteira de Otimalidade de Pareto quando o problema é resolvido através da metodologia proposta, aplicandose a Krigagem como técnica de interpolação a amostra determinística com diferentes grids, para o VaR Não-Paramétrico. Novamente, respeitam-se as restrições $\sum_{i=1}^{n} x_{i}=1$ e $x_{i} \geq 0, i=1, \ldots, n$.

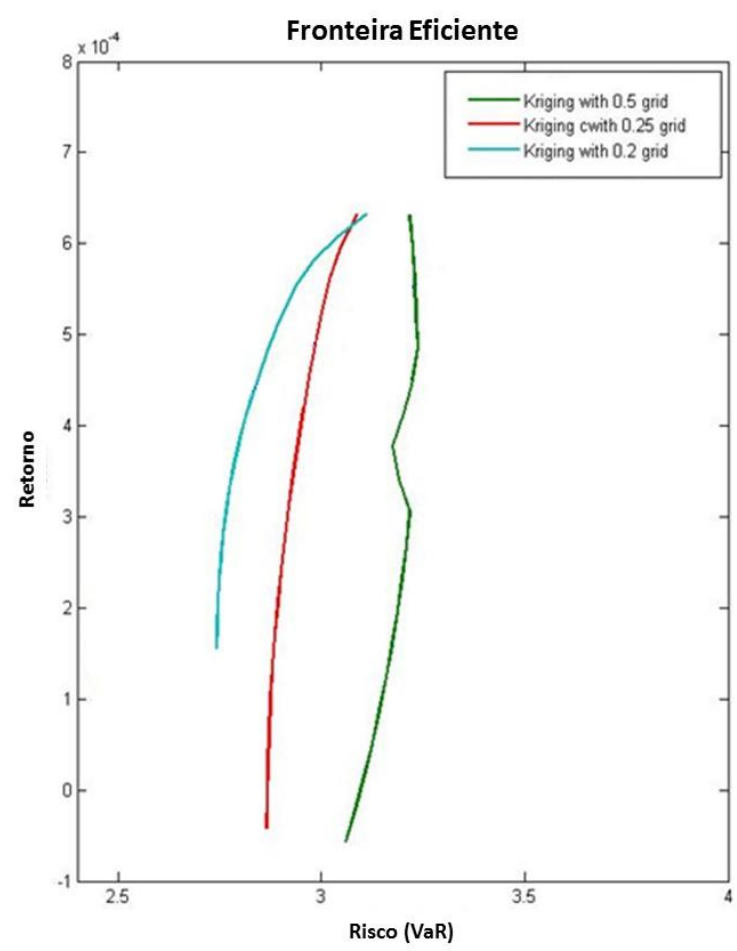

Figura 30: Fronteira Eficiente para carteira de dez ativos com o VaR Não-Paramétrico como medida de risco calculada através da metodologia proposta aplicando-se a Krigagem como método de interpolação, para diferentes grids.

Neste exemplo, observa-se que a metodologia proposta com o grid grosseiro (i.e. $d=$ 0.50) não aproxima a Fronteira Eficiente apropriadamente, apresentando comportamento aleatório, longe do esperado. Os outros grids (i.e. $d=0.25$ e $d=$ 0.20) apresentam o comportamento esperado da Fronteira Eficiente, mas uma avaliação quantitativa se faz necessária para se concluir sobre a precisão da 
aproximação. A Figura 31, abaixo, apresenta as composições ótimas de carteira ao longo da Fronteira Eficiente para a melhor solução apresentada na Figura 30 (i.e. $d=$ $0.20)$.

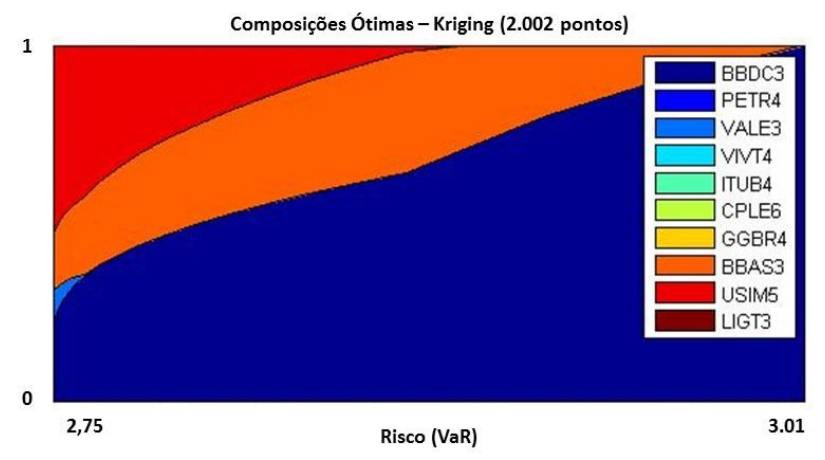

Figura 31: Composição ótima de carteira de dez ativos para diferentes de VaR nãoparamétrico, calculada através da metodologia proposta para o grid $d=0.2$.

O MSE da superfície de risco aproximada para a solução apresentada acima é de $2,38 \times 10^{-6}$. Novamente, para se obter melhor precisão neste resultado, aplica-se a metodologia proposta de forma iterativa, conforme Tabela 5, restringindo o domínio da função $\operatorname{VaR}(\boldsymbol{x})$ a cada ciclo de aplicação. Os resultados obtidos, após quadro ciclos adicionais de aplicação, estão apresentados na Figura 32, abaixo. 


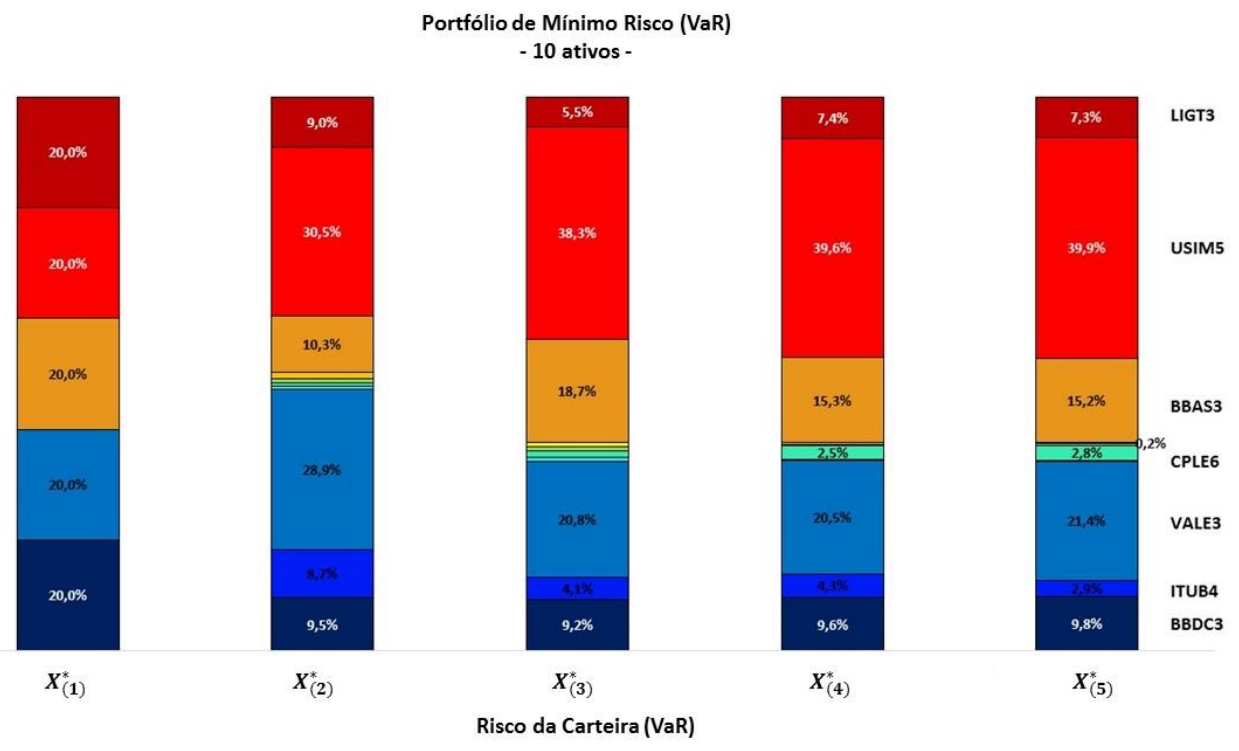

Figura 32: Composição ótima de carteira de dez ativos utilizando o VaR não-paramétrico como medida de risco para cada ciclo de aplicação da metodologia proposta.

Conforme mencionado anteriormente, os resultados obtidos pela metodologia proposta para aproximação da solução do problema de composição de carteiras, utilizando-se o VaR Não-Paramétrico como função objetivo, não possuem parâmetro de comparação. Entretanto, julgando pelo controle do experimento apresentado na seção anterior (i.e. Variância como medida de risco), é razoável assumir que os resultados apresentados na Figura 32, após quatro ciclos de refinamento da metodologia proposta, convergem para a solução do problema. 


\subsubsection{Valor em Risco Condicional}

A Figura 33, abaixo, apresenta a Fronteira de Otimalidade de Pareto para a carteira de dez ativos, com o problema resolvido pelo método de ROCKAFELLAR et. al. (2002), assumindo 2.224 cenários no processo de simulação, sua melhor performance sem a necessidade de se estabelecerem hipóteses restritivas acerca da distribuição de probabilidade dos retornos, e pela metodologia proposta, aplicando-se a Krigagem como método de interpolação para amostras determinísticas de tamanho variado. Respeitam-se, novamente, as restrições $\sum_{i=1}^{n} x_{i}=1$ e $x_{i} \geq 0, i=1, \ldots, n$.

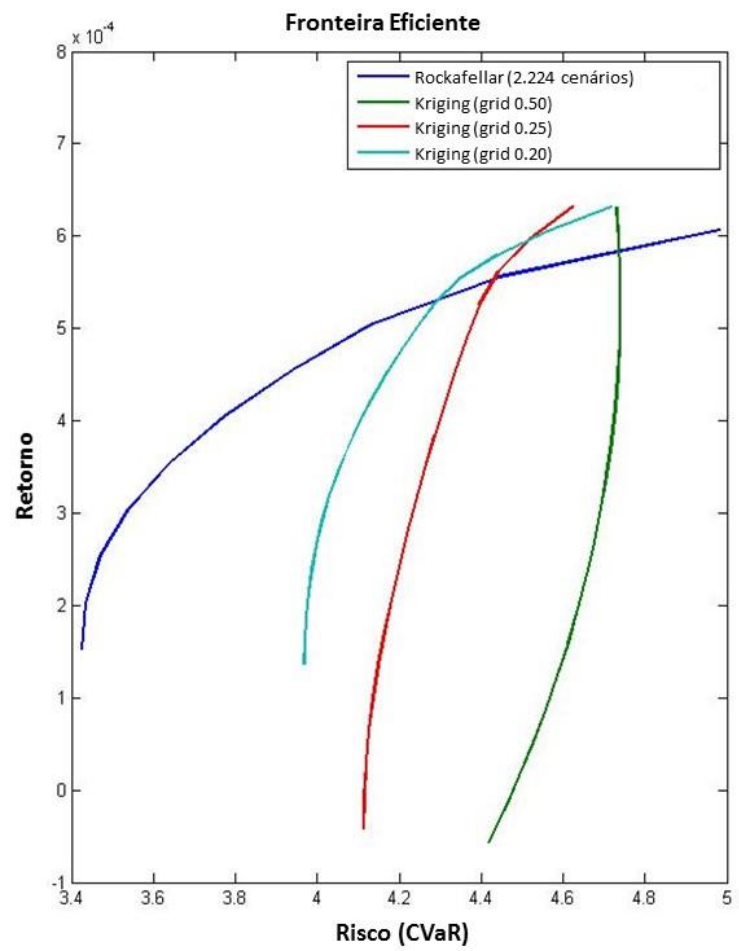

Figura 33: Fronteira Eficiente para carteira de dez ativos com o $\mathrm{CVaR}$ como medida de risco calculada através do método ROCKAFELLAR et. al. (2002), com 2.224 cenários, e através da metodologia proposta, aplicando-se a Krigagem como método de interpolação para diferentes grids.

A Figura 34, abaixo, mostra as composições de carteira ao longo da fronteira eficiente obtidas pela metodologia proposta, em sua melhor aproximação (i.e. $d=0.2$ ), e pelo método de ROCKAFELLAR et. al. (2002). 

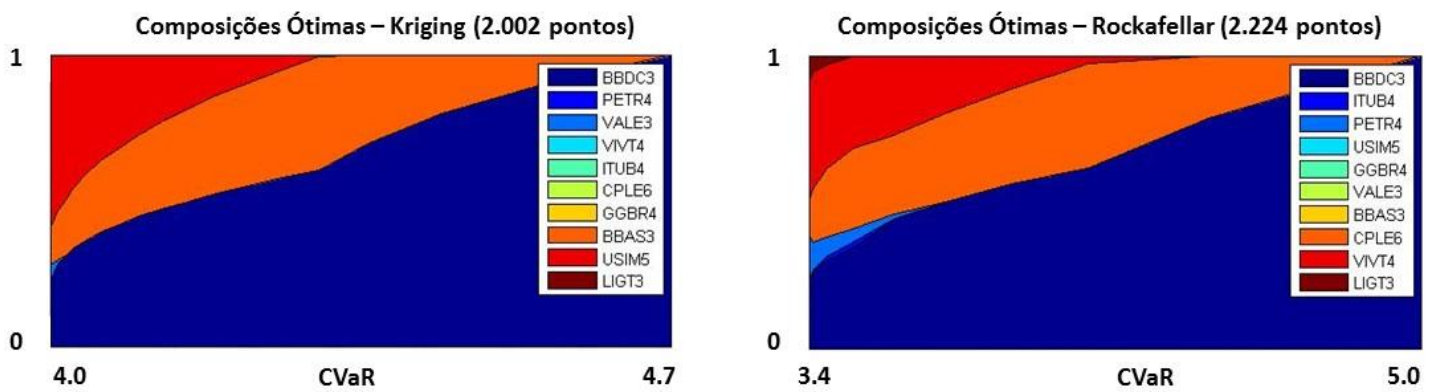

Figura 34: Composições ótimas de carteira de dez ativos para diferentes níveis de CVaR, calculadas através do método de ROCKAFELLAR et. al. (2002) e através da metodologia proposta, aplicando a Krigagem como técnica de interpolação para o grid $d=0.2$.

Neste caso, é reconhecido pelas discussões anteriores que a metodologia proposta é incapaz de aproximar a superfície de risco para uma carteira desta dimensão com erro satisfatório. De fato, o erro médio quadrático da melhor da aproximação obtida pela metodologia proposta e apresentada na Figura 34 é 5,22 $\times 10^{-6}$. Desta forma, para se obter melhor precisão neste resultado, aplica-se a metodologia de forma iterativa, restringindo o domínio da função $\operatorname{CVaR}(\boldsymbol{x})$ a cada ciclo de aplicação. Os resultados obtidos, após quadro ciclos adicionais de aplicação da metodologia proposta, estão apresentados na Figura 35, abaixo. 
Portfólio de Mínimo Risco (CVaR)

-10 ativos -

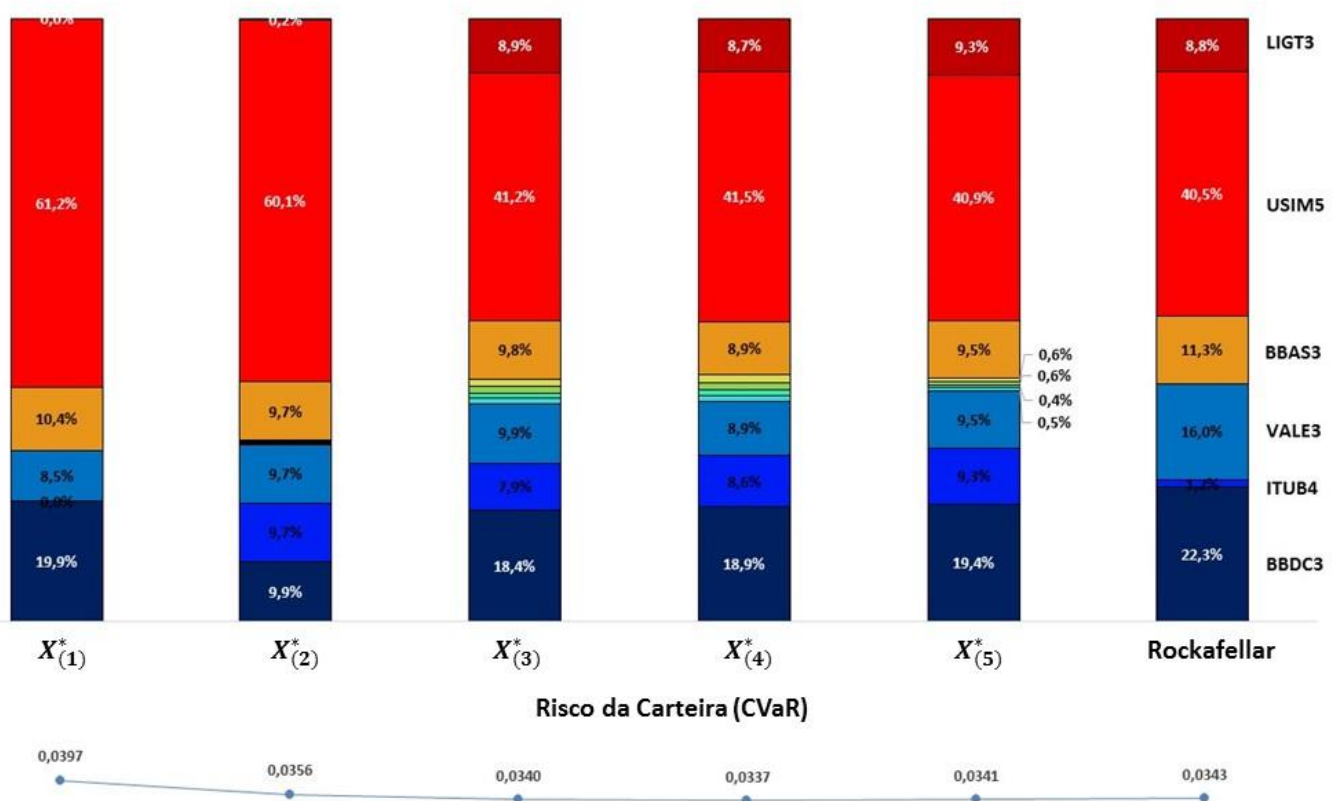

Figura 35: Composição ótima de carteira de dez ativos utilizando o CVaR como medida de risco para cada ciclo de iteração da metodologia proposta e segundo método de ROCKAFELLAR et. al. (2002).

Novamente, observa-se uma clara convergência da solução do problema obtida através da metodologia proposta àquela conhecida, embora esta última também seja baseada em aproximação da superfície de risco. Além disto, o valor calculado da função $\operatorname{CVaR}(\boldsymbol{x})$ também converge àquele calculado por metodologia de ROCKAFELLAR et. al. (2002). Estas observações indicam a elevada capacidade da metodologia proposta de resolver o problema de gestão de carteiras. 


\subsubsection{Erros}

Conforme observado ao longo deste texto, o erro quadrático médio obtido na aproximação da superfície de risco pela metodologia proposta varia de forma significativa conforme se altera o grid de simulação de pontos para interpolação. A decisão de se aplicar a técnica direta ou a técnica iterativa depende diretamente do MSE obtido na primeira aplicação da metodologia. A fim de facilitar tal decisão, a Figura 36, abaixo, apresenta o MSE para as três medidas de risco estudadas neste trabalho, variando-se o espaçamento do grid da amostragem determinística em $d=$ $[0,5 ; 0,25 ; 0,20 ; 0,10]$, e variando-se a quantidade de ativos na carteira, de 2 a 10 .
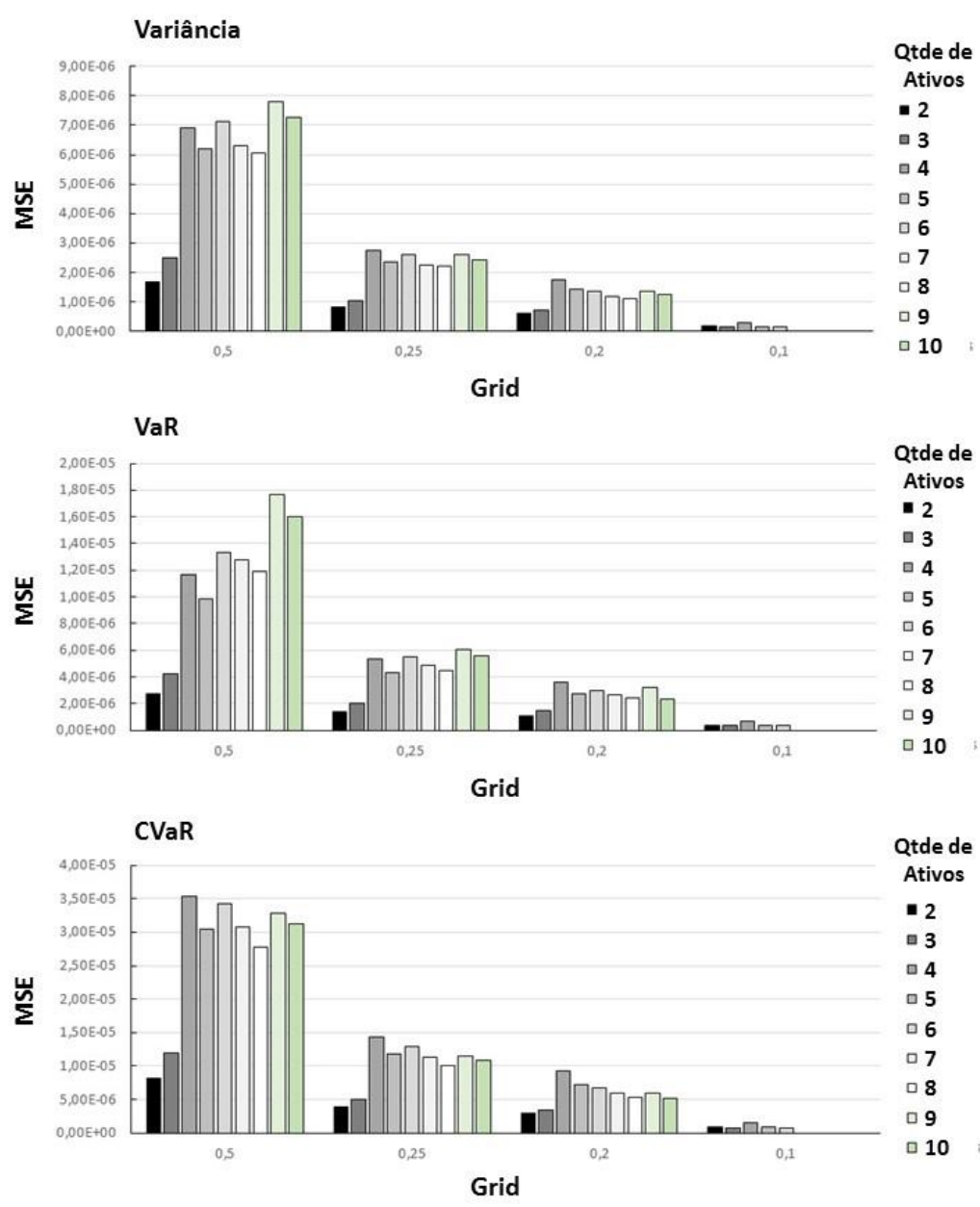

Figura 36: Erro Quadrático Médio na aproximação da superfície de risco pela metodologia proposta, aplicando-se a Krigagem como método de interpolação e variando o grid de simulação para amostra determinística, para a Variância, o VaR e o CVaR. 


\section{CONCLUSÃO}

Neste trabalho, propôs-se uma nova abordagem metodológica para a solução do problema de otimização de carteiras de investimentos. Esta metodologia consiste primeiramente na observação por amostragem de valores conhecidos de uma certa função $\operatorname{Risco}(\boldsymbol{x})$ em $R^{N}$, seguida da aproximação desta superfície de risco através da aplicação de métodos universais de interpolação, tais quais as Redes Neurais Artificiais e a Krigagem. Tal metodologia se destaca pela sua característica universal, aplicável a qualquer medida de risco já proposta na literatura. Mais ainda, sua ampla aplicabilidade permite que sejam relaxadas hipóteses restritivas necessárias para a solução do problema de otimização de carteiras através de métodos convencionais, principalmente quando funções de elevada complexidade são utilizadas como objetivo do problema. Sua contribuição se estende, então, desde o aprofundamento no entendimento do comportamento das medidas de risco atualmente disponíveis na literatura, bem como no conhecimento de novas medidas de risco que venham a ser propostas no futuro.

A nova metodologia foi aplicada ao problema de composição de carteiras reais, tomando como funções objetivo a Variância, o Valor em Risco (VaR), em sua forma não-paramétrica, e o Valor em Risco Condicional (CVaR). Observou-se que, tanto na aplicação das Redes Neurais Artificiais quanto na Krigagem como técnicas de interpolação, a aplicação de técnicas determinísticas de simulação e observação de cenários apresentam resultados mais precisos quando comparadas a técnicas de amostragens aleatórias de mesma dimensão.

As Redes Neurais Artificias foram aplicadas a uma carteira composta por quatro ativos, dado que esta técnica apresenta limitação quanto ao custo computacional no processo de interpolação e aproximação da superfície de resposta, de forma que sua 
aplicação, embora tenha apresentado resultados significativamente precisos, se limitou a problemas de baixa dimensão, ou carteiras com poucos ativos. A Krigagem, por sua vez, foi aplicada a carteiras reais compostas por cinco e por dez ativos. No primeiro caso, sua aplicação (direta) apresentou resultados satisfatórios e suficientemente precisos. No segundo caso, porém, devido à elevada dimensão do problema, sua aplicação foi realizada mais de uma vez, de forma sucessiva e iterativa, restringindo-se o domínio da função de risco a cada ciclo da aplicação, na busca por uma melhor aproximação do ótimo local da função $\operatorname{Risco}(\boldsymbol{x})$ em torno da solução original. Em todos os casos, os resultados obtidos pela metodologia proposta se aproximam suficientemente daqueles obtidos por metodologias conhecidas.

Reconhece-se que, embora os resultados da aplicação da metodologia proposta neste trabalho tenham convergido para soluções conhecidas nos exemplos aqui apresentados, existe o risco dos métodos de otimização aplicados aos problemas de grandes dimensões ficarem presos, por exemplo, em mínimos locais das funções objetivo. Além disto, não se pode garantir que a metodologia de busca pelo ótimo global a problemas de grande dimensão aplicada neste trabalho seja mais eficiente que outras opções disponíveis na literatura. Assim, uma possível extensão deste trabalho seria incorporar outros métodos de busca por ótimos globais de superfícies de resposta complexas, tais quais o Adaptative Response Surface Method. Outra possível extensão deste trabalho seria aproximar a superfície de risco por métodos de superfície de resposta não interpoladores, assumindo-se como hipótese simplificadora que a superfície representativa do risco pode ser aproximada por um polinômio de ordem baixa, e os parâmetros da função seriam obtidos através de regressão por mínimos quadrados, abordagem que simplificaria substancialmente o processo de construção e otimização da superfície de risco aproximada. 


\section{Referências}

ANDERSON, DAVID R. et al. Estatística Aplicada à Administração e Economia, Pioneira Thomson Learning, 2002.

ANDRADE, F.W.M., Alocação de Ativos no Mercado Acionário Brasileiro Segundo o Conceito de Downside Risk. Revista de Gestão USP, v.13.,n.2, p.27-36, 2006

ARTZNER, P. et al. Coherent mesures of risk. Mathematical Finance, v. 9, p. 203-228, July 1999.

ASSAF NETO, A. Mercado Financeiro. 9ª . ed. São Paulo: Editora Atlas, 2009.

BANGIA, A., F.X. DIEBOLD, T. SCHUERMAN, Modeling Liquidity risk with implication for traditional risk measures and management. J. Banking Finance 26 (1999) p. 445474

BAWA, V., Safety-first, stochastic dominance and optimal portfolio choice, Journal of Financial and Quantitative Analysis 13, p. 255-271, 1978.

BERK, J. e P. DEMARZO, Corporate Finance, Second Edition, Prentice Hall, 2009.

BERKOWITZ, J. Incorporating liquidity risk into value-at-risk models, University of California, Irvine, 2000

BERNOULLI, D., Exposition of a new theory on the measurement of risk. Econometrica 22, p. 23-36. Tradução de artigo original publicado em Latim em São Petersburgo em 1738.

BHADESHIA, Neural Networks in Materials Science, ISIJ International, Vol. 39, n. 10, p. 966-979, 1999.

BREALEY, R. and S. MEYERS, Principles of Corporate Finance, Seventh Edition, McGraw Hills, 2003

COSTA, P. e T. BAIDYA, Propriedades Estatísticas das Séries de Retornos das Principais Ações Brasileiras. Pesquisa Operacional, v. 21, n.1, p. 61-88, 2001.

COSTA NETO, P. L. O. Estatística. 2ª . ed. São Paulo: Editora Blücher, 2002. 
ERTAS, A. e J. JONES, The Engineering Design Process, Chapter $1,2^{\text {nd }}$ Edition, Wiley, 1993.

ESTRADA, J., Mean-Semivariance Behavior: A Note, Finance Letters, 1, 2003 p. 914.

FERNÁNDEZ, A. e S. GÓMEZ, Portfolio selection using neural networks, Computers and Operations Research, p. 1177-1191, 2007.

FISHBURN, P.C., Mean-risk analysis with risk associated with below-target returns, American Economic Review 67, n² 2, p. 116-126, 1977.

Group of Thirty, Derivatives: Practices and Principles, Group of Thirty, Washington D.C., 1994.

HEBB, D.O., The organization of behavior: a neural psychological theory. New York: Wiley, 1949.

HOPFIELD, J., Neural networks and physical systems with emergent collective computational abilities, Proceedings of the National Academy of Science (USA), Vol. 79, p. 2554-2558, 1982.

HULL, J. C. Options, Futures and Other Derivatives. Fourth. ed. Upper Saddle River: Prentice Hall, 1999.

JONES, D. R.; SCHONLAU, M.; WELCH, W. J. Efficient global optimization of expensive black-box functions. Journal of Global Optimization, v.13, n.4, 1998. p. 455492.

JONES, D. R., A Taxonomy of Global Optimization Methods Based on Response Surfaces, Journal of Global Optimization, v. 21, 2001, p. 345-383.

JORION, P. Value at Risk: the new benchmark of managing financial risk. 3th. ed. New York: McGraw-Hill, 1997.

J.P. MORGAN, Riskmetrics: Technical report, J.P. Morgan, New York, 1996.

KONNO, $\mathrm{H}$. and $\mathrm{H}$. YAMAZAKI, Mean-absolute deviation portfolio optimization model and its application to Tokyo stock market, Management Science 37, p. 519-531, 1991.

KUHN, H. W. e A. W. TUCKER. Nonlinear programming. Proceedings of 2nd Berkeley Symposium, 1951, Berkeley: University of California Press, p. 481-492. 
LIM, A., SHANTHIKUMAR G. and GAH-YI VAHN, Conditional Value at Risk in portfolio optimization: coherent but fragile. Operations Research Letters, Volume 39, Issue 3. p. 163-171, 2011.

LIU, Q., GUO, Z. e J. WANG, A one-layer recurrent neural network for constrained pseudoconvex optimization and its application for dynamic portfolio optimization, Neural Networks, p. 99-109, 2012

LOPHAVEN, S. N.; NIELSEN, H. B.; SONDERGAARD, J. DACE: a matlab kriging tollbox. Denmark: Informatics and Mathematical Modelling. Technical University of Denmark, p. 28 (Technical Report, IMM-TR-2002-12). 2002.

LUENBERGER, D. G. Investment Science. New York: Oxford University Press, 2008.

MARKOWITZ, H. Portfolio Selection. The Journal of Finance, v.7, 1952. p.77-91.

MARKOWITZ, H. Portfolio Selection: Efficient Diversification of Investments, Yale University Press, New Haven, 1970

MARKOWTZ, H. Mean-variance approximations to expected utility, European Journal of Operational Research, 2012

McCULLOCH, W.S., PITTS, W., A logical calculus of the ideas immanent in nervous activity. Bulleting of Mathematical Biology, Vol.5, n4, p. 115-133, 1943.

MONTGOMERY, D. C.; RUNGER, G. C. Estatística Aplicada e Probabilidade para Engenheiros. 2a․ ed. [S.I.]: LTC, 2003.

MURRAY, A. F., Applications of Neural Networks. The University of Edinburgh, Kluwer Academic Pub, 1995.

NETO, P. L. O. C.; CYMBALISTA, M. Probabilidades. São Paulo: Edgar Blucher Ltda, 2006.

NASCIMENTO, C.O., R. GIUDICI e R. GUARDANI, Neural network based approach for optimization of industrial chemical processes, Computers and Chemical Engineering 24, 2000, p. 2303-2314

O'NEIL; W. J. How to Make Money Selling Stocks Short. John Wiley \& Sons 2005. 
PAPALAMBROS, P.Y. e D.J. WILDE, Principles of Optimal Design, Cambridge University Press, 2000.

PARDALOS, P. M.; ROMEIJN, H.; TUY, H. Recent developments and trends in global optimization. Journal of Computational and Applied Mathematics, v.124, 2000. p.209228.

PEROLD, A. F., Large scale portfolio optimization, Management Science 30, p. 11431160, 1984.

PFLUG, G. C. Some remarks on the Value-at-Risk and Conditional Value-at-Risk. In: URYASEV, S. Probabilistic constrained optimization. [S.I.]: [s.n.], 2000. p. 272-281.

PONTIN, T., Otimização multidisciplinar distribuída aplicada a projetos de engenharia, Universidade de São Paulo, Tese de Doutorado, 2008.

QUARANTA, A. G.; ZAFFARONI, A. Robust optimization of condition value at risk and portfolio selection. Journal of Banking and Finance, v.32, 2008. 2046-2056.

QUEIPO, V. N. et al. Surrogate Modeling-based optimization for the integration of statistic and dynamic data into a reservoir description. Journal of Petroleum Science and Engineering, v.37, n.3-4, 2002. p.167-181.

RIBEIRO, C. O.; FERREIRA, L. A. S. Uma contribuição ao problema de composição de carteiras de mínimo valor em Risco. Gestão e Produção, v.12, 2004. p.295-304.

RIOS, L. M., N. V. SAHINIDIS, Derivative-free optimization: a review of algorithms and comparison of software implementations, Journal of global Optimization, v. 56, 2013, pp. 1247-1293.

ROCKAFELLAR, R. T.; URYASEV, S. Optimization of Conditional Value-at-Risk. Journal of Risk, v. 2, 2000. 21-41.

ROCKAFELLAR, R. T.; URYASEV, S. Conditional Value-at-Risk for general loss distributions. Journal of Banking and Finance, v.26, 2002. 1443-1471.

ROMAN, D., G. MITRA, Portfolio Selection Models: A Review and New Directions. Brunel University, UK, 2008.

ROSENBLATT, F., The Perceptron: A probabilistic model for information storage and organization in the brain. Psychological Review, Vol. 65, p. 386-408, 1958. 
ROY, A. D., Safety First and the Holding of Assets, Econometrica 20, p. 431-449, 1952.

RUBINSTEIN, M. Markowitz's "Portfolio Selection": A Fifty-Year Retrospective. The Journal of Finance, v.57, 2002. p.1041-1045.

RUMELHART, D., HINTON, G., WILLIAMS, R., Learning representations by backpropagating errors. Nature. Vol. 323, p. 533-536, 1986.

SARAIVA, A. Microeconomia. Instituto Superior de Contabilidade e Administração do Porto. Porto, Portugal, 2002.

SHARPE, W. F., A linear programming approximation for the general portfolio analysis problem, Journal of Financial and Quantitative Analysis 6, p. 1263-1275, 1971.

SHESKIN, D. J. Parametric and Nonparametric Statistical Procedures. 3ª . ed. [S.I.]: Chapman \& Hall/CRC, 2004.

STEEB, W., The Nonlinear Workbook, World Scientific, $4^{\text {th }}$ Edition, 2008.

SZEGÖ, G. Measures of risk. Journal of Banking \& Finance, v. 26, p. 1253-1272, June 2002.

WANG, G., ZUOMIN, D. e P. AITCHISON, Adaptative Response Surface Method - A global optimization scheme for approximation-based design problems. Engineering Optimization. Vol. 33:6, pp. 707-733, 2001.

YIN, J.; NG, S. H.; NG, K. M. Kriging metamodel with modified nugget-effect: The heteroscedastic Variance case. Computers \& Industrial Engineering, Singapore, 61, 2011. 760-777. 